\title{
A REVIEW OF METHODOLOGICAL TRENDS IN SOUTH AFRICAN SOCIOLOGY, 1990-2009
}

by

ISABEL BASSON

Thesis presented in partial fulfilment of the requirements for the degree of Master of Philosophy (Social Science Methods) in the Faculty of Arts and Social Sciences at Stellenbosch University

SUPERVISOR: Dr Heidi Eileen Prozesky

December 2013 


\section{DeClaration}

By submitting this thesis electronically, I declare that the entirety of the work contained therein is my own, original work, that I am the sole author thereof (save to the extent explicitly otherwise stated), that reproduction and publication thereof by Stellenbosch University will not infringe any third party rights and that I have not previously in its entirety or in part submitted it for obtaining any qualification.

Date: 15 November 2013

Copyright @ 2013 Stellenbosch University

All rights reserved 


\begin{abstract}
The thesis investigates the research methods employed by South African sociological researchers, as published in academic peer-reviewed journals during the period 1990 to 2009. Specific attention was given to the trends in terms of qualitative and quantitative methodologies and related methods employed. Methodological pluralism, the viewpoint that a mature sociology should incorporate explanatory, predictive and humanistic methods, has been the focus of various authors internationally and locally. A concern that has been reiterated in the literature is that an overemphasis on one methodology or one type of method is unhealthy for the development of the social sciences in a country. No recent review of the methods and methodologies employed in sociology in South Africa has been conducted, and with no clear view of the recent and current situation, no strategy can be formulated to address this potential concern. This thesis aims to address this issue by describing the situation in South Africa from 1990 to 2009. The empirical research presented in this thesis employed a content analysis design and quantitative methodology. Data were obtained from a sample of research articles collected from various online databases. Probability sampling was conducted, by making use of the method of stratified systematic sampling with a random start. Data analysis was both cross-sectional and longitudinal, and made use primarily of descriptive statistics, but bivariate analysis and chi-square tests were also employed. Various aspects of the research reported in the articles were analysed, which included methodology, research design, sampling methods, data collection methods, data analysis methods and author collaboration. The main findings of the thesis are that, during the past two decades both quantitative and qualitative methodologies have been employed to an equal extent, but that the use of non-probability sampling methods was higher than anticipated. Both local and international collaboration has increased over the past 20 years, and a quantitative methodology was significantly more likely if international collaborators were involved in the research. The thesis concludes that research methods in general, and sampling methods in particular, are poorly reported in published sociological research.
\end{abstract}




\section{OPSOMMING}

Die tesis ondersoek die navorsingsmetodes wat deur Suid Afrikaanse outeurs gebruik is tydens die tydperk 1990 tot 2009 wanneer hulle sosiologiese artikels in akademiese, eweknie-beoordeelde vaktydskrifte gepubliseer het. Aandag is spesifiek verleen aan metodologiese tendense in terme van kwalitatiewe en kwantitatiewe metodologie en gepaardgaande metodes. Verskeie internationale en plaaslike outeurs fokus op metodologiese pluralisme: die standpunt dat 'n gesonde sosiologie ondersoekende, voorspellende en humanistiese metodes moet gebruik. Die besorgdheid wat herhaaldelik voorkom in die literatuur is dat 'n oorbeklemtoning op net een metodologie en dié se verwante metodes ongesond is vir die ontwikkeling van die sosiale wetenskappe in 'n land. Daar is geen onlangse oorsig van die metodes en metodologieë wat in die sosiologie in Suid Afrika gebruik word nie, en sonder hierdie inligting kan daar nie 'n strategie ontwerp word om die potensiële besorgdheid aan te spreek nie. Hierdie tesis het ten doel om hierdie kwessie aan te spreek deur die situasie in Suid Afrika vanaf 1990 tot 2009 te beskryf. Die empiriese navorsing in die tesis wend 'n inhouds-analise navorsingontwerp en 'n kwantitatiewe metodologie aan. Data is ingesamel deur gebruik te maak van 'n steekproef van navorsings-artikels wat versamel is vanaf verskeie aanlyndatabasisse. 'n Waarskynlikheidsteekproef is getrek deur gebruik te maak van gestratifiseerde sistematiese steekproefneming met 'n lukrake beginpunt. Data-ontleding was beide kruissnydend en longitudinaal, en het hoofsaaklik vanbeskrywende statistiek gebruik gemaak, maar tweeveranderlike ontleding en chi-kwadraat toetse is ook aangewend. Verskeie aspekte van die navorsing wat in die artikels geraporteer word, is ontleed, insluitend: metodologie, navorsingsontwerp, streekproefmetodes, data-insamelingsmetodes, en outeursamewerking. Die hoofbevindinge van die tesis was dat beide kwantitatiewe en kwalitatiewe metodologieë in 'n gelyke mate aangewend word, maar dat nie-ewekansige steekproefmetodes meer gebruik word as wat te verwagte is. Samewerking, beide tussen plaaslike outeurs asook tussen plaaslike en internasionale outeurs, het oor die afgelope 20 jaar toegeneem, en ' $n$ kwantitatiewe metodologie was beduiend meer waarskynlik as internasionale medewerkers in die navorsing betrokke was. Die tesis kom tot die gevolgtrekking dat navorsingsmetodes oor die algemeen, en steekproefmetodes in besonder, swak gerapporteer word in gepubliseerde sosiologiese navorsing. 


\section{ACKNOWLEDGEMENTS}

Firstly I would like to thank my supervisor Dr Heidi Prozesky. She was the one who encouraged me to follow through with my interest in social research and I could not have asked for more than to have my role model as my supervisor.

Secondly I want to thank my parents, Diedius and Cornelia Basson for their patience and supporting me throughout the years and making my studies possible. I also want to thank the rest of my family for their loving support throughout my studies.

Thirdly, I want to thank my partner Jean Marais for his understanding and help, for keeping me focused and confident in my work and in my abilities. I also would like to thank my friends, especially Dr Henri Hakl for his support and assistance and Cassey Toi for all the editing work she has done for me.

I would also like to thank Mr N. Hendriksz and the library staff for their assistance with the many requests I had as well as Prof Martin Kidd at the Centre for Statistical Consultation for his assistance with my statistical questions.

A special thanks to Ms M. van Niekerk and Ms W. Fourie for their administrative assistance and support throughout my undergraduate and postgraduate studies. Lastly I want to thank the Ernst and Ethel Eriksen Trust for their bursaries for 2009 and 2010. 


\section{TABLE OF CONTENTS}

ChaPTER 1

INTRODUCTION

1. Background to the study

2. Preliminary reading and influences

3. Research problem statement and question

4. Research methodology

5. Outline of the thesis

CHAPTER 2

LITERATURE REVIEW AND CONCEPTUALISATION OF KEY TERMS

1. Introduction

2. Concerns regarding a lack of methodological pluralism in the social sciences 9

2.1. Over-representation of qualitative articles in British sociological publications $\quad 10$

2.2. The South African historical context 12

2.2.1. South African sociological associations 12

2.2.2. Quantitative research in South Africa 13

2.2.3. Methodological development in the South African social sciences and the 14 international context

3. Previous empirical research on methodological trends 15

3.1. British sociology 15

3.2. Japanese sociology 16

3.3. African sociology 17

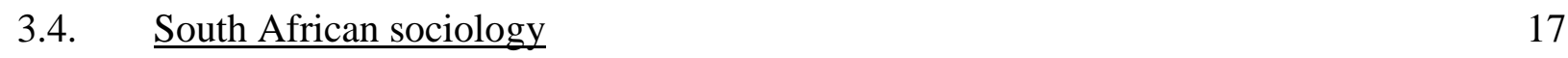

3.4.1. Contributions to the South African Journal of Sociology during the eighties 17

3.4.2. Sociological research in contemporary South Africa 19

3.5. Conclusions 19

4. Influences on research publication 20

4.1. $\underline{\text { Research aims }} 20$

4.2. Cognitive cronyism 22

4.3. Public sociology $\quad 22$

4.4. Summary 22

5. Key concepts defined $\quad 23$

5.1. Empirical research, non-empirical research and theoretical contribution 23

5.2. Methodology 24

5.2.1. Quantitative methodology 25

$\begin{array}{ll}\text { 5.2.2. Qualitative methodology } & 27\end{array}$

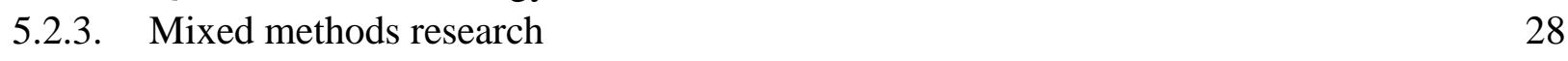

5.3. $\quad \underline{\text { Research designs }} 29$

5.4. Methods, tools and techniques $\quad 30$

6. Chapter summary 31 


\section{CHAPTER 3}

RESEARCH METHODOLOGY

1. Introduction $\quad 32$

2. $\quad$ Research questions and hypothesis $\quad 32$

3. $\quad$ Research design $\quad 33$

4. Sampling design and methods $\quad 33$

4.1. $\quad$ Pilot study $\quad 33$

4.2. Construction of the sampling frame: Databases 35

4.3. Construction of the sampling frame: Articles 37

4.4. $\quad$ Sampling $\quad 40$

5. Data collection, capture and editing $\quad 41$

5.1. The data collection process 41

5.2. Conceptualisation and operationalisation of central variables 43

5.2.1. Operationalisation example $\quad 48$

6. Data processing and analysis $\quad 49$

7. Shortcoming of the study 50

8. Summary $\quad 52$

CHAPTER 4

PRESENTATION AND DISCUSSION OF RESUltS $\quad 53$

1. Introduction $\quad 53$

2. Background: Journals and publication rates 53

3. $\quad$ Research methodologies $\quad 56$

4. $\quad$ Research designs $\quad 58$

5. $\quad$ Sampling methods $\quad 59$

5.1. $\quad$ Probability and non-probability sampling methods $\quad 60$

5.2. $\quad$ Sampling methods and techniques as the unit of analysis $\quad 61$

5.3. Summary 62

6. Data collection methods $\quad 63$

6.1. $\quad$ Data collection methods $\quad 63$

$\begin{array}{ll}\text { 6.1.1. Interview techniques } & 64\end{array}$

6.1.2. Questionnaire techniques 65

6.2. Data collection methods and techniques as the unit of analysis 65

7. Data analysis methods $\quad 67$

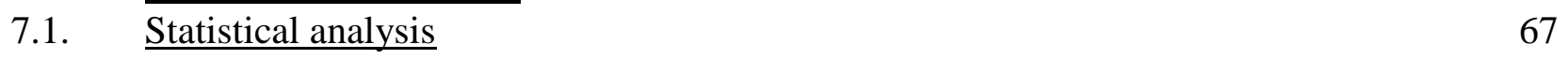

$\begin{array}{lll}\text { 7.2. } & \text { Quantitative and qualitative data analysis } & 68\end{array}$

7.3. Descriptive statistics $\quad 69$

7.4. Data analysis methods and techniques as the unit of analysis 69

8. Other methodological features $\quad 71$

$\begin{array}{ll}\text { 8.1. Time dimension } & 71\end{array}$

8.2. $\quad$ Tendency to pilot $\quad 72$

9. $\quad$ Author collaboration $\quad 73$

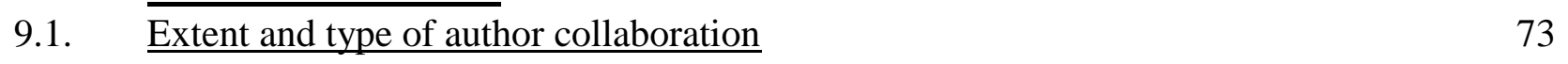

9.2. The relationship between type of author collaboration and methodology $\quad 74$

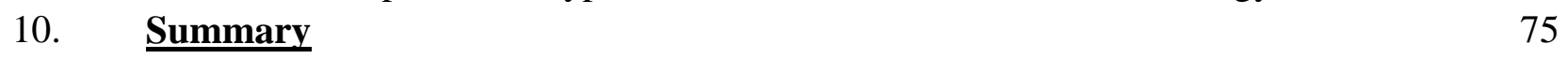




\section{Chapter 5}

CONCLUSIONS AND RECOMMENDATIONS

1.

Introduction

2. Summary of the results

2.1. Methodologies

2.2. Research designs

2.3. Sampling methods

2.4. Data collection methods

2.5. Data analysis methods

2.6. Author collaboration

3. $\quad$ Key insights

3.2. Coding system

3.3. $\quad$ Rhetoric

4. Concluding comments

LIST OF REFERENCES 


\section{LIST OF TABLES}

Table 1 Database hits 38

Table 2 Methodology $\quad 43$

Table 3: $\quad$ Research design 44

Table 4: Sampling $\quad 45$

Table 5: Data collection $\quad 46$

Table 6: Time frame $\quad 47$

Table 7: Disciplinary nature of the journals included in the sample 54

Table 8: Changes over time in research methodology employed, 1990-2009 58

Table 9: Research designs employed 59

Table 10: Sampling methods and techniques employed $\quad 62$

Table 11: Data collection methods employed 63

Table 12: Interview techniques employed 64

Table 13: Data collection methods and techniques employed 66

Table 14: Prevalence of statistical analysis, 1990-2009 67

Table 15: Prevalence of quantitative and qualitative analysis methods, 1990-2009 69

Table 16: Data analysis methods and techniques employed 70

Table 17: Time dimension, 1990-2009 72

$\begin{array}{ll}\text { Table 18: } & \text { Longitudinal subtypes }\end{array}$

$\begin{array}{lll}\text { Table 19: } & \text { Frequency of author collaboration } & 73\end{array}$

$\begin{array}{lll}\text { Table } 20 & \text { Author collaboration, 1990-2009 } & 74\end{array}$

Table 21 Methodology employed by type of authorship collaboration 75

$\begin{array}{ll}\text { Table 22 Reported methods } & 76\end{array}$ 


\section{LIST OF FIGURES}

Page

Figure 1: Publication rates, 1990-2009 56

\begin{tabular}{ll} 
Figure 2: & Research methodology employed \\
\hline
\end{tabular}

$\begin{array}{ll}\text { Figure 3: } & \text { Sampling strategy employed } \\ \end{array}$

Figure 4: Prevalence of quantitative and qualitative analysis methods 68 


\section{ACRONYMS AND ABbREVIATIONS}

ASSA Association for Sociology in Southern Africa

ASSAf Academy of Science for South Africa

BSA British Sociological Association

DoE (South African National) Department of Education

DHET (South African National) Department of Higher Education and Training

ESRC (British) Economic and Social Research Council

HIV Human Immunodeficiency Virus

HIV+ HIV positive

HSRC Human Sciences Research Council

IBSS International Bibliography of the Social Sciences

IEASA International Education Association of South Africa

ISAP Index to South African Periodicals

ISSN International Standard Serial Number

MS Microsoft

NRF National Research Foundation

PAR Participatory Action Research

SAS Statistical Analysis System

SASA South African Sociological Association

SAJS South African Journal of Sociology

SASOV Suid-Afrikaanse Sosiologie Vereniging

SDA Secondary Data Analysis

IBM SPSS International Business Machines Corporation's Statistical Package for the Social Sciences

WoS (Thomson Reuters) Web of Science 


\section{CHAPTER 1: INTRODUCTION}

\section{Background to the study}

Some are of the opinion that the social sciences do not yet, or ever will, have a fixed set of unifying principles and standards, i.e. as being pre- or post-paradigmatic (Della Porta \& Keating, 2008:20). This may be argued as particularly relevant to sociology: as a discipline it does not limit itself to a single meta-theory, as the presence of various approaches - e.g. positivism, phenomenology, hermeneutics, and critical theory - demonstrates (Smelser 1994, as cited in Sztompka, 2010:21). This diversity can be considered an asset to sociology, as it may be argued that understanding the social world with its multiple facets requires knowledge in more than one field, and skills in more than one method (Payne, 2007:901). A corollary concern is that an over-emphasis within the discipline on one type of method or approach could lead to, or be indicative of, a lack of skill in other types of methods, which could lead to certain topics being ignored or explored in an inappropriate manner. This relates to the topic of methodological pluralism: the viewpoint that a mature sociology should incorporate a variety of approaches, e.g. explanatory, predictive and humanistic methods, to enable the development of an informed understanding of the topics that sociology covers (Greener, 2011; Payne, 2007; Payne, Williams \& Chamberlain, 2004; Alexander, 2004b).

Concern has been raised in both international and local (South African) literature about a lack of diversity of methods and methodologies in academic sociological research, as this could have a detrimental effect on the discipline's ability to sufficiently explore a variety of sociological topics. Specifically, since the early 1990s the possibility has been raised that a qualitative methodology and related methods seem to be used in the majority of sociological research, and that this is perhaps due to (and perpetuated by) a lack of statistical skills among the researchers (Payne, 2007; Seekings, 2001; Oosthuizen, 1991:45; Oosthuizen, 1991:96-97). With regard to the South African case in particular, scholars argue that, even though sociological departments do teach quantitative methods, these methods are often not used when research is conducted, possibly due to distrust of these methods, or time and budgetary constraints (May, 2005; Seekings, 2001). When quantitative methods do feature, they tend to be applied with the assistance of researchers outside of South Africa (Seekings, 2001:26-27).

This raises concerns about the state of sociology in South Africa, both in terms of the skills available to the discipline, but also its ability to explore a wide variety of social topics adequately. A lack of a variety of research approaches may bode ill for the development of a sociological understanding of the complicated social issues facing South Africa, as it limits the ways in which 
these multiple-faceted issues can be explored. The aim of this thesis is to explore the extent of methodological pluralism in sociological research and to determine whether one type of approach is preferred above others.

Methodological pluralism in its wider interpretation also refers to collaboration between researchers with different knowledge and skill sets (Payne, 2007:904-905). As mentioned above, in the South African literature it has been suggested that research published in collaboration with international authors is more likely to be of a quantitative nature than those which only South African authors worked on (Seekings, 2001:26-27), and thus the topic of collaboration is also explored in this thesis.

As indicated above, not only is a lack of methodological pluralism detrimental to the health of a discipline, as the topics are not investigated from all angles and a comprehensive understanding of the subject is thus not possible, but it could also be indicative of a lack of skills in a variety of methods. For any strategy to be employed to improve the skills of researchers, it is necessary to know in which aspects of research improvements are needed. This thesis also sets out to investigate some of the statements made by other social researchers on the topic of methodology in South African sociology. As there has been no recent empirical review of the methodological practices in sociology in South Africa that can answer these questions, this thesis aims to fill this gap.

\section{2. $\quad$ Preliminary reading and influences}

The research question for this thesis evolved from the coursework I completed in partial fulfilment of an MPhil Programme in Social Science Methods. This included modules intended to introduce and equip students with both quantitative and qualitative research skills, which sparked my interest in determining which methodology - quantitative or qualitative - is most prominently employed by academic researchers in the social sciences in South Africa.

The preliminary reading on the topic of methodology in the social sciences started with Payne (2007), who introduced me to the concept of methodological pluralism and the potential issues related to the lack thereof in sociology. This discussion specifically focused on British sociology and its lack of published research that is of a quantitative nature. One of the possible reasons cited for this, was that sociologists are not confident using quantitative methods due to lack of expertise. Further reading was required to determine what research has been conducted in South Africa on the topic of methodology in the social sciences. A search for articles describing methodological trends in the South African social sciences led to an article reporting on methods used, as reported in research articles in the South African Journal of Sociology (SAJS) during 1980 to 1990, and which covered various aspects of social research (Van Staden \& Visser, 1991). The authors, Van Staden 
and Visser, investigated what proportion of articles in the SAJS is of an empirical nature; whether authors reported how sampling was conducted and defined their target populations; whether authors reported limitations of their sampling methods; how often cross-cultural research was conducted; what research designs were employed; and what type of statistical methods were employed. Their research painted a very different picture from what Payne describes, as the methods were heavily quantitatively focused. Another article by Van Staden and Visser (1992) reported on similar studies comparing the findings in the South African Journals of Sociology Education and Psychology. The results showed that in only a quarter of the cases a representative sample was drawn and almost a third of the articles did not explain how sampling was conducted. Only 5\% of all the sampled articles reported on a qualitative methodology, and basic statistical techniques were favoured over more advanced ones (Van Staden \& Visser, 1992:77).

Further exploration of the South African literature showed that Van Staden and Visser's analysis of the methods used in the SAJS was the first and last to investigate the topic of methodology empirically, and in such detail, in relation to South African sociology. Their study was followed by articles commenting on the results and the implications thereof, and these articles were next in the preliminary readings. J.S. Oosthuizen (1991) noted the importance of such a review, especially to identify shortcomings in sociological research in South Africa and the need for improvement in the next decade. The shortcomings he focused on concerned the lack of empirical research, as many of the articles were of a theoretical or review nature; the almost complete lack of qualitative research; and the lack of statistical sophistication which he indicated could be due to shortcoming in research training. Groenewald (1991), on the other hand, criticised Van Staden and Visser's review stating that the analysis was "done according to very rigid and standardised scientific criteria which portrayed a-historical positivism not sensitive to trends in the development of local and international sociology" (1991:46). Examples hereof are that the questions Van Staden and Visser set out to investigate are heavily focused on quantitative research and that there is no explanation why cross-cultural research should be important in South Africa. Also Groenewald argues that the works published in the SAJS are not a representative collection of all the research published by South African sociologists at that time, and that Van Staden and Visser's generalisations are therefore not valid.

Oosthuizen's statement that Van Staden and Visser's article: “opens our eyes for some serious shortcomings in our published sociological output - shortcomings that need urgent attention in the nineties" echo's the goal of this thesis. This statement calls for these methodological questions to be revisited to determine whether these shortcomings have been improved upon. As such, the initial inspiration for this thesis was to replicate the study by Van Staden and Visser (1991) to investigate 
the methods used in the 20 years since their study. However, as Groenewald's article pointed out, the methods used to investigate the topic would have to be adapted in the thesis to avoid the overemphasis on quantitative methods.

Seekings (2001) and Alexander (2004b) touched on some of the topics raised earlier. The former commented on the development of quantitative research in the social sciences, introducing the idea that the methodologies favoured in social sciences in South Africa might be different from those in the USA and Europe. He also suggests that since 1990 various new data sources and other opportunities for quantitative research have become available, and various social sciences (economics, political science, criminology, sociology and education) in South Africa have reacted in different degrees to these, with sociology responding the slowest. Specifically, Seekings also suggests that quantitative research in South Africa is often conducted with assistance from outside of South Africa; however, this claim has yet to be substantiated empirically. It is therefore investigated in this thesis, by considering whether research published with international collaborators is more likely to have employed a quantitative methodology than research published solely by South African authors. Also, statements that South African social sciences have not been following international methodological trends (Seekings, 2001; Oosthuizen, 1991) render an investigation of the South African case relevant.

In a paper written for the National Research Foundation (NRF), Alexander (2004b) touches on the subject of methodological pluralism, even if he does not explicitly use the term, when he suggests that social scientists with different methodological expertise should co-operate and use insights and approaches from both the qualitative and quantitative methodologies (2004b:10). The document claims that scholars at Afrikaans-medium universities focus more on quantitative research, while those at English-medium universities prefer to conduct qualitative research. Even though his claim is not investigated in this thesis, it does touch on the concept of methodological pluralism, the need for it in South African sociology, and the differences between academic institutions within the South African context.

Practical considerations which influenced the choice of research question for this thesis were my interest in replication studies and my academic background. During my undergraduate studies I have developed an interest in replication studies that update findings of older studies, or conduct similar studies in different contexts. This thesis gave me the opportunity to make a contribution to the information South African sociologists have at their disposal when discussing the topic of methodological pluralism, by replicating earlier research with a more recent analysis of articles published by South African authors. Secondly, as I did not gain much exposure to the discipline of sociology during my undergraduate studies (it was not one of my majors), this thesis provided an 
opportunity not only to learn more about the process of reporting on social research, but also on the topics covered by sociologists.

\section{3. $\quad$ Research problem statement and question}

For the purposes of a Master's thesis, the scope of the research problem needed to be reduced to manageable proportions, and the first step was to narrow down the topic to a single discipline, i.e. sociology. Even though some of the literature consulted at the preliminary stage of this research covered the social sciences as a whole, and others covered a range of social science disciplines, sociology was selected, as I am registered in the Department of Sociology and Social Anthropology, supervised by a sociologist, and my preliminary literature search yielded a variety of articles on the topic of methodological pluralism with a specific focus on sociology.

The thesis study was intended to be a replication of Van Staden and Visser's study (1991). However, after reviewing the literature it was decided to deviating somewhat from their approach, primarily to improve on the shortcomings highlighted by their critics. Although the aspects investigated in this thesis are similar to those Van Staden and Visser dealt with, there are a number of differences as well. First, a greater variety of journals was included to avoid the main critique that Groenewald had with Van Staden and Visser's study. Secondly, Van Staden and Visser included both empirical and theoretical contributions in their population, whereas this thesis (after much deliberation) only included empirical contributions. Thirdly, Van Staden and Visser focussed on finer details of sampling design, which included defining the accessible population. Also, the thesis research problem statement was expanded to include an investigation of the methods used during different stages in the research process (i.e. sampling, data collection and data analysis), and research designs. Lastly, mixed methods research was considered a separate methodology, in addition to quantitative and qualitative methodologies.

The fact that this thesis was intended as a follow-up to Van Staden and Visser's study informed the time frame for the research: the starting point (1990) was when Van Staden and Visser's study ended (1989), and the year in which data were collected for this thesis (2009) was defined as the end point. The research question to be addressed by the thesis was then re-articulated as follows: which methods and methodologies have been employed by South African sociologists from 1990 to 2009? This can be divided into four research questions:

- What are the sampling, data collection and data analysis methods that South African sociologists have used during the past two decades?

- Have there been any changes in the methods used since 1990?

- $\quad$ Has collaboration (local and international) increased since 1990 ? 
- Does collaboration with non-South Africans have an effect on the methodology employed?

"South African sociological research" was operationalised as the content of full-length, empirical research articles published in peer-reviewed journals by at least one author with a South African institutional address, and which deals with a sociological topic. Only articles from peer-reviewed journals were included as generally only these are included in bibliometric studies (Prozesky, 2006:144).

The first research question required a cross-sectional analysis. Sampling methods were investigated by examining the type of sampling (probability or non-probability) methods, as well as the variety of techniques, employed. Data collection methods were investigated by considering the variety of methods used. Data analysis methods were investigated by examining the frequency with which statistical analysis occurred, and the variety of methods that were used. The second research question required the data to be analysed longitudinally. The third research question required a longitudinal, the fourth a cross-sectional analysis. The expectation was that the methods would be different from what Van Staden and Visser (1991) found: not only had time passed, but this study used a variety of journals as data sources, while Van Staden and Visser only used one. The prediction was that, over the years more qualitative (and eventually much more than quantitative) research would be published, in line with international trends, which since the 1990s have been followed more closely due to increasing international interaction (Payne, 2007; Seekings, 2001; Oosthuizen, 1991). It was also expected that the reporting on sampling would improve and the relatively extensive use of non-probability sampling would decrease as the discipline became more aware of the limitations of such practices. International collaboration was expected to have increased, due to South Africa becoming less isolated, and research produced through international collaboration would most likely be of a quantitative nature, as suggested by Seekings (2001).

The overall goal of this thesis is therefore to provide a follow-up on Van Staden and Visser's study, in order to provide a more recent picture of what methodological practices have been prominent during the past two decades in South African sociology. An attempt was made to avoid the same pitfalls the critics of their study highlighted, and to provide a more representative picture by including a wider variety of journals as data sources and, consequently, qualitative and mixed methods methodologies as well. Specific attention was devoted to predictions made by Van Staden and Visser (1991) and other scholars, such as Seekings (2001) and Alexander et. al. (2006).

\section{4. $\quad \underline{\text { Research methodology }}$}

The study reported in this thesis employed a quantitative methodology in the sense that a probability sample - a stratified systematic sampling with a random start - was drawn, and the aim 
is to generalise to the population from which this sample was drawn, i.e. all articles with at least one South African author, published in English from 1990 to 2009 in a peer-reviewed journal and on a sociological topic. Furthermore, it involved the predominantly statistical analysis of data that are either quantitative in nature, or were quantified by coding the methods described in the sampled articles. Where appropriate, chi-square tests were used to test whether differences observed across cases and over time are statistically significant.

The research design is categorised as content analysis, because the data sources (research articles) constitute written forms of communication, which provided textual data for analysis during which specific themes (i.e. methodological trends) were explored. A pilot study was conducted to test the appropriateness of different sampling strategies, as well as to pre-empt potential problems that could arise during data collection.

\section{Outline of the thesis}

Chapter 2 presents the empirical and theoretical literature that has been reviewed for the purpose of this study, and provides a conceptualisation of the key terms used in this thesis. The literature review commences with a discussion of methodological pluralism, and considers what has been written about related concerns in international and local literature. It also elaborates on the history of the different sociological organisations in South Africa, to indicate its relevance to and influence on the study design. The literature review concludes with examples of previous studies on topics similar to the focus of this thesis. The second half of Chapter 2 elaborates on the meaning of different methodological terms and explains how they should be understood in the context of this thesis. These terms include, but are not limited to: empirical research, non-empirical research, methodology, quantitative methodology, qualitative methodology, mixed methods research methodology, participatory action research, methods, tool, techniques, and research design.

Chapter 3 elaborates on the research methodology and methods employed in the study reported in this thesis, which also includes a discussion of the pilot study, and shortcomings of this thesis. In this chapter, the research questions are operationalised, the quantitative content analysis research design is explained, and the steps of the sampling method are described in detail. The rationale underlying the choice of databases for the collection of the articles, as well as the different strategies employed to ensure that only those articles that meet the selection criteria were included in the sampling frame and sample, are explained. Lastly, the data analysis process is described with reference to the fact that the study is primarily descriptive in nature, and makes use of both crosssectional and longitudinal analysis. 
Chapter 4 constitutes a presentation and discussion of the results of both the cross-sectional and longitudinal analysis of the variables discussed in Chapter 3. The results are presented in tables and figures, which are discussed along with the results of chi-square tests of statistical significance of the observed differences and trends. Chapter 4 concludes with comments and observations which are further elaborated upon in Chapter 5, in the form of conclusions of, and recommendations that flow from, this thesis. This last chapter revisits the research problem statement and research questions in the light of the findings, which are then also related to the literature. This is followed by a critical reflection on the databases used for data collection, the coding system used for analysis, and on the research article as a rhetorical device, which leads the author to conclude with suggestions for future studies. 


\section{CHAPTER 2: LITERATURE REVIEW AND CONCEPTUALISATION OF KEY TERMS}

\section{Introduction}

The first part of this chapter, which present a review of the literature relevant to the research problem formulated in the previous chapter, aims to outline some recent methodological issues concerning methodological pluralism that have been raised in relation to sociology as a discipline, both internationally and locally. In subsequent sections, the chapter reviews the way in which other researchers have examined topics similar to the one investigated in this thesis, and what can be learnt from such a review. Potential influences on research and publication trends are also investigated, such as the separation of sociological associations in the past in South Africa. This chapter concludes with a conceptualisation of the key terms (such as methodology and research design) that are relevant to the thesis.

\section{Concerns regarding a lack of methodological pluralism in the social sciences}

This thesis investigates the distribution of different methods and methodologies in sociological research in South Africa, by investigating the research published by South African authors from 1990 to 2009. To be able to investigate this, first a literature review was conducted to determine whether any methodological trends have been observed elsewhere. Various studies have been conducted on methodological practices that are favoured in different countries around the world. Differences in their results may be due to variations in the time when the observations were made (and the articles that were used as data sources, were published), as well as influences specific to the country on which the studies focus. Some argue that American social science research articles show a high level of sophistication in terms of the quantitative methods employed (especially in comparison to South African research) (Seekings, 2001:1; May, 2005:521; Olzak, 1990; Van Staden \& Visser, 1991), while other authors express concern about qualitative methodology dominating the publications of leading British sociology journals. What follows is a review of literature discussing recent methodological trends in British sociology, as well as those that relate specifically to South African sociology. The literature on British sociology is reviewed, as it includes a variety of scholarly articles that deal with methodological pluralism - a key term in this thesis. Literature on South African sociology is then reviewed, with a specific focus on work that touches on issues related to methodological pluralism. 


\subsection{Over-representation of qualitative articles in British sociological publications}

Payne (2007) and Payne et al. (2004) raise a concern that British sociology, as published in some of the British Sociology Association's (BSA's) journals, lacks “methodological pluralism”, and they discuss the causes and potential dangers of its absence. Methodological pluralism refers to a knowledge and appreciation of a variety of methods and methodologies which arguably leads to more informed research. With knowledge of, and at least some skill in, multiple methods and methodologies, researchers might approach their research problems in a more informed manner, and not avoid questions that require a different approach than the one they have become accustomed to (Della Porta \& Keating, 2008:36-37; Payne, 2007; Neuman, 2011:91). This argument could be taken a step further by stating that methodological specialists should be encouraged to engage in more collaborative research, through which a topic can be investigated extensively, using multiple methods and a variety of researchers' shared knowledge and fields. This is based on the assumption that "[e]xploring multidimensional social life requires knowing about more than one field and having skills in more than one method" (Payne, 2007: 901).

Williams, Payne, Hodgkinson \& Poade (2008:1017) and May (2005:521-522) elaborate on how the British Economic and Social Research Council (ESRC) encouraged and funded training in research methods to enhance researchers' competency in multiple methods, albeit with a noticeable focus on strengthening skills in quantitative research methods. This initiative was fuelled by the acknowledgement of the need for methodological pluralism, as well as concerns about the dominance of one methodology - in this case qualitative methodology - in British sociological research publications. The fear that qualitative research is overrepresented in these publications seems to be confirmed by a study (Payne et al., 2004:156) conducted using four leading British sociological journals as data sources: Sociology, British Journal of Sociology, Sociological Review and Sociological Research Online. The study investigated, amongst other topics, what methods were used in articles published in these journals during 1999 and 2000, and it was found that qualitative methods were indeed dominant.

A high percentage of qualitative (or quantitative) research articles is not an indication that qualitative (or quantitative) methods are more suited for sociological research. No one methodology is superior to another; different methodologies merely aim for different goals and produce different types of data. The types of data needed to answer a question are dependent on the research question. In that sense, one particular methodology is not inherently more likely to produce good research; certain research questions require a certain logic which is more suited to certain methodologies (Payne, 2007:903; Greener, 2011:2-3; Neuman, 2011:91). For example, if a study aims to determine how many students on Stellenbosch campus speak both Afrikaans and English, then 
using a qualitative approach with in-depth interviews is quite unlikely to answer the question sufficiently. On the other hand, if one intends to investigate the experienced lives of street children in Stellenbosch, then a qualitative approach seems more appropriate, as one is not interested in numbers, but rather meaning and in-depth description.

One of the central concerns with the over-representation of qualitative research is that those questions requiring a quantitative approach might simply be avoided by sociologists when selecting topics for their research. With regard to British sociology, Payne (2007:903-904) notes that questions which involve sociological relevant topics and which utilise quantitative methods are still conducted and published; however, they are not appearing in sociology journals and are not published by sociologists. This raises the concern that quantitative studies are being avoided, at least by sociologists, because qualitative methods might be the only ones with which researchers are comfortable, and thus they avoid topics that are sociologically relevant. The ESRC's attempt to rectify this is to cultivate competency in quantitative methods through training in these methods. Williams et al. (2008) conducted a national survey of British sociology undergraduates studying methodology, and found that more than half of them are anxious about statistical methods. Moreover, focus group interviews illustrated that qualitative methods are highly preferred, which could perpetuate the avoidance of quantitative research questions and the over-utilisation of qualitative research methods.

Payne cites possible reasons for the observed lack of methodological pluralism, which include researchers' lack confidence in quantitative methods, a bias among editors of sociological research journals against articles reporting on the use of quantitative methods, and a possible lack of interest in research questions which require a quantitative approach. A potential side effect of a lack of skill and/or interest in quantitative methods among British sociologists is that it would make it more difficult for the discipline in that country to compete with other disciplines for resources when exploring topics which need more than a qualitative approach (Payne, 2007:903; Payne et al., 2004:162). In response to Payne et al. (2004), May (2005) mentions other possible reasons for the observed over-representation of qualitative research in British sociology. First, he suggests that the journals Payne et al. (2004) used as data sources are more inclined to attract qualitative research, and that sociologists are still publishing their quantitative findings, but simply in other journals, including those published in other countries. May further suggests that conducting and publishing qualitative research might be more suited and advantageous to young sociological researchers, and is thus published more. Qualitative research is generally perceived as requiring fewer resources to conduct, as it is usually undertaken on a smaller scale and mostly requires only time and effort (although May neglected to consider that the need of fewer resources is also true of secondary data 
analysis). Another factor that renders qualitative research more suited for postgraduate and junior researchers is that it considers the individual researcher as the research instrument, and this works in the researcher's favour in the academic context where a researcher's productivity as an individual is valued, especially for career advancement. This stands in contrast to large, quantitative, experimental studies that require comparably more time, resources and expertise from different fields, and are thus often published by multiple authors (May, 2005:523).

This section described the concerns some British sociologists express with regards to a lack of methodological pluralism as well as the consequences thereof that they foresee for British sociology. The situation in British sociology raises the question: to what extent does this lack of methodological pluralism in sociological research publications apply to South African sociology? Before continuing, the historical context of institutionalised, academic sociology in South Africa needs to be considered.

\subsection{The South African historical context}

This sub-section commences with a brief history of the context and development of South African sociology from 1960 to 2009, with a focus on the development of sociological associations and journals. Thereafter it provides an overview of how quantitative sociological research has developed in South Africa, as well as a review of the literature on methodological trends in the social sciences of South Africa.

\subsubsection{South African sociological associations}

During a meeting held on 16 June 1966 the divide between the two sociological associations in South Africa started, i.e. the Suid-Afrikaanse Sosiologie Vereniging (SASOV) and the Association for Sociology in Southern Africa (ASSA), only to reunite in the early 1990s. The concurrent existence of two sociological associations not only split sociological publication in the country according to race and university, but also according to language. Language is an important consideration, as international journals generally publish articles written in English. Even before this divide between organisations South African universities were split between Afrikaans-medium and English- medium universities (Groenewald, 1984).

The associations also followed different professional and ideological, and thus methodological, paths. Seekings (2001) elaborates on the distrust of quantitative methods that existed in the Marxistdominated ASSA and in the English-medium universities. Also, as mentioned earlier, these associations each had their own journal and the nature of research published in each differed dramatically (Webster, 2004:29). However, in 1992 the sociological associations merged to become the South African Sociological Association (SASA) and in 1997 instituted one official journal, 
Society in Transition, which in 2005 changed its name to the South African Review of Sociology (SARS) (Jubber, 2007:528).

Of particular relevance for this thesis, which aims to describe the methodological nature of sociological research in South Africa over the past 20 years, is the need to analyse the content of more than one journal, as on their own the journals of the various associations would not provide a complete picture of sociological research in South Africa. Also, it should be taken into consideration that sociologists do not only publish in the abovementioned journals (Webster, 2004:30; Botes, Van Rensburg \& Groenewald, 1991; Groenewald, 1991). After the advent of democracy in South African, the state demanded research that was policy-orientated and internationally competitive (Mouton, Boshoff \& Tjissen, 2006). This drew attention away from critical and public sociology towards an instrumental approach to sociology, which arguably translated into an increase in social scientists publishing in accredited ${ }^{1}$ journals, and perhaps a decrease in public sociology, which is not necessarily published in academic journals.

\subsubsection{Quantitative research in South Africa}

In 1990, Olzak wrote a report on the state of sociology for the Human Sciences Research Council (HSRC), in which she provides an account of some of the most prominent issues she observed in sociology in South Africa at the time. Some of the issues she touched on were a lack of interaction between Afrikaans- medium and English-medium universities and between universities and the HSRC; as well as concerns about the privatisation of research and the outdated skill sets of researchers. Commenting on Olzak's report, K. Oosthuizen in the early nineties noted a concern she expressed about the lack of statistical sophistication in conducting and planning research projects (Oosthuizen, 1991:96-97). Olzak is specifically concerned with the level of computer literacy, outdated statistical textbooks and the lack of advanced research methods in graduate coursework. Possible explanations for the generally low quality of statistical methods used by social scientists are also provided. These relate mostly to the lack of expertise at South African universities, which was aggravated by the isolation that South Africa experienced because of apartheid, as well as the lack of interchange between Afrikaans-medium and English- medium universities.

A further concern that Oosthuizen raises is that a lack of statistical expertise would eventually lead researchers to adopt qualitative rather than quantitative methods, which in turn would lead them to specialise in those methods and render them unable to competently train future researchers in quantitative methods (Oosthuizen, 1991: 96-97). Thus, the concern expressed by Payne that

\footnotetext{
${ }^{1}$ In this thesis, the term "accredited" refers to journals that publish peer-reviewed articles that the Department of Higher Education and Training (DHET, previously the Department of Education [DoE]) has approved, based on quality considerations, for subsidy. It is through the provision of this subsidy to Higher Education Institutions (HEIs) for their research outputs that the DoE aimed, and the DHET still aims, to promote the publication of scientific articles.
} 
British sociology tends towards a hyper-specialisation of method might apply to South African sociology as well, where the problem could become self-perpetuating.

\subsubsection{Methodological development in the South African social sciences and the international context}

Some trends with regard to the research methodologies used by South African sociologists have been identified in the literature. According to Seekings (2001), quantitative research suffered during the apartheid era, not only in sociology, but in the disciplines of economics, political sciences, criminology, and education as well. This is due to the state not providing or producing the data necessary for such research. The availability of quantitative data improved after South Africa became a democracy, but the various social science disciplines reacted to this differently. In particular, Seekings deems sociology to be the social science discipline that responded the slowest to the new availability of data. However, Seekings's assessment is based on research conducted more than 10 years ago, and there is no empirical evidence that this is still the case. Furthermore, Seekings (2001) only mentions that not enough quantitative methods are used, and those that are used, are not sophisticated enough when compared to those used in Europe and the USA with no indication what the case is with qualitative methods. In addition, he assesses a range of research projects, which are not necessarily all published as journal articles, thus his research does not provide a valid indication of the type of methodology researchers favour when conducting research they later publish as articles

Finally, of relevance to this thesis is a characteristic of social research in South Africa noted by Seekings, i.e. that much of the quantitative research has been conducted by international scholars and sponsors (Seekings, 2001:26-27). This raises interesting questions concerning the extent to which South African sociologists tend to publish with researchers from other countries, and whether research conducted in that manner tends to be of a quantitative nature. This assessment by Seekings is more than a decade old, and not based on an empirical, representative and systematic analysis of the frequency with which methods are employed. It therefore raises multiple questions which this thesis seeks to address. The literature reviewed in this and the previous section shows that at least some British and South African sociologists are concerned about a lack of methodological pluralism and, in particular, an increasing tendency among sociologists to give precedence to qualitative methods. Possible reasons for this phenomenon have been cited, including funding strategies, political "steering" of academic research, and the teaching environment in academia and these are elaborated on later in this chapter. The next section discusses a few other studies, both local and international, that have investigated empirically the type of research methodologies employed by social scientists in a country, or as reflected in a specific journal, by using scientometrics and 
bibliometrics, i.e. a quantitative investigation of science through the analysis of published work (Hood \& Wilson, 2001).

\section{Previous empirical research on methodological trends in the social sciences}

Reviewing other research with similar goals and methods (i.e. making use of scientometrics and bibliometrics to analyse the type of research methodologies employed by social scientists in a country) to this thesis allowed the author to make an informed decision as to the most appropriate strategy to employ in order to address the research problem guiding this thesis. Various scholarly articles are reviewed, which include the previously mentioned work by Payne et al. (2004), but here the focus is on the research process and the lessons to be learned for designing the research for this thesis. Other articles include an overview of sociology in Japan, a review of the African Sociological Review and lastly, a section dedicated to sociological research in South Africa.

\section{1. $\quad$ British sociology}

As referred to earlier in this chapter, Payne et al (2004) conducted a study to investigate national patterns in research methods used by sociologists, as deduced from an analysis of articles published in 1999 and 2000 in four leading, general British sociology journals and another more specialised journal, as well as papers presented at a British Sociological Association annual conference during the same period.

The aspects investigated were: 1) the research field the studies covered; 2) type of methods used, categorised as non-empirical, qualitative, quantitative, or qualitative-and-quantitative; 3) level of quantitative analysis; 4) sex of authors; 5) the universities with which the authors were affiliated; and 6) the status of authors, categorised as junior staff, senior staff, mixed and non-academic. Focussing on a small sample of journals and years, it was possible to collect more data on the authors themselves, and by not limiting the data collection to one journal, a broader scope of articles could be analysed. However, the short timeframe of two years did not allow an investigation of trends over time, as this thesis aims to do.

On a methodological level, May (2005) critiques the study by suggesting that those journals that were selected as data sources may attract qualitative research in particular, while quantitative research may be published in other journals, specifically specialised journals. In the design of the research for this thesis, it was therefore considered important to analyse articles published in as wide a variety of journals as possible, without losing the focus on sociology. Payne et al. (2004:159) also included non-empirical methods alongside quantitative and qualitative methods 
when they analysed research methods, which was something that needed to be considered for this thesis.

\subsection{Japanese sociology}

Nakao (1998) conducted a study aimed as describing trends in terms of theory, methods and empirical research in the field of contemporary sociology in Japan, by analysing scholarly publications of the preceding 30 years. Nakao stresses that it is important to consider the conditions in a country when evaluating the sociology practised in that country, as sociology is the study of society and thus directly influenced by its national context. He describes the historical context of Japan, which assists the reader in interpreting the descriptive data that were collected (Nakao, 1998:499-508). As Japan has a unique history that influenced the type of research that could be conducted and the topics that were considered relevant, so does South Africa. It is thus important in this thesis to take cognisance of national historical context, which will therefore form the backdrop against which the data will be interpreted.

After describing the context and discussing the topics covered over the preceding 30 years, Nakao's focus then shifts towards the types of sociological research that were conducted. This description mainly focuses on the distinction between theoretical and empirical research, as well as the methods (qualitative or quantitative) used. Content analysis was applied to the content of articles published in the primary Japanese sociology journal, Shakaigaku Hyouron, and to Riron-toHouhou, a journal publishing empirical, methodological and mathematical articles. It became clear that in more recent years the majority of articles were theoretical ${ }^{2}$ rather than empirical in nature, although empirical research still enjoyed much attention. Nakao further shows that in Japan in the period 1990-1994, the type of empirical research conducted changed as what had until then been mainly quantitative research (perhaps reflecting the influence American research had on Japan) was gradually being replaced by qualitative research (Nakao, 1998).

Nakao expresses concern about the trends identified, but his concern is not directly expressed in terms of methodological pluralism; rather, his concern is that theoretical work is not substantiated by empirical research in Japanese sociology, especially as represented in Shakaigaku Hyouron, and Riron-to-Houhou, and in that sense one type of research is over-presented in the literature to potential detrimental effect (Nakao, 1998:510-512). Nakao states that the Japanese university structure encourages field specialisation, but not extensive methodological training. Both of these aspects are viewed as barriers to Japanese sociology becoming truly competitive internationally (Nakao, 1998:514).

\footnotetext{
${ }^{2}$ The terms "theoretical scholarship", "theoretical works", "theoretical papers", and "purely theoretical" all refer to nonempirical research, as explained later in this chapter.
} 


\subsection{African sociology}

Oloyede (2006) also applied scientometrics and bibliometrics to assess and describe the content of the journal African Sociological Review during the period 1997-2006. Of particular interest in his study were the types of articles and other documents published, the methods used in the empirical research, the topics covered by the articles, and the authors' institutional and country affiliation. Even though most of the data collected related to the authors, Oloyede provides an example of how one could analyse publication trends, and therefore valuable insights as to how the research for this thesis could be approached.

The content of the empirical papers were classified and coded using predefined categories used in the journal Contemporary Sociology to classify books reviewed. The empirical articles were categorised according to the "primary evidentiary base" (Oloyede, 2006:198) used by researchers, as reported in their articles. This involved first distinguishing whether an article reported the use of mostly primary or secondary data, and then whether qualitative or quantitative methods were used in the research. As all the articles also included information on authors and their affiliations, these data were also collected and analysed, either to determine how many times an author published in the journal, or from which institutions or countries the articles originated (Oloyede, 2006:198-199).

For this thesis it was also decided to use pre-defined categories to classify article types and research designs, but not for research methods, as these are described and analysed in more detail than simply distinguishing between the use of primary and secondary data and whether the methods were qualitative or quantitative in nature. Thus, while Oloyede focuses more on who contributes to the African Sociological Review, the nature of the journal (including the topics covered) and what it had achieved during its first ten years of publication (Oloyede, 2006:205), this thesis incorporates a variety of journals, and focuses on a more detailed description of the methods and methodologies employed.

\section{4. $\quad$ South African sociology}

A review of studies with similar goals to those of this thesis, and with an explicit focus on South Africa, has a two-fold goal. Firstly, it can assist in identifying issues unique to the South African context and secondly, it uncovers areas of interest which have not been researched yet.

\subsubsection{Contributions to the South African Journal of Sociology during the eighties}

More than two decades ago, Van Staden and Visser (1991) investigated the content of the South African Journal of Sociology (SAJS), as published during the eighties. They considered the types of documents published, the research designs that were reported in the research articles, and the sophistication of the statistical tools used. They also evaluated whether statistical methods were 
used correctly by researchers (i.e. for them to be able to draw valid conclusions and generalisations), as well as the level of sophistication of the quantitative analysis methods employed. The limitations non-randomness pose in terms of the external validity of some studies, specifically those which aim to use inferential statistics, received special attention in Van Staden and Visser's analysis. They observed that $63 \%$ of the research they analysed made use of nonrandom (or non-probability) sampling methods, while in $24 \%$ of the cases no explanation was offered of how sampling was conducted (Van Staden \& Visser, 1991:38). It was found that during the eighties, sociology in South Africa was dominated by quantitative methods (Van Staden \& Visser, 1991: 33-37).

The study, even though limited to one journal, forms the starting point of the research conducted for this thesis. It is one of the few empirical studies that aim to describe South African sociology with reference to the research designs and methods employed. Van Staden and Visser also took a longitudinal approach, covering the time period 1980-1989, which allowed for trend examination. The choice of time period (1990-2009) for this thesis also allows for longitudinal analysis, and was informed by Van Staden and Visser's work. In addition, Van Staden and Visser's study is one of the only empirical studies of social science research in South Africa that involved a detailed investigation of research designs and methods used in sociological publications.

The study was criticised by Botes et.al., (1991:50-51) for generalising from the SAJS to all South African sociological research, which is published in a variety of different journals. Van Staden and Visser's review was further critiqued for being a-historical and positivistic (Groenewald, 1991:46). Even though it set criteria for the evaluation of statistical methods, it paid little attention to how research that does not apply a quantitative methodology, should be evaluated. The authors also did not take note of the historical or political context that prevailed at the time the research they reviewed was conducted, which could have provided possible explanations for the trends they had found. For example, their research showed an interest among sociologists in crosscultural research, but they did not provide any explanations as to why this would have been the case in South Africa at the time. Furthermore, they did not mention the different sociology associations, nor of the influence these might have had on methodological trends, thereby again limiting the degree to which they could generalise to all South African sociological research.

During the same time period covered by Van Staden and Visser's study, Europe and America experienced a shift towards qualitative methods, but this was not the case in the SAJS. This shows that, at least during the 1980s, methodological trends evident in sociological research published in the SAJS did not reflect those evident in non-South African journals. 


\subsubsection{Sociological research in contemporary South Africa}

A few years ago, Alexander, Basson and Makhura (2006) described trends in South African sociological publications. Similar to Oloyede, they focused primarily on the demographics of the researchers and the topics that had been covered.

To identify sociological research, the Nexus Database of Current and Completed Research Projects was searched for items including the word "sociology". This approach leaves it to the creators of the database and the researchers who conduct the research to identify a body of work as sociological (Alexander et al., 2006:228-229). A number of databases were also considered as data sources for this thesis (see Chapter 3).

Even though their research included documents which are not research articles published in journals, some of their findings and conclusions are relevant to this thesis. First, they found that a surprising amount of the articles are published in Afrikaans. This finding served as a reminder to be mindful of language when conducting database searches. Alexander et al. also mention factors in recent years that could have affected trends in research methods. For example, they argue that fieldwork may become less prominent, as primary data collection is time-consuming, while there may be an increase in research using secondary sources, the internet and telephone interviews, all which are investigated in this thesis. Other factors include the merging of universities, an increase in the number of researchers leaving academia, the aging of academics and the merging of the sociology associations. Universities merging and sociology associations merging could lead to researchers being exposed to new ideas and methodologies by their new associates, thereby encouraging methodological pluralism. However, the aging of academics and researchers leaving academia represent knowledge leaving academia, which the decline in membership of SASA is indicative of (Alexander, et al., 2006).

\subsection{Conclusions}

Through this review it became clear that methodological pluralism is deemed important by both British as well as South African sociologists in particular and social scientists in general. In this chapter the factors that might be contributing to a lack of methodological pluralism and the dangers it poses to the future health of the discipline were discussed.

In the process of discussing other empirical research, it was found that the topic of this thesis (i.e. methodological trends in a South African social science, with a specific focus on methods) has received little detailed empirical attention in South Africa. The most recent study was conducted in the eighties, and only articles published in the SAJS were included. Its results, i.e. that quantitative methods dominated during the eighties, stand in opposition to what other literature would lead one 
to predict. More recently, sociological research in South Africa has mainly been discussed without referring to specific methods. The empirical research that did aim to describe sociological research publication trends either focused on aspects other than those considered in this thesis, or only focused on evaluating the quantitative methods used in research reported in sociological publications. South African scholars have also expressed concern that qualitative methods may be dominant in the discipline, but no recent review of research publications has been conducted to substantiate this concern.

This thesis thus aims to investigate this gap in our knowledge of South African sociological research, by collecting empirical data to investigate which methods South African researchers working within the field of sociology have used during the past 20 years, and whether this has changed from the 1980s, as assessed by Van Staden and Visser (1991). The next section of the literature review investigates factors that may influence the research methods social science researchers employ, as well as other factors that may influence publication trends relevant to this thesis and as much, would provide the context against which the results could be interpreted.

\section{Influences on research and its publication}

This next section discusses the factors that may have an effect on research methods used, which relate to aims of the research and design, as well as institutional pressures and audiences. The aspects examined are: research aims (which includes a discussion of applied or basic research), research steering, cognitive cronyism, and public sociology.

\section{1. $\quad$ Research aims}

As suggested by Mouton (2006:103-104), one way of categorising research is by considering the aims and the state of background knowledge that is available. Ideal types of different aims can be described as follows:

Exploratory research is conducted to establish the "facts" when not much is known about a particular field, and/or to establish which topics need to be investigated. Qualitative research is well suited to this goal, as it tends to follow an inductive approach. The aim of replication studies, on the other hand, is to validate the findings of a previous study, or to determine whether the same findings will be achieved in a different context. This is done when a well-established body of knowledge exists, and quantitative studies are well suited to achieve this aim.

Hypothesis-generating studies aim to generate explanations for findings, as expressed in the form of hypothesises. This type of research is often non-empirical in nature. Finally, theory-testing 
studies aim to test the theories generated by hypothesis-generating studies. The methodology best suited for theory-testing depends on the theory in question (Mouton, 2006:103-104).

Another way to express research aims is by classifying research as either basic or applied. The main goal of the former is to contribute to the existing body of academic knowledge by filling a gap in the academic knowledge base related to a certain topic, and to build or test theory with a focus on explanation. Applied research takes a specific problem in the social world as its point of departure, and its goal is to find practical solutions to current problems (Blaikie, 2010:48-50; Neuman, 2011:26-27; Mouton, 2006:105).

Themes which touch on the distinction between basic and applied research are referred to by Oosthuizen (1991), Olzak (1990) and Alexander et al. (2006), especially in relation to the pressures on academics when conducting and publishing research. Olzak is concerned about the privatisation of research, especially at the HSRC, and that this would cause the focus to move away from basic to applied research. Her concern is that, in such an environment, less time would be spent on deciding on and developing good research practices and methods, in favour of fast results. Oosthuizen mentions that a factor that may have an influence on the research academics pursue, is that in South Africa (as in many other developing countries) academics experience a heavy teaching load which directly effects the amount of time they have available to dedicate to research, which influences the types of projects they engage in, and thus the methods they choose to employ (Oosthuizen, 1991:96-97). Arguably, basic research takes up a lot more time than applied research, and, coupled with the need to address South Africa's social problems, applied research with its problem-focused approach then becomes dominant.

Alexander et al. (2006) argue that the topics researchers investigate are influenced by the extent to which topics receive funding. With the government's top-down approach in establishing research priorities, and the NRF and HSRC's responsibility to respond to these priorities, the topics deemed important to government receive funding, thus those topics will attract more attention among researchers. Topics do not necessarily dictate the methods to be used, but the aim of these research priorities is to alleviate social problems in South Africa, and thus applied research would be more valued (Alexander, et al., 2006:219). An increase in applied research could then lead to certain types of methods or designs being employed more often than others, for example it could lead to research making use of an action research or evaluation research design and making use of expert sampling (White, 2009:29-30). Steering through funding definitely has an influence on what research gets produced, though the full (indirect) effect of this influence on methods is not clear. Research aims are not investigated explicitly in this study; however they have an influence on who the intended audience is. 


\section{2. $\quad$ Cognitive cronyism}

A factor that could play a role in the frequency with which articles with a certain methodology are published, is a perceived bias against that methodology by the editors of academic journals, a possibility also mentioned by May (2005). The reasoning is that, because of such cognitive cronyism (Hess, 1950: 65), editors would reject manuscripts that do not fit their own intellectual style. Even if the editors are not biased against a certain methodology, a perception that this is the case (e.g. due to a coincidental low number of articles reporting on a specific methodology in the journal) could lead researchers to consider alternative outlets for their work if their research made use of that methodology, which in turn will lead to a self-fulfilling prophesy. This yet again highlights the importance of selecting articles from a wide variety of journals, as this thesis has done.

\section{3. $\quad$ Public sociology}

South African sociology has a rich history of public sociology, and the sociologists who practise this version of sociology do not necessarily publish their research in journals (Webster, 2004:3031). Public sociology can be understood as engaging the public with social issues, where the audience is the public (in contrast to academic peers). The questions and discussions are aimed at public interest and the public is involved (Cock, 2006:303\&305; Burawoy, 2005:7). An example of a sociological publication which caters for a wider audience than journal-reading academics is the American magazine Contexts, which publishes short articles that are of general public interest (Burawoy, 2004:16). South African examples include books such as A human being died that night by Pumla Madikizela, and The Afrikaners: A biography of a people, by Herman Gilomee (Cock, Hassim \& Webster, 2004:328). Publishing for the public domain receives little funding, and with strong funding pressures to publish academic articles in accredited journals, the attractiveness and extent of public sociology has been greatly reduced in South Africa (Alexander, 2004a).

\subsection{Summary}

The aims of recent sociological research in South Africa (including whether it is applied or basic in nature) are not investigated empirically in this thesis, as these intentions are rarely stated explicitly. It is important though, to keep in mind that these factors could have an influence on the type of methods employed. If the research in a country is steered towards certain topics with an applied research aim, this too will influence how those topics would be investigated, arguably leading to less hypothesis-generating and replication studies. Although an investigation of the aims and 
steering pressures of recent South African sociological research is beyond the scope of this thesis, they still have an indirect influence on the discussion of methodological pluralism in a country.

The same applies to perceived or actual cognitive cronyism: although its influence is not empirically investigated in this thesis, it could lead to certain journals being (or perceived to be) biased towards a particular methodology. For this reason, and others mentioned earlier, this thesis examines research published in as wide a variety of journal as possible. The fact that not all research efforts are published in academic journals also needs to be recognised when generalising the findings of the thesis to the wider community of South African sociological researchers. This thesis does not comment on all research that has been conducted, as for various reasons not all of it reaches academic journals. The findings for this thesis thus only pertain to the specific population, as defined in Chapter 3. However it is reasonable to assume that it covers the majority of research published, as funding pressures in South Africa greatly favour publications in academic peerreviewed journals. This concludes the literature review, which is now followed by a clarification of the meaning of concepts central to this thesis.

\section{5. $\quad$ Key concepts defined}

As this study focuses on describing methodological trends, it is important that the meanings associated with the methodological terms used in this thesis, are clarified. In this section, the term methodology is elaborated upon, and the following types of methodologies are discussed: quantitative methodology, qualitative methodology and mixed methods research. Other concepts related to the research process and types of research contributions are also discussed, i.e. empirical and non-empirical research, research design, theoretical contribution, research stages, methods, tools and techniques.

\subsection{Empirical research, non-empirical research and theoretical contribution}

In the literature that was reviewed for this thesis, the terms "empirical research", "non-empirical research" and "theoretical contribution" were used without the authors clarifying what distinguishes these terms. However, it seemed that in most cases the terms "theoretical contribution" and "nonempirical research" refer to the same concept. For example, Nakao uses the terms "theoretical scholarship", "theoretical works", "theoretical papers", and "purely theoretical" articles, all in contrast to empirical research or methodological articles (1998:499\&510). He does not define theoretical scholarship in any detail, but based upon the contrast he draws between theoretical scholarship and empirical research, it is assumed to be non-empirical research of some kind (1998: 499,510,513). 
It was difficult to find a definition for either empirical research or non-empirical research, as most literature consulted seemed follow the empiricist viewpoint, which holds that research needs to be "empirical" to be classified as research (Blaikie, 2010; Greener, 2011; Henn, Weinstein \& Foard, 2009; Della Porta \& Keating, 2008; Crotty, 1998). In other words, in this view non-empirical research is conceived of as an oxymoron, and referring to research as "empirical" is redundant.

In the literature that does acknowledge the existence of both empirical and non-empirical research, the topic is only discussed briefly (Babbie \& Mouton, 2008:77-78; Mouton, 2008; Mouton, 2006:102-104). The distinction lies in the nature of the data collected for the study (if at all) and what types of questions are explored in the research. For a study to be classified as empirical research, primary data need to be collected for the study, or secondary data from a previous study need to be analysed. For research to be termed as non-empirical, no new data are collected, nor are exiting data analysed; rather, the study deals with meta-scientific questions about conceptual, philosophical and theoretical problems, or reviews a body of scientific knowledge (Mouton, 2008:49-55).

\subsection{Methodology}

A study's methodology can be understood as the combination of methods and techniques, and their underlying assumptions, employed in a specific research project (Babbie \& Mouton, 2008:48-49). In this thesis different types of methodologies are distinguished by the type of data used for analysis and the types of analysis conducted. Certain methods and certain techniques produce certain types of data, and in that sense one can speak of, for example, quantitative or qualitative data collection methods.

However, it is not sufficient to consider only one of these aspects to determine which type of methodology a research project employs, as a methodology comprises the combination of these aspects. The methodological assumptions underlying a study are hardly ever explicitly stated, and methods and techniques can be used in different and innovative ways, or a variety of methods can be used within one research project (Creswell, 2009:4-5). It is for this reason that one cannot simply, on the basis of a keyword search, classify research reported in an article as being, for example either quantitative or qualitative. One has to consider how the different methods and techniques were used in the study and for what purpose they were used, the type of data collected and analysed, as well as for what understanding and/or goal the study was conducted. The research process can be divided into different stages in which these issues can be explored. These stages refer to the different tasks that need to be performed when conducting research, i.e.: 
- $\quad$ Problem formulation: clarifying what will be studied and why it should be studied

- $\quad$ Conceptualization: identifying and explaining concepts and describing the context

- Operationalisation: developing a data collection tool with which to collect data

- $\quad$ Selection of cases: sampling the cases about which data will be collected

- Data collection: applying the measurement tool to the sample selected

- Data analysis: interpreting the data collected

These stages are further elaborated upon in Mouton (2006:65-67). This thesis will mainly be examining the selection of cases, data collection and data analysis phases to determine the methodology of the research reported on in the articles. During the pilot study for the thesis, it became apparent that these three phases and the methods and techniques used to execute them are most often reported and described. They tend to provide answers to the previously mentioned questions, i.e. what type of data was used and what the purpose of the study is.

However, it is the combination of epistemology ${ }^{3}$ (i.e. the assumptions referred to earlier), methods and techniques that form the methodology of a research project, and only by considering all the aspects can one determine what the methodology of a research project is. As this thesis aims to identify methodologies and methods used in sociological research (as reported in articles), it is necessary to describe the traditional types of methodologies that can be identified, not only to identify the conventional methods associated with each, but also to describe the type of reasoning used within each methodology. It is important to note that the differences between the "ideal" types of methodologies described here are more complex than presented, the approaches can be mixed in a variety of ways, and what is presented is an overview and an abstraction (Della Porta \& Keating, 2008:20-21).

Following the classifications by Creswell (2009), Creswell \& Plano Clark (2011), Greener (2011), and Mouton (2006), the types of methodologies to be described are: quantitative research methodology, qualitative research methodology and mixed methods research. Presented in the next sections are brief descriptions of each to provide a conceptualisation of these methodologies according to the commonly associated assumptions, methods and techniques associated with each.

\subsubsection{Quantitative methodology}

The quantitative methodology is an approach to research that aims to investigate the relationships between variables to be able to describe and predict social life by deduction (Creswell, 2009:4; Greener, 2011: 3). To be able to further conceptualise the quantitative research approach its

\footnotetext{
${ }^{3}$ Epistemology is the theory of knowledge which explains what is considered valid knowledge (Greener, 2011:4).
} 
associated ontology ${ }^{4}$ and epistemology are described below. The quantitative approach adopts the empiricist theory of knowledge, which claims that the source of all knowledge should be based on observation. It is therefore also the view (referred to earlier) that all scientific research, social or natural, has to, per definition, be empirical. In this sense, positivism corresponds with this view, as it argues that the social world should be investigated using similar procedures to those used by the natural sciences to study the natural world. This tradition sees the successes that the natural sciences have had in investigating the world, and attributes these to the methodology of the natural sciences (Babbie \& Mouton, 2008:20-21\&27). It follows that, if the social sciences were to view the social world as similar to the natural world, they would conduct research in a similar manner to attain similar success at describing and predicting social trends. This argument relates to the type of data that are considered acceptable as a source of scientific knowledge, i.e., only data that can be verified through the senses are accepted as valid.

Objectivity is also highly regarded in the quantitative methodology. Objectivity is understood here as resulting from a clinical, value-neutral and controlled research environment. It is generally considered as a goal to be strived for in the social sciences, but many factors inherent in the human condition work against the attainment of the ideal of objectivity. One such difficulty involves the observation of subjects in a controlled environment without them reacting to that environment, or to being observed. It is also difficult for a researcher to not let his/her own context or expectations (which do not constitute observable data) influence a study. This leads to quantitative researchers using a variety of methods to reduce these "sources of error", for example unobtrusive methods or double-blind experiments.

To attain value-neutral data, social scientists of the quantitative persuasion value statistics and numbers, as it is argued that the systematic application of statistical techniques can control for the biases that researchers might inadvertently introduce. Statistics also allow researchers to investigate correlations and predict human behaviour, as well as to generalise to a wider population and to know whether a result is statistically significant. To enable the use of statistics, quantification is necessary, which means that observations need to be expressed in numerical form. Even "unobservable" elements of human nature can be investigated, as long as numbers can be systematically attributed to them, based on observable behaviour expressed through the operationalisation of the concepts under investigation (Neuman, 2011:95; Creswell, 2009:4; Babbie \& Mouton, 2008:27\&52-53). A simple illustration hereof would be to link certain behaviours to emotional states, for example tying the action of crying (observable) to a depressed mood (unobservable), and then the frequency of such behaviour can be measured.

\footnotetext{
${ }^{4}$ Ontology is the study of reality and what is considered real. In this context, it relates to the extent to which the social world can be said to exist objectively (Della Porta \& Keating, 2008:21-22)
} 
In conclusion, some examples of methods and techniques associated with a quantitative methodology will be presented, as well as an explanation of why these are associated with a quantitative methodology. During the selection of cases, a probability sample (e.g. simple random sampling) would allow for inferential statistics to be used and results to be generalised to the population being studied. By making use of an interview-administered questionnaire with closedended questions during the data-collection phase, unobservable aspects of the respondents can be measured, and these can be quantified through, for example, the use of scales in the questionnaire. The use of a well administered and structured questionnaire also ensures consistency in terms of which questions are asked and how, thereby maintaining the reliability of the data collected. Lastly, during data analysis various statistical analysis techniques, such as the chi-square test and regression analysis, could be used to identify trends and identify relationships between variables.

\subsubsection{Qualitative methodology}

The qualitative methodology is often explained by contrasting it with the quantitative methodology. This approach to describing it is useful, as the qualitative methodology emerged as a perspective to challenge the quantitative approach that was dominating social science research in the 1960s (Babbie \& Mouton, 2008). However, by contrasting these approaches, one eliminates the possibility of mixed methods research, i.e. a methodology that incorporates methods, techniques and aims employed by both types of methodologies. Thus, the qualitative methodology will be described here in its own right, not merely in opposition to the quantitative research methodology. However, some reference is made to the contrasts between these two methodologies.

Qualitative research aims to explore and understand, to produce a rich, descriptive account of an actor's reality that is true to his/her experience thereof. People are viewed as spiritual and intellectual beings, able to form and attribute meaning to life and events in life. These aspects of people - the meaning they attach to events and concepts, their values and beliefs - are the objects of qualitative research. One of the fundamental assumptions in qualitative research is that meaning is subjective, that reality is socially constructed and as such, qualitative research is interested in the specific case and not in generalising to a larger population (Merriam, 2002). This view, according to which non-observable data such as intentions and reasons are valid sources of data, is the idealist theory of knowledge, which is applied in the qualitative methodology (Babbie \& Mouton, 2008:33).

In a qualitative study, a rich description of contextual data, often collected from multiple sources, is presented. These descriptions include, for example, quotes from conversations, pictures or photographs, and narrative descriptions (Creswell, 2007). A common phrase used when describing qualitative research is that the researcher aims to gain an "insider's perspective". 
The qualitative researcher also follows an inductive approach to his/her research. This means that the researcher immerses him-/herself in the natural setting, from which research themes develop inductively through the observations made by the researcher. The research process is an iterative process in which themes are identified as data are collected, and the research participants are often involved in shaping these themes and the way in which they interlink. The research design itself is emergent, as the research question(s) can change to better investigate a topic, and more participants can be included to further help clarify the concepts and meanings attached to them (Creswell, 2007).

Qualitative studies are concerned with attaining confirmability and credibility. Confirmability refers to the degree in which researchers can show how they arrived at their findings, that their findings are not the result of preconceptions of the researcher, and how they are collaborated by others (Kumar, 2011:381). Credibility refers to the degree to which a particular description reflects the reality of the research participants accurately, which is often attained by immersing oneself in their world. Qualitative research acknowledges that researchers bring their own understanding of concepts to a study, and that this could be considered a bias. However, rather than denying these, or using methods to reduce these biases, they are acknowledged and their influences are also reported on (Babbie \& Mouton, 2008:33\&271-278 ; Creswell, 2009:4).

In conclusion, methods and techniques commonly associated with a qualitative methodology will be described, alongside explanations for why this is the case. Expert sampling, a method according to which respondents that are known experts in a field are selected, would work well for selecting cases for a qualitative study, as these informants can provide detailed, in-depth insight into the topic under investigation, and these data can be collected through in-depth interviews, enabling the themes to emerge according to how the respondents understand the concepts and not how the literature presents it (as would be the case with a structured interview). Discourse analysis could be used to explore and analyse the themes that emerge from the interviews.

\subsubsection{Mixed methods research}

While the quantitative and qualitative methodologies are often discussed in contrast to each other, it is not always easy to distinguish between qualitative and quantitative methodologies (Creswell, 2009:3). The reason is that a single study can make use of a variety of methods and may have multiple goals, which require different types of data to achieve. It is in instances such as these that the term "mixed methods research" becomes relevant.

One way of viewing mixed methods research, as the name suggests, is as research which uses both qualitative and quantitative research methods. However, it can also refer to more than that, i.e. a different type of methodology, as it may incorporate techniques, methods and assumptions of both 
the quantitative and qualitative approaches to social research (Creswell \& Plano Clark, 2011:4-5). Furthermore, it also makes use of a pragmatic world view, in the sense that it is not committed to a specific ontology or epistemology. A pragmatist's starting point is the research problem, which determines what type of data will bring the best understanding to light. This arguably leads to mixed methods research addressing a research problem in a more comprehensive way than either of its constituent methodologies is able to do individually (Creswell, 2009:10-11).

In mixed methods research, both qualitative and quantitative data are collected and used in combination to build arguments. Choices made during each of the research steps are guided by assumptions from both the qualitative and the quantitative methodologies, as needed by, and relevant to, a study. The aim is to use what will best fit a situation, not to force both qualitative and quantitative aspects into every step of the research process (Creswell \& Plano Clark, 2011:5).

Some of the other terms used to refer to mixed methods research are: mixed research, blended research, integrative research, multi-method research and triangulated studies (Johnson, Onwuegbuzie \& Turner, 2007:118). Mixed methods research in this thesis does not refer simply to studies that use a variety of methods in a specific phase of a research project, but refers to multiple approaches used within a specific phase, or multiple research phases. A study that involves conducting individual, face-to-face interviews to collect rich descriptions, as well as focus-group interviews for the same reason, would not be considered mixed methods research in this thesis. Mixed methods research is understood as involving the mixing of methodological approaches, not merely the triangulation of data (Johnson et. al., 2007).

\section{3. $\quad \underline{\text { Research designs }}$}

The term research design and research methodology are often used interchangeably, but in this thesis it will be argued that they refer to different concepts. Research design is concerned with specific techniques and is focused on how a study will be implemented. It is at a lower level of abstraction than methodology, as research design is concerned with the practical aspects of addressing the research problem (Henn et al., 2009:49-50; Mouton, 2008:55-58). A pre-existing typology of research designs - as drawn from Mouton (2008), with some clarifications on those designs from Bryman (2008) - was used in this thesis to classify published research according to research design (see Chapter 3), and includes designs such as survey, secondary data analysis, participatory action research, and content analysis.

Participatory action research (PAR) is often described as another methodology alongside qualitative methodology, quantitative methodology and mixed methods research. However, for the purpose of this thesis it is not considered the case, as PAR is classified as a type of research design. 
This is done, firstly, because the classifications for research designs in this thesis are heavily influenced by Mouton (2008), who classifies PAR as a type of research design. Secondly, one way to distinguish in this thesis between methodologies, is to compare published research according to the type of data produced and analyse, as well as the way in which sampling was conducted to collect those data. The unique features of PAR are not described in these terms; instead, the focus lies in its advocacy worldview, which encourages researchers to assist research participants in overcoming power disparities, as well as to collaborate with the participants who have an active part in designing and conducting the research (Creswell, 2009:9-10; Neuman, 2011:30-31).

As the above discussion shows, there is not much consensus on what exactly a research design entails, or how they should be classified. The typology used in this thesis has its weaknesses, as many of the categories are not mutually exclusive or exhaustive. The combination of these two challenges relating to research design needed to be addressed during data collection in this thesis (as will be discussed in more detail in Chapter 3).

\section{4. $\quad$ Methods, tools and techniques}

Methods are strategies employed when performing the tasks that form part of a stage in the research process. Methods describe what will be conducted during a particular stage, but not specifically how it will be done. The following, drawn from Mouton (2006:36-37), are examples of methods used to execute different tasks at different stages of the research process:

- $\quad$ Methods of definition: theoretical and operational definitions

- Measurement methods: scales, questionnaires and observation schedules

- Data-collection methods: participant observation, unobtrusive measurements and systematic observation

- Data-analysis methods: statistical methods, mathematical methods and qualitative methods

- $\quad$ Sampling methods: probability and non-probability methods

Techniques are the strategies that are employed to perform specific tasks (Mouton, 2006:36), and describe how a method will be carried out. Tools refer to the actual instruments used. The following are examples of techniques used for different tasks at different stages of the research process:

- $\quad$ Sampling techniques: snowball sampling, stratified systematic sampling

- Data-collection techniques: semi-structured interviews, mailed questionnaires

- Data-analysis techniques: narrative analysis, descriptive statistics

There are numerous tools and they are often uniquely created for a specific study. It would therefore be difficult, while at the same time not very useful, to provide examples in a similar fashion as techniques were illustrated. Tools would refer to the specific questionnaire created to collect data, 
or the specific interview guide that was used to guide the interviewing process (method), which was executed through semi-structured interviews (technique) during the data collection (research stage) phase.

\section{6. $\quad$ Chapter summary}

The chapter started with a description of the concern with the lack of methodological pluralism, as expressed in relation to British sociology, as well as by some social scientists in South Africa. Different aspects of South Africa's past, especially the split between two sociology journals during apartheid, were discussed, as well as other publication-related issues, such as research aims and research steering, and how it might influence sociological research on a methodological level. Some international and local examples of analysis of published sociological research, in which methodological pluralism and other issues are noted, were considered. It is thus clear that these issues do not present themselves only in theoretical discussions, but have also been noted in empirical research, both internationally and locally.

Based upon the literature review, it can be concluded that, in the South African context, it would not be sensible to consider methodological trends as they are reflected in only one journal, as this is would not provide a representative account of published sociological research in the country. The review also indicated that methodological features of South African sociology might have changed over the years, although no systematic enquiry has been conducted in more recent years to determine whether this is actually the case, and if so, how it has changed,. The theoretical literature predicts that qualitative research may have become dominant, and it is therefore the aim of this thesis to determine empirically whether this is indeed the case.

In the second part of the literature review, the term "methodology" was conceptualised, as were related concepts, including research designs, research stages, methods, techniques and tools. In addition, three types of methodologies -quantitative methodology, qualitative methodology and mixed methods research - were briefly elaborated upon. The next chapter builds upon the knowledge gained from the literature review and conceptualisation of methodological concepts to describe the research design, methodology and methods employed for this thesis. It also provides detail on the issues encountered during operationalisation of key concepts and during data collection. 


\section{CHAPTER 3: RESEARCH METHODOLOGY}

\section{Introduction}

The research methodology chapter commences with a description of the way in which the research problem was operationalised into research questions and hypotheses. This is followed by a description of the pilot study, which assisted in the sampling design for the study, and in preempting potential sampling and data collection issues. Thereafter the different phases of the sampling process are described, followed by a discussion of data collection, the variables investigated, and the methods used during data analysis. The chapter concludes with potential shortcomings of the overall research design and how some of these were overcome.

\section{2. $\quad$ Research questions and hypotheses}

To investigate the methodological trends in South African sociology, the research problem - i.e., what methodologies and methods have been employed by South Africans publishing research in the field of sociology between 1990 and 2009? - was divided into four research questions:

- What are the methods that South African sociologists have used for sampling, data collection and data analysis?

- Have there been any changes in the methods used since 1990?

- Has collaboration (local and international) increased since 1990?

- Do South African researchers who publish in collaboration with international authors tend to employ different methodologies compared to those that do not?

The first question is addressed by means of a cross-sectional analysis of all the data collected on each variable. With regard to the second research question, it was hypothesised on the basis of the literature review that, over time quantitative methods have lost the prominence, while qualitative methods have become more popular. Secondly, it could be expected that the reporting of sampling methods would have improved, and that the use of probability sampling would have increased, as sociologists become more aware of the limitations of such practices (cf. Van Staden and Visser, 1991). A further expectation is that the collection of primary data would have decreased, due to its time-consuming nature which would make it less attractive to researchers (the majority of which have been facing increasing teaching loads at South African universities), or that electronic or telephonic data collection methods would have increased to reduce fieldwork expenses (Alexander et. al., 2006). 
With regard to the third and fourth research questions, the hypothesis was, first, that international collaboration has increased since 1990, and secondly, that research published in collaboration with international authors would more likely be of a quantitative nature than that which is published by South African authors only, as suggested in Seekings (2001: 26-27).

\section{3. $\quad \underline{\text { Research design }}$}

Content analysis was chosen as the research design for this thesis, as the research problem statement entails examining written communications, i.e. research articles. Content analysis is well suited for studies such as this one, which investigates a phenomenon over a long period of time, as the information has already been recorded, and the data do not need to be collected from respondents who may suffer from memory decay. It is also an unobtrusive and non-reactive research design, as there is no contact with the authors. The data collected are of a quantitative nature, as the aim is to describe the frequency with which methods occurred in published works over a period of 20 years, and to ascertain whether any statistically significant trends could be identified in this regard. The following sections describe the methods employed in the different research phases (i.e. sampling, data collection and data analysis), starting with an explanation of the sampling process which includes a description of the pilot study and lessons learned from it. Thereafter the data collection process is explained with specific reference to data capture and editing. Lastly, data analysis is described with reference to the statistical methods, techniques and tools used.

\section{Sampling design and methods}

The following section describes a pilot study that was conducted prior to the main study, which was primarily aimed at exploring potential obstacles related to sampling, and to devise strategies to overcome those obstacles. Thereafter, the different sampling phases are explained: first, how and which online research article databases were selected and secondly, how the final sample of articles was selected. At each step, crucial methodological choices were made and the reasoning behind those choices is explained.

\subsection{Pilot study}

For the pilot study, all of the 67 articles published from 2006 to 2009 in the journal, The South African Review of Sociology, were downloaded. From the outset it became clear that non-research articles, such as book reviews, editorials, letters, comments and the like, should not be included in the study population, and a strategy on how to exclude these needed to be formulated (see the following two sections). The next task was to decide on the best way to sample the articles and 
probability sampling was chosen as the most appropriate design. Random or probability sampling designs allow for every element in the population to have an equal, known chance to be included into the sample. This allows for the use of inferential statistics, in the case of this thesis to infer if any statistically significant change had occurred over time (Howell, 2008:23), or if the measured methodological differences between internationally collaborative research and local research are statistically significant. A probability sampling design was also feasible, because a sampling frame, a list of all the articles that constitute the population, could be constructed.

In terms of sampling method, stratified systematic sampling, with year of publication and journal volume and issue number as the stratification variables, was deemed the first choice, as the data on the stratification variables are easily available. Stratification ensured that a proportionally representative numbers of articles would be sampled from each year, and is therefore considered a more rigorous method than simple random sampling (Babbie \& Mouton, 2008: 191). It involved sorting the sampling frame, a list of articles compiled in Microsoft (MS) Excel, according to year of publication. A sample size of 22 articles was decided upon, due to the limited time available for a pilot study. After having decided on a sample size, the sampling interval $(k=3)$ was calculated, and every $k$ th or $3^{\text {rd }}$ article was selected from the stratified sampling frame.

The pilot study also involved reading the sample of articles to identify potential data collection issues. From this it became clear that a very close reading of the articles would be needed in the main study. For example, in some instances it was unclear from a cursory reading whether an article merely reviewed an author's past research, or whether the article reported on a new and original piece of research. In addition, many of the authors of the articles did not explicitly name their sampling method, and/or the method(s) they used to collect their data, although in some cases at least these methods were described. Fortunately, other authors devoted specific sections to methods used for sampling and analysis, with clear section titles applying methodological terminology commonly taught at universities and used in social research textbooks.

This highlighted the issue of deciding on the type of coding method that would be used in the thesis. It was decided that an inductive method would primarily be used, in other words the terminology and definitions used in the articles were to be used to develop coding categories, instead of coding deductively in terms of a pre-defined coding scheme based on definitions compiled from methodology textbooks. If the author(s) assigned a name to a method used, it was recorded and coded as such. If the author(s) did not name a method, but explained it in sufficient detail, it was classified and coded according to the types of methods and their definitions found in a variety of methodology textbooks. The exception was, as mentioned earlier, in the case of research designs where Mouton's (2008) existing typology was used. The resulting coding categories and 
their definitions are listed in section 5.2. This inductive approach was judged most appropriate, as even from the small pilot study sample it became clear that a large array of different methods and techniques are available, and developing exhaustive typologies beforehand would not be possible. Also, the inductive approach assisted in identifying variations in the naming of methods, and inconsistencies in the use of the terms "methodology" and "research design".

It was also discovered that more than one method was often used for a step in the research process (i.e. sampling, data collection or data analysis); for example, face-to-face interviews and observations can both be used as data collection methods in a single study. This rendered the development of a mutually exclusive coding system challenging. What also became apparent was that authors did not distinguish between methods, tools and techniques in the same way most methodology textbooks consulted did. It would thus not be possible to collect these separately, as first intended.

To conclude, the pilot study highlighted the need to formulate a strategy to identify nonresearch documents; allowed the researcher to make an informed decision in favour of stratified systematic sampling; identified data collection issues emerging from the lack of detailed description and/or consistent use of terminology by authors; highlighted the need for a coding scheme that could accommodate multiple methods applied in a single phase of the research process; and lastly, showed that drawing a distinction between method, tool and technique would not be feasible.

\subsection{Construction of the sampling frame: Databases}

A number of research-output databases were selected to compile a list of references which would constitute the initial sampling frame for the main study. What follows is a discussion of how the different databases were selected, as well as an explanation of how the references, and then the sampled articles themselves, were collected from these databases.

The first database used to select articles was the Thomson Reuters Web of Science (WoS). This database indexes the content of high-impact journals in the natural sciences, social sciences, arts and humanities, dating back to $1900^{5}$ (Yong-Hak, 2011). Using the WoS, however, would exclude the primarily South African research published in the majority of the peer-reviewed South African journals, as very few of those journals' content is indexed by WoS. Many authors publishing in South African journals publish for a South African audience, and these journals, even though most are of high quality and peer-reviewed, would not be published in a WoS-indexed journal, due to their local focus (Alexander, 2004a:325-326). To illustrate, in 2003/2004, of the 225 South African scientific and scholarly journals recognised for subsidy by the then Department of Education (DoE),

\footnotetext{
${ }^{5}$ The Science Citation Index Expanded and Social Sciences Citation Index date from 1900 to the present, while the Arts and Humanities Citation Index covers 1975 to the present.
} 
220 were not included in any of the WoS citation indexes (Mouton et.al., 2006:29). This indicated that more databases needed to be consulted to draw up a sampling frame from which a representative sample of South African peer-reviewed articles could be drawn.

Other limitations of the WoS came to light with the recent (2013) publication of an article by Harzing. It was published after the sampling was conducted for this study, but should also be elaborated upon here, as it is relevant to understanding the limitations of the WoS. What Harzing found was that original research articles, particularly in the social sciences, were being misclassified in the WoS as "review" or "proceedings" papers. Articles in the social sciences which had more than 100 references were often misclassified as reviews, and those which mentioned that an earlier version was presented at a conference were often misclassified as proceedings (Harzing, 2013:32). As mentioned above, on the basis of the pilot study, these document types were defined as nonresearch articles, and thus not included the sampling frame in both the pilot and main study. If WoS was used exclusively, many original research articles would have been excluded for this reason. The other databases might also set criteria such as these, which would erroneously exclude relevant articles from searches, but including more databases would arguably lessen the probability and/or negative effect of this occurrence.

The additional databases available at the time of data collection were those online ones that students and staff at Stellenbosch University may access via the JS Gericke Library. The relevant databases were selected with the help of the subject librarian. To be considered for the study, a database also needed to meet the criterion of allowing searches in the following fields: date, institutional affiliation of author(s), language, subject, document type, and whether the journal's content is peer-reviewed or not. Not all of the relevant databases allowed for searches in all of the fields, but this limitation was addressed in a manner that will be explained later in this chapter. In addition to WoS, the following additional online databases were consulted: SABINET's Index to South African Periodicals (ISAP), JSTOR, Scopus, CSA Sociological Abstracts and EBSCOhost.

The ISAP database indexes many South African peer-reviewed journals in addition to others periodicals, but unfortunately does not allow one to automatically exclude non-peer-reviewed articles from searches. To overcome this obstacle, the same criterion was used that the then DoE, now the Department of Higher Education and Training (DHET), uses to determine which journals' content qualifies for subsidy purposes. The DHET considers the following journals as accredited: journals appearing on the International Bibliography of the Social Sciences (IBSS), journals appearing in the three WoS indexes, and journals in a separate "DoE list" compiled on the basis of the following criteria: 
The purpose of the journal should be to disseminate research results; the articles must be peerreviewed, the articles in the journal should be from a variety of institutions, the journal must have an International Standard Serial Number (ISSN), it must be published regularly, it should be distributed beyond one institution and members of the editorial board must be from more than one institution (Stellenbosch University, 2010).

The version of the "DoE list" that was downloaded in 2009, proved useful to judge the status and quality of journals. After the databases were selected, the article references needed to be collected from these. The next section explains the collection of these references as well as the process of checking whether the articles met the criteria for inclusion in the population, as defined below.

\section{3. $\quad$ Construction of the sampling frame: Articles}

The construction of a sampling frame of articles involved conducting searches of the online databases referred to above. Each database was searched for articles that met certain inclusion criteria, as reflected in the definition of the population for the study, i.e.: 1) peer-reviewed articles; with 2) a publication date falling in the $1990-2009^{6}$ range; 3 ) in the field of sociology; 4) with at least one author with a South African address at the time of publication; and 5) written in English. As far as possible, each of these criteria or fields (year, topic, authorship, peer-review, document type, and language) had to be taken in consideration during searches. The strategies used in the case of databases that did not allow for searches in one or more of these fields, are elaborated upon later in this section. Table 1 presents the main and affiliate databases that were searched, as well as the number of articles that corresponded to the search criteria in each database.

Search results were exported directly from the databases to Refworks, an online tool which facilitates the management, storing and sharing of citations and bibliographies, among other functions (RefWorks, 2012). Fortunately all the websites were compatible with RefWorks, even though this was not one of the criteria used to select the databases. After all the references were imported into RefWorks, it became clear that the list needed further refinement before it could be used as a sampling frame. In particular, the following issues needed to be addressed before a final sample could be drawn:

- $\quad$ some references were duplicated;

- $\quad$ searches of some databases still produced references for book reviews and editorials, even though the search criteria were set to explicitly exclude those;

- $\quad$ the JSTOR database did not allow automatic refinement according to authors affiliation;

\footnotetext{
${ }^{6}$ It should be noted that not all the relevant articles published in 2009 were included in the sampling frame, as the list of articles to be collected was created during the course of 2009, thus not all articles with a 2009 publication date had been published and/or indexed at that time.
} 
- $\quad$ the ISAP database included the content of periodicals that are not peer-reviewed;

- $\quad$ not all the articles seemed to be of a sociological nature; and

- $\quad$ not all the articles were available online in full-text format, and copies had to be requested from other libraries, where possible.

The first step was to remove duplicate references. If duplicate titles were found, the source (journal title), page numbers, and in some cases the articles' content, were compared to determine whether they were indeed duplicates ${ }^{7}$. If that was established to be the case, one of the duplicates was removed from the sampling frame

Table 1: Database hits

\begin{tabular}{l|r}
\hline Database & Hits \\
\hline WoS & 2054 \\
Sociological Abstracts & 952 \\
Scopus & 78 \\
JSTOR & 353 \\
Sabinet ISAP & 292 \\
EBSCO Host & \\
$\quad$ Africa-Wide Information & 81 \\
CAB Abstracts & 74 \\
$\quad$ Econlit & 5 \\
$\quad$ MEDLINE & 1 \\
$\quad$ Waters and Oceans Worldwide & 12 \\
\hline Total $\quad$ & $\mathbf{3 9 0 2}$ \\
\hline
\end{tabular}

The collection of almost 4000 articles were then checked to assess whether they were indeed research articles and not book reviews, comments or editorials. This was done by scanning the sampling frame for documents that 1) contained either "book review", "comment" or "editorial" in the title or abstract; 2) contained an author's name or initials in the title ${ }^{8}$; and/or 3) started at page 1 of a journal (as these are often editorials). When such a document was found then, if possible, the document itself was checked and, only if confirmed to be a book review, comment or editorial, was it removed from the sampling frame.

Although the affiliation of authors was not available as a search field in JSTOR, all the articles themselves are available for download directly from the database. The articles that met all the other

\footnotetext{
${ }^{7}$ Two sets of duplications without corresponding journal titles, were found. In the first set (Coutsoudis, Coovadia \& Wilfert, 2008a; Coutsoudis, Coovadia \& Wilfert, 2008b), the one article referred to the other and indicated which one was the original, and the former was therefore deleted from the sampling frame, while the latter was retained In the other set (Zuzowski, 1992, Zuzowski, 1994) no such reference was found and, although published in different journals, the content was judged to be similar enough to justify removing one of the duplicates from the sampling frame.

${ }^{8}$ This was included as a criterion as during the initial pilot sampling it was noted that author's whose books were reviewed were often referred to by name in the article which reviewed their book.
} 
criteria were therefore downloaded and checked to determine whether the authors' affiliations met the criteria for inclusion in the sampling frame (i.e. at least one South African-affiliated author). Although this was time-consuming, the JSTOR database was considered too important to exclude on the basis of this limitation, as it indexes and provides digital copies of the older content not available in the other databases, which tended to provide only references or abstracts of older articles and thus the articles themselves needed to be downloaded or photocopied elsewhere.

The next step in cleaning the sampling frame was to ensure that all the journals in the sampling frame were indeed peer-reviewed journals, as Sabinet's ISAP indexes both peer-reviewed and nonpeer-reviewed journals, and does not draw a distinction between them or allow one to select only the former. This database was used in spite of this limitation, as its focus on South African and Southern African publications increased the likelihood of the inclusion in the sampling frame of South African articles authored by South Africans. In order to identify and delete the non-peerreviewed articles from the sampling frame, the articles were sorted by journal title in order to create an alphabetic list of all the journals, which were checked against the DoE list, the master journal list of WoS, and the IBSS. If they were not found in any of those lists or indices, the journals - and thus the articles published in them - were deemed non-peer-reviewed, as they are not accredited for subsidy purposes by the DoE. The articles published in those journals (listed in Addendum A) were thus removed from the sampling frame.

It further emerged that databases sometimes classified an article as being sociological when neither the journal nor the article dealt with sociological topics. An example of such an article was "Why do pouched mice (Saccostomus campestris) hoard food?" in "Physiology and Behaviour" (Ellison, 1996). The research reported in the article involved observation of mice in different areas in Africa to determine which factors influence how much food they hoard. Many other articles similar to this one was found, and it was therefore decided that another level of cleaning of the sampling frame was needed to remove articles that were clearly not sociological in nature. This involved checking each article for the presence of the term sociology or its derivatives in the title, the contents, or keywords of the article. However, merely searching for the term "sociology" in an article proved insufficient. It was found that often the term (or its derivatives) is not stated in articles that are clearly sociological. An example is "A career-history analysis of gender differences in publication productivity among South African academics" (Prozesky, 2008). A search of the article for the term "sociol" did not produce any results, except in the reference list. However, the journal within which it had been published, Science Studies, identifies itself on its website as a journal that covers the discipline of sociology (Science Studies, 2012), and the author is affiliated to an academic department of sociology. A further cleaning strategy was therefore devised, which 
involved the application of one or more of the following additional selection criteria: 1) the journal contains "sociology" or its derivatives in its title; 2) the journal is described (on its website or on a flyleaf of the journal itself) as dealing with the topic of sociology; and/or 3) at the time of publication the author was affiliated with a department or other grouping that contains sociology or its derivatives in its name. Applying the second criterion proved quite difficult, as many of the journals simply stated that they were multi-disciplinary. In those cases the articles were retained in the sampling frame.

Another issue to be addressed was whether non-empirical ${ }^{9}$ research articles should be included in the sample, and decisions made in this regard changed multiple times during the research process, but eventually it was decided to exclude these articles. Originally the sampling frame, and therefore the sample, was meant to exclude all non-empirical research. To ensure this, online database searches specified, for example, that only research articles should be included in the results. However, it emerged - but only during data collection - that these search criteria did not ensure the exclusion of non-empirical research. Also, some of the key empirical literature reviewed for this thesis (e.g., Payne et. al., 2004) incorporated these types of research articles in their analysis of methodological trends. On the basis of these two considerations, and an argument that nonempirical research is also a type of research published by South Africans in the field of sociology, it was decided to include non-empirical research articles in the study population. However, during data analysis it was removed once again, as the lack of methods in non-empirical research tended to draw attention away from the original focus of the thesis: the methods and methodologies used in these articles.

Finally, due to monetary and time constraints, articles that were not available in South Africa, and thus would have had to be ordered from overseas, could not be included in the sampling frame. After applying all these selection criteria, the sampling frame was reduced in size from 3505 articles to a more refined set of 906 , and the sample could be drawn.

\section{4. $\quad$ Sampling}

On the basis of a pilot study, stratified systematic sampling was selected as the most appropriate sampling method for the study, as explained in section 4.1 above. As a central hypothesis in the study was that over the past 20 years quantitative methods have lost their prominence, while qualitative methods have become more popular, time of publication (not only publication year, but where possible volume and issue number as well) was chosen as a stratification variable. Most of

\footnotetext{
${ }^{9}$ The distinction between empirical and non-empirical research was elaborated on in Chapter 2 section 5.1
} 
the data needed to stratify the sampling frame according to this variable were available from the RefWorks references.

As mentioned in the previous section, the final sampling frame consisted of 906 articles. A sample size of 151 articles was decided upon, and the sampling interval was therefore 6. A technique similar to the one in the pilot study was used to draw the sample. A six-sided dice was used to determine a random start, and every $6^{\text {th }}$ article after that was sampled. It was decided beforehand that, in the case of complications arising with a sampled article, for example the article not being available in South Africa, the article directly below it in the sampling frame will be used as its replacement. A total of 8 articles (listed in Addendum B) had to be replaced in this way. After the non-empirical articles were removed during the analysis phase, the realised sample from which data were collected constituted 111 articles. Non-empirical articles therefore constituted just more than a quarter $(26.5 \%)$ of the original sample.

\section{Data collection, capture and editing}

After a sampling frame had been constructed and the sample drawn, the next step was to collect the data. In this section the data collecting process, the conceptualisation and operationalisation of the variables on which data were collected, and the issues encountered during data collection, are described.

\subsection{The data collection process}

First, copies of all the sampled articles were obtained. A separate MS Excel sheet was created for each of the 111 empirical articles sampled, in which data collected on each article were captured. Data were collected on the following variables:

- $\quad$ methodology;

- $\quad$ research design;

- $\quad$ author affiliation (South African or not);

- $\quad$ whether a pilot study was conducted;

- $\quad$ data collection method(s);

- $\quad$ data collection technique(s) ${ }^{10}$;

- $\quad$ sampling strategy (probability, non-probability, or both);

- $\quad$ sampling method(s);

- $\quad$ analysis strategy (statistical or not);

\footnotetext{
${ }^{10}$ As mentioned earlier, data on techniques and methods, initially separate variables, were eventually merged
} 
- $\quad$ analysis method(s); and

- $\quad$ time frame (cross-sectional or longitudinal).

For the purpose of data collection, each article was read in its entirety and classified in terms of the variables listed above. As mentioned in section 4.1 above, it was decided, on the basis of the pilot study, that, as far as possible, an inductive coding method would be used, i.e. the categories of variables and even variables themselves emerged from or were adapted to what was encountered in the articles. For example, initially data on whether a pilot study ${ }^{11}$ had been conducted were not collected, but after encountering examples of pilot studies multiple times during data collection, it was added as a variable, and data on previous articles were updated accordingly. In other words, data collection was an iterative process, which also involved adding other variables, namely time frame, type of data, analysis strategy and research design.

Content, face and construct validity were enhanced by the inductive coding method, as it involved using terms exactly as they were used in the article, thereby capturing the intended meaning of the authors' use of a term as accurately as possible. For example, to collect data on which methodology was employed in an article, the articles were read, and if it was explicitly stated that a particular methodology was used, it was recorded as such. However, explicitly stating which methodology was used is rarely done (Neuman, 2011:91). If the researchers did not label the methodology, then the types of methods and techniques chosen, and the rationale for doing so, was checked against definitions of the various methodologies (see 5.2 below), to determine which methodology fitted best.

Some inconsistencies existed between the terminology used in the articles and the way in which these terms were used in the thesis. For example, two articles stated a research design as the research methodology employed: participatory research ${ }^{12}$ in the one case, and case study ${ }^{13}$ in the other. These two cases were re-classified as employing one of the three methodologies considered in this thesis (i.e. qualitative, quantitative or mixed methods research methodology) ${ }^{14}$, according to the methods and logic used in the respective articles, and consulting the definitions provided in section 5.2.

\footnotetext{
${ }^{11}$ A study was considered to be a pilot or as having made used of a pilot when mention was made of an additional study that had been conducted together with, or prior to, the study described in the article, and which had the purpose of investigating possible problems, or of testing a questionnaire and/or the feasibility of a larger study. The following terms were recognised as synonyms of "pilot (study)": pre-test, preliminary investigation and trail survey (Kumar, 2011:385\&393).

${ }^{12} \mathrm{~A} 654$

${ }^{13}$ A846

${ }^{14}$ The former was classified as employing a qualitative methodology, while the latter was classified as mixed methods research
} 
Other information also recorded in the MS Excel sheets included: whether a classification was derived directly from the wording in the article, or whether it was based on an interpretation by the researcher; the page number where the wording or evidence for the interpretation can be found; and an explanation of the interpretation.

\subsection{Conceptualisation and operationalisation of central variables}

The following section includes various tables and descriptions which provide the conceptualisation and/or operationalisation of all the categories of the variables which required some measure of interpretation during coding of the articles. All the other variables were coded as they appeared in the articles. Most of the definitions were greatly influenced by Mouton (2008), however a wide range of textbooks were used to create conceptualisations and operationalisation of the categories (Babbie, 2011; Kumar, 2011; Creswell, 2009; Babbie \& Mouton, 2008; Bryman, 2008; Creswell, 2007; Creswell \& Plano Clark, 2007).

The categories for methodology included the qualitative, quantitative and mixed methods research methodologies. How these were conceptualised and operationalised, as based upon their descriptions in Chapter 2 (see section 5.2), is summarised in the following table:

Table 2: Methodology

\begin{tabular}{l|l}
\hline Category & Conceptualisation and operationalisation \\
\hline quantitative & $\begin{array}{l}\text { Variables are measured in numerical form and analysed using statistical } \\
\text { methods. The aim is to generalise to a larger population, predict and } \\
\text { consider relationships between variables (Creswell, 2009:4). Aspects of } \\
\text { qualitative methodology do not feature. }\end{array}$ \\
\hline qualitative & $\begin{array}{l}\text { The aim is to explore and understand the meaning individuals or groups } \\
\text { ascribe to a social or human problem; to describe in an in-depth manner a } \\
\text { research problem, as well as the context in which meaning is ascribed. The } \\
\text { data analysis is inductive and considers patterns and themes. The aim is to } \\
\text { show the importance and complexity of a situation, not to generalise to a } \\
\text { larger population (Creswell, 2009:4; Creswell, 2007:36-39). Aspects of } \\
\text { quantitative research do not feature. }\end{array}$ \\
\hline mixed methods & $\begin{array}{l}\text { The term mixed methods (research), or both the terms quantitative and } \\
\text { qualitative are used to describe the methodology or methods used. Both } \\
\text { quantitative and qualitative aspects (as described above) appear. Mixed } \\
\text { methods research has been and still is variously labelled. Some of the other } \\
\text { terms used to refer to mixed methods research are: mixed research, blended } \\
\text { research, integrative research, multi-method research and triangulated } \\
\text { studies (Johnson, Onwuegbuzie \& Turner, 2007:118; Creswell \& Plano } \\
\text { Clark, 2007:5). }\end{array}$ \\
\hline
\end{tabular}


The typology used to classify research designs in this thesis has its weaknesses, as many of the categories are not mutually exclusive or exhaustive, as previously mentioned. To overcome these challenges, Mouton's (2008) original typology was refined by consulting Bryman (2008), and by clarifying some of the potentially confusing categories. Table 3 presents the results of these efforts, but only the designs that appeared in the sample are listed. The designs which were not used are: statistical modelling and computer simulation studies, participatory research/action research (PAR), methodological studies, and experimental designs. All three instances of evaluation research were coded as interventions, as this term appeared in all of those articles.

Table 3: Research design

\begin{tabular}{l|l}
\hline Category & Conceptualisation and operationalisation \\
\hline $\begin{array}{l}\text { ethnographic } \\
\text { research: participant } \\
\text { observation studies }\end{array}$ & $\begin{array}{l}\text { Based on participant observation. The goal is to gain an in-depth description } \\
\text { of a group of people or a community and investigates practices and } \\
\text { perceptions of the group (Mouton, 2008:148-149). }\end{array}$ \\
\hline surveys & $\begin{array}{l}\text { Data are collected predominantly by means of self-administered } \\
\text { questionnaires, or less often by structured interviews. Quantifiable data on } \\
\text { two or more variables are examined to describe patterns or detect } \\
\text { relationships between variables, often with large-scale description (i.e. } \\
\text { univariate analysis) is an objective (Bryman, 2008:699). }\end{array}$ \\
\hline $\begin{array}{l}\text { SDA } \\
\begin{array}{l}\text { content and textual } \\
\text { analysis / discourse }\end{array}\end{array}$ & $\begin{array}{l}\text { Involves the analysis of written texts, with reference to specific themes and } \\
\text { discourses (Mouton, 2008:165 \&168-169). Discourse analysis therefore } \\
\text { also forms part of this category. }\end{array}$ \\
\hline $\begin{array}{l}\text { historical studies \& } \\
\text { narrative analysis }\end{array}$ & $\begin{array}{l}\text { Attempt to reconstruct the past and the chronology of events (Mouton, } \\
\text { 2008:170-171). }\end{array}$ \\
\hline $\begin{array}{l}\text { life histories } \\
\text { national studies }\end{array}$ & $\begin{array}{l}\text { Focus on reconstructing the life of an individual, and in particular on the life } \\
\text { story of the individual as expressed by him- or herself (Mouton, 2008:172- } \\
173 \text { ). }\end{array}$ \\
\hline $\begin{array}{l}\text { Studies of two or more cases, comparing or contrasting the cases, using } \\
\text { cultural and cross-national research (Bryman, 2008:58). }\end{array}$ \\
\hline
\end{tabular}

Sampling strategy was divided between non-probability and probability methods, and each sampling method that appeared in the sample of articles could be assigned to one of these categories. The following table provides the definitions for probability and non-probability sampling strategies, as well for the methods which required interpretation. 


\begin{tabular}{|c|c|c|}
\hline \multicolumn{2}{|l|}{ Category } & Conceptualisation and operationalisation \\
\hline \multirow{4}{*}{$\begin{array}{l}\text { Non-probability } \\
\text { (not based on the } \\
\text { logic of } \\
\text { probability } \\
\text { theory [Babbie \& } \\
\text { Mouton, } \\
\text { 2008:644]) }\end{array}$} & purposive & $\begin{array}{l}\text { Sampling on the basis of the researcher's judgement as to who } \\
\text { would provide the best information. This also includes the } \\
\text { selection of key informants, and expert sampling, i.e. when } \\
\text { research participants are selected based on the researcher's } \\
\text { knowledge that they are experts in a field (Kumar, 2011:385\& } \\
\text { 207). }\end{array}$ \\
\hline & convenience & $\begin{array}{l}\text { Sampling on the basis of the availability of sampling units. This } \\
\text { is also referred to as accidental or availability sampling, and the } \\
\text { selection of volunteers formed part of this category (Kumar, } \\
2011: 380,207) \text {. }\end{array}$ \\
\hline & quota & $\begin{array}{l}\text { Sampling on the basis of pre-defined, visible characteristics of } \\
\text { the sampling units. The purpose is to imitate the distribution of } \\
\text { these characteristics as they are assumed to appear in the } \\
\text { population being studied (Babbie, 2011:515). }\end{array}$ \\
\hline & snowball & $\begin{array}{l}\text { Sampling with the help of research participants who identify } \\
\text { other relevant participants (Kumar, 2011:208,399). }\end{array}$ \\
\hline \multirow{3}{*}{$\begin{array}{l}\text { Probability } \\
\text { (based on the } \\
\text { logic of } \\
\text { probability } \\
\text { theory; each case } \\
\text { has an equal } \\
\text { chance to be } \\
\text { included in the } \\
\text { final sample } \\
\text { [Babbie \& } \\
\text { Mouton, } \\
\text { 2008:645]) }\end{array}$} & $\begin{array}{l}\text { random } \\
\text { (unspecified) }\end{array}$ & $\begin{array}{l}\text { The sampling method was referred to as random, but no further } \\
\text { details were provided. }\end{array}$ \\
\hline & $\begin{array}{l}\text { stratified } \\
\text { (unspecified) }\end{array}$ & $\begin{array}{l}\text { The sampling method was referred to as stratified, but no } \\
\text { further details were provided. }\end{array}$ \\
\hline & $\begin{array}{l}\text { not } \\
\text { applicable }\end{array}$ & $\begin{array}{l}\text { When a census was conducted, or when SDA was conducted on } \\
\text { the whole dataset of a previous study. }\end{array}$ \\
\hline
\end{tabular}

The data collection categories are presented in the following table. Interviews were assumed to be individual interviews, except when otherwise specified. 
Table 5: Data collection

\begin{tabular}{|c|c|}
\hline Category & Conceptualisation and operationalisation \\
\hline $\begin{array}{l}\text { semi-structured } \\
\text { interviews }\end{array}$ & $\begin{array}{l}\text { Conducted by means of an interview schedule, but the majority of the } \\
\text { questions tend to be open-ended without pre-defined response options. The } \\
\text { interviewer is allowed to ask further relevant questions and change the order of } \\
\text { the questions during the interview (Bryman, 2008:196). }\end{array}$ \\
\hline $\begin{array}{l}\text { focus group } \\
\text { interview }\end{array}$ & $\begin{array}{l}\text { An interview with a group of interviewees was conducted using predominantly } \\
\text { open-ended questions to ask about a specific topic (Bryman, 2008:196). Focus } \\
\text { groups, group interviews, or group discussions all refer to the same concept. }\end{array}$ \\
\hline $\begin{array}{l}\text { structured } \\
\text { interview }\end{array}$ & $\begin{array}{l}\text { Conducted with the help of an interview schedule, or by an interviewer } \\
\text { administering a questionnaire, which asks questions in the same order and } \\
\text { wording across different research participants. The majority of the questions } \\
\text { tend to be closed-ended with pre-coded response options (Bryman, 2008:193). }\end{array}$ \\
\hline $\begin{array}{l}\text { interview } \\
\text { (unspecified) }\end{array}$ & $\begin{array}{l}\text { Interviews (usually also including those conducted telephonically) took place, } \\
\text { but the type (e.g. structured or semi-structured) is not specified. }\end{array}$ \\
\hline $\begin{array}{l}\text { self-administered } \\
\text { questionnaires }\end{array}$ & $\begin{array}{l}\text { Respondents complete questionnaires themselves, without the help of an } \\
\text { interviewer. }\end{array}$ \\
\hline $\begin{array}{l}\text { administered } \\
\text { questionnaire }\end{array}$ & $\begin{array}{l}\text { It was explicitly stated that a questionnaire was administered, without reference } \\
\text { to an interview or an interviewer. }\end{array}$ \\
\hline $\begin{array}{l}\text { questionnaire } \\
\text { (unspecified) }\end{array}$ & $\begin{array}{l}\text { A questionnaire was used, but without specifying whether it was self- or } \\
\text { interviewer-administered, i.e. there is no reference to interviews having been } \\
\text { conducted. }\end{array}$ \\
\hline $\begin{array}{l}\text { observation } \\
\text { (unspecified) }\end{array}$ & $\begin{array}{l}\text { Collected data are described in such a way as to indicate that the data could } \\
\text { only have been collected through observation, or observation is reported as the } \\
\text { data collection method, but without specification or description of the type of } \\
\text { observation. }\end{array}$ \\
\hline $\begin{array}{l}\text { collection of } \\
\text { textual data }\end{array}$ & $\begin{array}{l}\text { Data collection from documents, for example articles, reports, letters and } \\
\text { newspapers. }\end{array}$ \\
\hline
\end{tabular}

The analysis-strategy variable measured whether any form of statistical analysis was conducted, or not. A category that emerged during data collection was that of "analysis not yet conducted", i.e. it is explicitly stated by the author/s that an analysis of the data collected had not yet been conducted. Most of the data analysis methods were reported as they appeared in the articles, and then re-coded into different variables, which are therefore presented in Chapter 4, Table 16. The categories that required more explicit conceptualisations were: descriptive statistics, computer-assisted quantitative analysis and computer assisted qualitative analysis. Descriptive statistics included all references to frequencies, percentages and measures of central tendency (i.e. means, modes and/or medians). 
Computer-assisted quantitative analysis referred to cases in which it was explicitly stated that SPSS or SAS was used to analyse the data. Computer-assisted qualitative analysis referred to the use of Atlas.Ti to analyse the data ${ }^{15}$.

The time-frame variable included the categories cross-sectional, longitudinal and historical study (the latter was deemed necessary as some studies fitted into neither the cross-sectional or longitudinal category). When a study involved both a cross-sectional and a longitudinal analysis, it was coded as the latter. The following table presents the definitions of these categories of the timeframe variable:

Table 6: Time frame

\begin{tabular}{l|l}
\hline Category & Definition \\
\hline $\begin{array}{l}\text { Cross- } \\
\text { sectional }\end{array}$ & $\begin{array}{l}\text { Results represent a single point in time, and the article reported when or how long } \\
\text { data collection took place (Babbie \& Mouton, 2008:641). }\end{array}$ \\
\hline Longitudinal & $\begin{array}{l}\text { The analysis is conducted to reflect changes over time by means of comparison } \\
\text { between two or more data points (Babbie \& Mouton, 2008:644). }\end{array}$ \\
\hline $\begin{array}{l}\text { Historical } \\
\text { study }\end{array}$ & $\begin{array}{l}\text { Covers a lengthy time period, but does not involve systematically collecting data at } \\
\text { different points in time in order to draw comparison across data points. Focuses on } \\
\text { describing the context of, or reconstructing, an event in the past. }\end{array}$ \\
\hline
\end{tabular}

Longitudinal studies were subdivided, where possible, into their different varieties: trend, cohort and panel. In a trend study a given characteristic of some population is monitored over time, while in cohort studies some specific group is studied over time by collecting data from different members of the group in each wave. In panel studies some specific group is studied over time by collecting data from the same members of the group in each wave (Babbie \& Mouton, 2008:640,645\&648).

In some cases, a "not applicable" category had to be included, e.g. where it is explicitly stated that data analysis had not (yet) been conducted, statistical analysis categories would not, per definition, apply. Even if a variable was applicable, not all articles provided data on all of the variables, and thus a "not reported" (missing-data) category was created for most variables. In cases where descriptions were deemed too vague or otherwise insufficient to allow for reliable classification, the category "not reported" was also used.

\footnotetext{
${ }^{15}$ These were the only computer analysis packages referred to in the sample.
} 


\subsubsection{Operationalisation example}

To illustrate how the different variables were operationalised in the study, and to illustrate potential issues for data collection, an example is provided below, making use of an article which is not part of the sample drawn for the thesis.

From the article text, the following information could be derived: the research design is described as "a quasi-experimental descriptive survey" and the aim of the research is "to determine whether the buddy system would impact positively on the self-care behaviours of HIV+ women in Botswana”. The researchers collected primary data through the use of interviews, although questionnaires were employed as data collection method in the pre-test phase. The interviewers made use of structured interview schedules, which included Likert scales. Non-probability sampling methods (snowball sampling and availability sampling) were used. The data that were collected were analysed and presented using statistical methods (Zuyderduin, Ehlers \& Van der Wal, 2008: 7-13).

Classifying the research design was complicated, as the study uses both the terms "survey" and "quasi-experimental" (implying an experiment), and "quasi-experimental descriptive survey" does not exist in the typology (see section 5.2). After close reading of the article, it was decided against classifying the design as a survey, as this term referred more to how the data were collected (which would be coded in a different variable, i.e. data collection method). Rather, it was coded as "field experiment", as this seemed to best reflect the goal of the research. It was coded as a longitudinal analysis of the panel type as measurements were taken twice, each time of the same respondent. The goal and type of data that are valued (the goal to be able to generalize to all HIV+ women in Botswana through the use of statistics) both fit in with a quantitative methodology The study made use of quantitative methods (e.g., descriptive statistical analysis) for the analysis phase. The tools (e.g., a structured interview schedule consisting primarily of scales) were also designed to collect quantitative data during the data collection phase. Although non-probability sampling (i.e. snowball sampling), a method usually associated with qualitative studies was used, the purpose was not to collect rich descriptions from this sample, but the sampling method was necessitated by the fact that the population was not recorded on any list and therefore a probability sampling method was not feasible. After considering all these aspects holistically, the study was classified as predominantly quantitative. 


\section{Data processing and analysis}

After all the data had been collected and stored in the MS Excel files, they were entered into an IBM SPSS Statistics (v. 20) dataset and data analysis could be conducted. Although this software (henceforth referred to as SPSS) was used for the majority of the data analysis, MS Excel was also employed.

As the categories of the variables were, in most cases, created directly from the terms used in the articles, the raw data, the distinctions among them were as fine as they could possibly be. Due to the great range of variation of categories in the case of some variables (e.g. data collection methods used), each category had very few cases. Therefore, to facilitate data analysis, some of the variables' categories had to be combined (re-coded).

The way in which data are captured in SPSS, with articles as the unit of analysis, renders it difficult to analyse the great variety of combinations of methods that were reported in the articles. For example, a category for analysis methods would be "grounded qualitative analyses and frequency analysis", which made it difficult to determine how many times "frequency analysis" (with or without other methods) was conducted in the sample as a whole. In this regard, MS Excel was found to be more useful to capture the frequency with which individual methods appear in the sample (i.e. to use those methods as the unit of analysis).

Most of the data analysis was of a descriptive, cross-sectional nature. However, to describe trends over time, a descriptive longitudinal analysis was also conducted. The results of the descriptive analysis were mostly presented in frequency tables, bar charts and pie charts, depending on which would visually present the data best. These were accompanied by a narrative description of the results, as well as their implications, and additional findings. Percentages and averages were the statistical methods most often used, although for the longitudinal analysis it was necessary to conduct a test to assess whether the change over time was statistically significant. After a consultation with Stellenbosch University's Centre for Statistical Consultation, the chi-square test used in this instance as a goodness-of-fit test - was chosen as the most appropriate. The null hypothesis, as assumed by SPSS, was that there had been no change over the years. The specified level of $\alpha .05$ was selected, which meant that, if the chi-square test indicated a result to be statistically significant, there was only $5 \%$ chance that the result was due to sampling error. The next section examines limitations of the study, and how they were addressed, where possible. 


\section{Shortcomings of the study}

During this chapter a number of obstacles have already been described, and therefore in this section only those not already mentioned previously, are elaborated upon. The main focus of this section is on potential problems with the databases, unattainable articles, limitations associated with the way in which the notion of a "sociological article" was operationalised, the presence of non-empirical articles and, lastly, articles' representation of research,

Firstly, the databases used to construct the sampling frame do not index all research conducted in the field of sociology during the time period that was investigated. It needs to be kept in mind that the thesis focussed only on research published as articles in peer-reviewed academic journals (the target population). Sociological research that has appeared as "grey" literature, i.e. as conference and seminar papers, or unpublished dissertations and government reports, was therefore excluded. Another possible limitation related to the databases' coverage is that not all peerreviewed journals were indexed by them, and thus articles in those journals were excluded from the analysis. However, they still produced a sample that is more representative of the population that if one were to focus on, for example, one database or one journal only.

The initial intension was to select information on sociological articles from SA Knowledgebase in order to construct a sampling frame. It is a comprehensive database of South African research and contains, amongst others, longitudinal information on articles published in journals indexed in the WoS and in other government-accredited journals (CREST, 2007), and therefore its content meets the criteria listed in section 4.3 above. This would have saved a lot of time, but unfortunately SA Knowledgebase was not available when the sampling frame had to be constructed.

Another dataset that was considered is the Nexus database, a database maintained by the NRF which "contains information on research projects of all research organisations, e.g. universities...NGOs, museums etc. as well as master's and doctoral studies in South Africa" (Alexander et al., 2006:228). This was the database used by Alexander et al. (2006). However, Nexus includes non-journal research output, as well as non-peer-reviewed and Afrikaans articles. If this database were to have been used, it would have produced an initial sampling frame consisting of many articles not relevant to this thesis, and attempts to gain access to that dataset proved unsuccessful. Instead, the enormous task (especially for a single researcher), was undertaken to construct a sampling frame from scratch.

Secondly, as previously mentioned, articles that could not be located, or were too costly to order from overseas, were excluded from the sample, and therefore from the study population. Although this created the potential for bias, it is unlikely that any such bias would be correlated with methodology, i.e., it is implausible that articles published in journals not available in South 
Africa would be any more or less likely to report on a certain methodology than articles published in journals that could be located in South Africa.

Thirdly, searching for the term "sociol" in journals and articles has its own limitations as an operational definition of what a sociological article is. Not all articles that report on sociological research explicitly state that the topic being dealt with is sociological, or even directly refer to the term "sociology". For example, research on "social mobility" does not necessarily use the term sociology. The sampling frame therefore also included articles authored by researchers affiliated with a sociology department or other grouping, but not all researchers with such an affiliation are sociologists, and sociological topics are not researched only by sociologists. Moreover, sociology as a discipline does not have fixed boundaries, and overlaps frequently with other social sciences, such as social psychology. Sociology also has many inter-disciplinary ties, which further complicates the definition of what is considered sociology (Scott, 2005). This limitation was addressed by consulting the journals: if they identified themselves as a sociological or multi-disciplinary journal, their articles were considered sociological. However, the inclusion criteria might have erred on the side of being too lenient by including multi-disciplinary journals.

Another shortcoming relates specifically to non-empirical articles. As mentioned previously, non-empirical articles were initially excluded, then included in the final sampling frame, and then again excluded during data analysis for various reasons, but primarily as most of the central variables did not apply to them. If clarity on this aspect of the study had been gained earlier, more empirical articles could have been included in the sample, which would have benefitted the data analysis in many ways.

Lastly, the data collection and analysis conducted for this thesis are, for pragmatic reasons, based on the assumption that each article represents a unique research effort, which in reality is not the case. Data collected in a single study can be published in multiple articles (Hess, 1950:78), and authors would often state that the research in the article is part of a larger research project, and refer to other articles. In a similar vein, the thesis is based on the assumption that what is reported in the article mirrors exactly how the research was conducted, which in reality is seldom the case. It is not possible to provide all the methodological details of a research project in one article, due to the constraints on the length of manuscripts submitted for publication. Also, a research article is an attempt to convince the audience of the findings of the research, which implies that the author would present the research in the most convincing way, possibly only including the most prominent findings and details of the research (Sismondo, 2004:142-143). It is important to keep this in mind when interpreting findings concerning the "not reported" categories. When, for example, sampling 
was categorised as "not reported", it could mean either that the original study did not involve sampling, or that the articles simply did not report on how sampling was conducted.

\section{8. $\quad$ Summary}

Chapter 3 commenced with an exposition of the main research questions and the data that would have to be collected to answer them. Following this was a description of a pilot test conducted to identify potential methodological issues, select a sampling method and refine the way in which data would be recorded.

Constructing the sampling frame consisted of a number of steps. Firstly, databases from which article references could be collected had to be selected. The requirements that the databases had to meet were elaborated upon in this chapter, and strategies to overcome obstacles were formulated. After the references were collected, some addition cleaning of the sampling frame had to be done before a final sampling frame was available and a sample could be drawn.

This chapter also discussed the data analysis process, as well as the different tools and techniques used to analyse the data. It was explained that both descriptive cross-sectional and descriptive longitudinal analysis would be conducted, and the various techniques used to visually present the data analysis were outlined. The chi-square test was selected to test for statistically significant results. The last section of the chapter discussed limitations and obstacles that had not been mentioned previously. Limitations that need to be borne in mind during the interpretation of the results were also highlighted. Chapter 4 further elaborates on the analysis of the data, and presents the results obtained. 


\section{Chapter 4: Presentation And discussion OF Results}

\section{Introduction}

The aim of this thesis is to describe methodological trends in South African sociology during the period of 1990 to 2009. In order to achieve this, data on various aspects of the research presented in a representative sample of peer-reviewed articles were collected. As described in Chapter 3, data on the research methods and techniques employed, the authors of the articles, and other aspects of the research (e.g. whether a pilot was conducted) were collected. In Chapter 4 the results of the data analysis is presented with the aim to explore the types of methods used across the selected time period, as well as other aspects of the articles. The analysis is mainly descriptive, and includes both cross-sectional and longitudinal elements. As methodological pluralism is a central concept to this thesis, specific attention was devoted to methods and techniques traditionally associated with qualitative and quantitative methodologies.

The presentation of the results of the analysis is divided into three main foci, i.e. sampling methods, data collection methods, and data analysis methods. However, other aspects of the research communicated in the articles were also analysed. These relate to methodology, but not directly to the methodological-pluralism debate. Examples include the cross-sectional or longitudinal nature of the studies, and whether pilot studies were conducted. In addition, some features of authorship, in particular the extent and type of author collaboration and the latter's relationship to methodology employed, were analysed.

\section{Background: Journals and publication rates}

The realised sample consists of those 111 articles which report on research of an empirical nature. This section presents some background information on the sample, i.e. the journals included in the sample, as well as the distribution of the publication years of the articles.

In the previous chapter it was mentioned that due to the overlaps between sociology and other social science disciplines, articles from multi-disciplinary and inter-disciplinary journals were also included in the sample. The following table presents the frequencies with which each journal occurred in the sample, as well as the disciplines they aim to cover.

Table 7 divides journals into five categories: journals which state that they only cover sociology; journals which state that they cover a variety of disciplines and explicitly name sociology as one of those; journals which state that they cover the social sciences and include multidisciplinary and/or inter-disciplinary research; and lastly, the "other" category includes journals 
which were included because the authors of the sampled articles published in them were either sociologists, or stated that their articles cover a sociological topic.

\begin{tabular}{|c|c|c|}
\hline Journal name & Frequency & Percentage \\
\hline \multicolumn{3}{|l|}{ SOCIOLOGY } \\
\hline Society in Transition & 3 & 2.7 \\
\hline British Journal of Sociology of Education & 2 & 1.8 \\
\hline Discourse and Society & 2 & 1.8 \\
\hline Media, Culture and Society & 2 & 1.8 \\
\hline Sexualities & 2 & 1.8 \\
\hline International Journal of the Sociology of Language & 2 & 1.8 \\
\hline Sociology of Health and Illness & 1 & 0.9 \\
\hline Sub-total & 14 & 12.6 \\
\hline \multicolumn{3}{|l|}{ INTER-DISCIPLINARY/MULTI-DISCIPLINARY (INCLUDING SOCIOLOGY) } \\
\hline Social Science and Medicine & 12 & 10.8 \\
\hline AIDS Care: Psychological and Socio-Medical Aspects of AIDS/HIV & 7 & 6.3 \\
\hline Journal of Biosocial Science & 4 & 3.6 \\
\hline Social Psychiatry and Psychiatric Epidemiology & 4 & 3.6 \\
\hline African Journal of AIDS research & 3 & 2.7 \\
\hline African Studies & 2 & 1.8 \\
\hline Journal of Religion in Africa & 2 & 1.8 \\
\hline Malaria Journal & 2 & 1.8 \\
\hline Scandinavian Journal of Public Health & 2 & 1.8 \\
\hline Sociologia Ruralis & 2 & 1.8 \\
\hline Urban Studies & 2 & 1.8 \\
\hline Adolescence & 1 & 0.9 \\
\hline African Affairs & 1 & 0.9 \\
\hline Archives of Suicide Research & 1 & 0.9 \\
\hline Armed Forces and Society & 1 & 0.9 \\
\hline Critical Public Health & 1 & 0.9 \\
\hline Ethnic and Racial Studies & 1 & 0.9 \\
\hline Health and Place & 1 & 0.9 \\
\hline Human Ecology & 1 & 0.9 \\
\hline International Journal of Eating Disorders & 1 & 0.9 \\
\hline International Journal of Intercultural Relations & 1 & 0.9 \\
\hline International Journal of Law, Policy and the Family & 1 & 0.9 \\
\hline International Journal of the Sociology of Law & 1 & 0.9 \\
\hline International Migration & 1 & 0.9 \\
\hline Journal of Comparative Family Studies & 1 & 0.9 \\
\hline Journal of Conflict Resolution & 1 & 0.9 \\
\hline Journal of Eastern African Studies & 1 & 0.9 \\
\hline Journal of Environmental Systems & 1 & 0.9 \\
\hline Journal of Multilingual and Multicultural Development & 1 & 0.9 \\
\hline Men and Masculinities & 1 & 0.9 \\
\hline Pediatrics & 1 & 0.9 \\
\hline
\end{tabular}


Table 7 cont.

\begin{tabular}{|c|c|c|}
\hline Journal name & Frequency & Percentage \\
\hline \multicolumn{3}{|c|}{ INTER-DISCIPLINARY/MULTI-DISCIPLINARY (INCLUDING SOCIOLOGY) } \\
\hline Qualitative Health Research & 1 & 0.9 \\
\hline Reviews on Environmental Health & 1 & 0.9 \\
\hline Science, Technology and Society & 1 & 0.9 \\
\hline Sexually Transmitted Infections & 1 & 0.9 \\
\hline Social Behavior and Personality & 1 & 0.9 \\
\hline Social Psychology Quarterly & 1 & 0.9 \\
\hline The Journal of Peasant Studies & 1 & 0.9 \\
\hline Violence against Women & 1 & 0.9 \\
\hline Violence and Victims & 1 & 0.9 \\
\hline Sub-total & 71 & 64.0 \\
\hline \multicolumn{3}{|l|}{ INTER-DISIPLINARY/MULTI-DISIPLINARY (UNSPECIFIED) } \\
\hline Journal of Southern African Studies & 6 & 5.4 \\
\hline Journal of Social Aspects of HIV-AIDS & 2 & 1.8 \\
\hline Africa Insight & 1 & 0.9 \\
\hline Health Policy and Planning & 1 & 0.9 \\
\hline International Journal of Social Welfare & 1 & 0.9 \\
\hline International Journal of Urban and Regional Research & 1 & 0.9 \\
\hline Journal of Advanced Nursing & 1 & 0.9 \\
\hline Journal of Rural Studies & 1 & 0.9 \\
\hline Journal of Women and Aging & 1 & 0.9 \\
\hline Language in Society & 1 & 0.9 \\
\hline Perspectives on Global Development and Technology & 1 & 0.9 \\
\hline Race, Ethnicity and Education, & 1 & 0.9 \\
\hline Reproductive Health Matters & 1 & 0.9 \\
\hline Third World Quarterly & 1 & 0.9 \\
\hline Sub-total & 20 & 18.0 \\
\hline \multicolumn{3}{|l|}{ OTHER } \\
\hline South African Medical Journal & 2 & 1.8 \\
\hline Development Southern Africa & 1 & 0.9 \\
\hline Politikon: South African Journal of Political Studies & 1 & 0.9 \\
\hline Journal of Health Population and Nutrition & 1 & 0.9 \\
\hline Agenda & 1 & 0.9 \\
\hline Sub-total & 6 & 5.4 \\
\hline TOTAL & 111 & 100.0 \\
\hline
\end{tabular}

The majority (82.0\%) of the articles are from interdisciplinary journals, and most of those (78.0\%) are from journals which explicitly state that they also cover sociology. Only $12.6 \%$ of the articles are from journals that exclusively cover sociology and only a small percentage (5.4\%) of the articles are from journals which do not state that they are multi-disciplinary or that they cover the topic of sociology. 
The distribution of the articles across the time period investigated (see Figure 1 below) had some implications for the longitudinal analysis conducted in this thesis.

Figure 1: Publication rates, 1990-2009

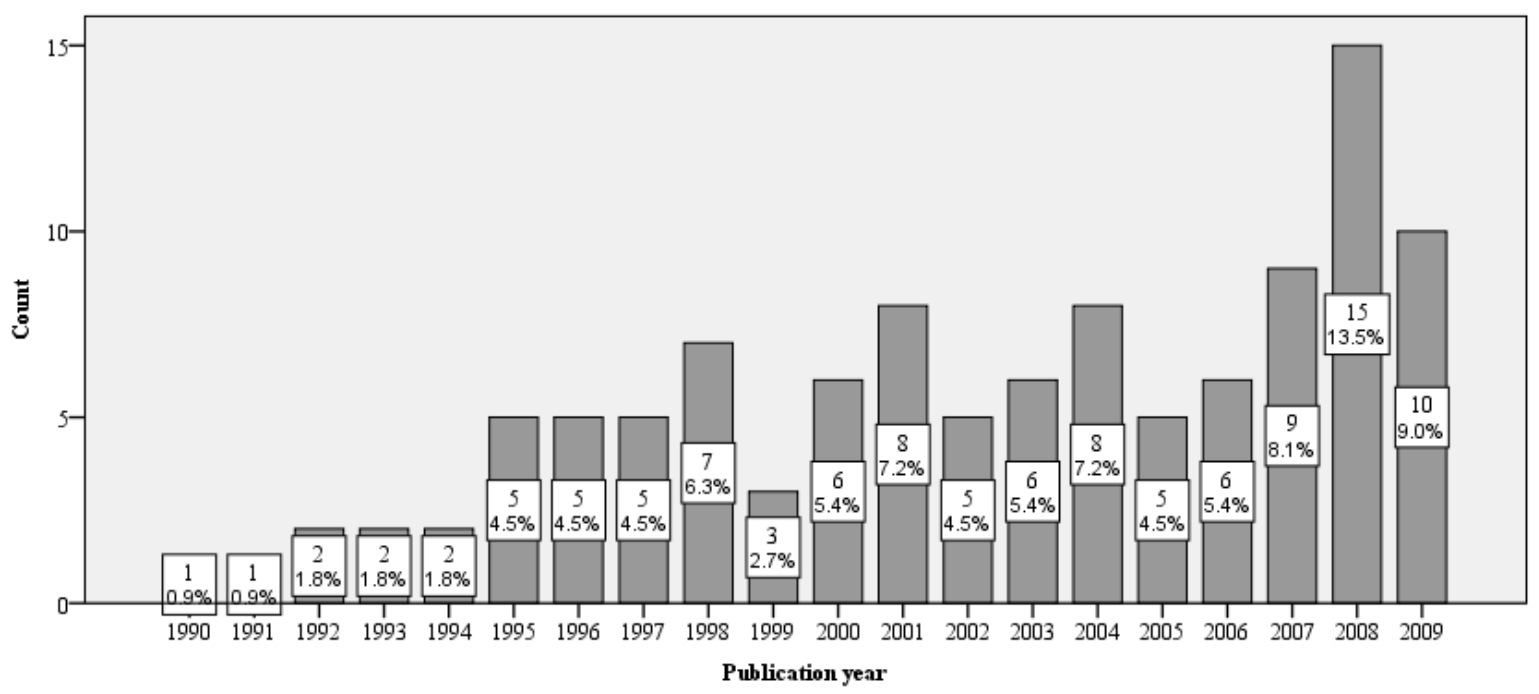

What is evident from Figure 1 is that in some years relatively few articles were published, which led to very small numbers of articles with certain publication years to be sampled. To elaborate, one may combine the time periods into large time intervals: during the period 1990-1994 only $7.2 \%$ of articles in the sample were published, but this figure rose steadily from $22.5 \%$ in $1995-1999$, to $29.7 \%$ in 2000-2004 and 40.5\% in 2005-2009. With such an uneven distribution across the publication years, and a small proportion of articles in the early years, it would not be useful to analyse the data across discrete years, and even the five-year-each intervals described above would be problematic.

The most appropriate strategy was to collapse discrete publication years into the following year intervals for all the other longitudinal analyses: 1990-1999, 2000-2004 and 2005-2009. These intervals, the first ten years and then two groupings of five years thereafter, were decided upon because each of the three groupings were deemed to contain a sufficient number of articles to allow for longitudinal analysis. The first and second intervals contained the same percentage of articles (29.7\%), while the last interval comprised $40.5 \%$ of the sample.

\section{3. $\quad$ Research methodologies}

A central question in this thesis is whether a single methodology has been more prominent than others in sociological research conducted and published by South Africans over the past two decades. Stated differently, this thesis investigate to what extent quantitative, qualitative and mixed methods methodologies are represented in research publications (and, by extension, research 
practice), and whether any trends in this regard can be identified in the period from 1990 to 2009 . This is an indication used in this thesis to determine the extent to which methodological pluralism is present in South African sociological research. Only 22 articles explicitly stated the methodology that was used in the research. Interestingly, those that were the most likely to do so, reported the use of a qualitative methodology (14), while six reported mixed methods, and only two articles explicitly stated that a quantitative methodology had been employed. However, for most (107 or $96 \%)^{16}$ of the sampled articles it was possible to deduce the research methodology employed. The results presented in the following figure and table therefore pertain to those 107.

Figure 2: Research methodology employed
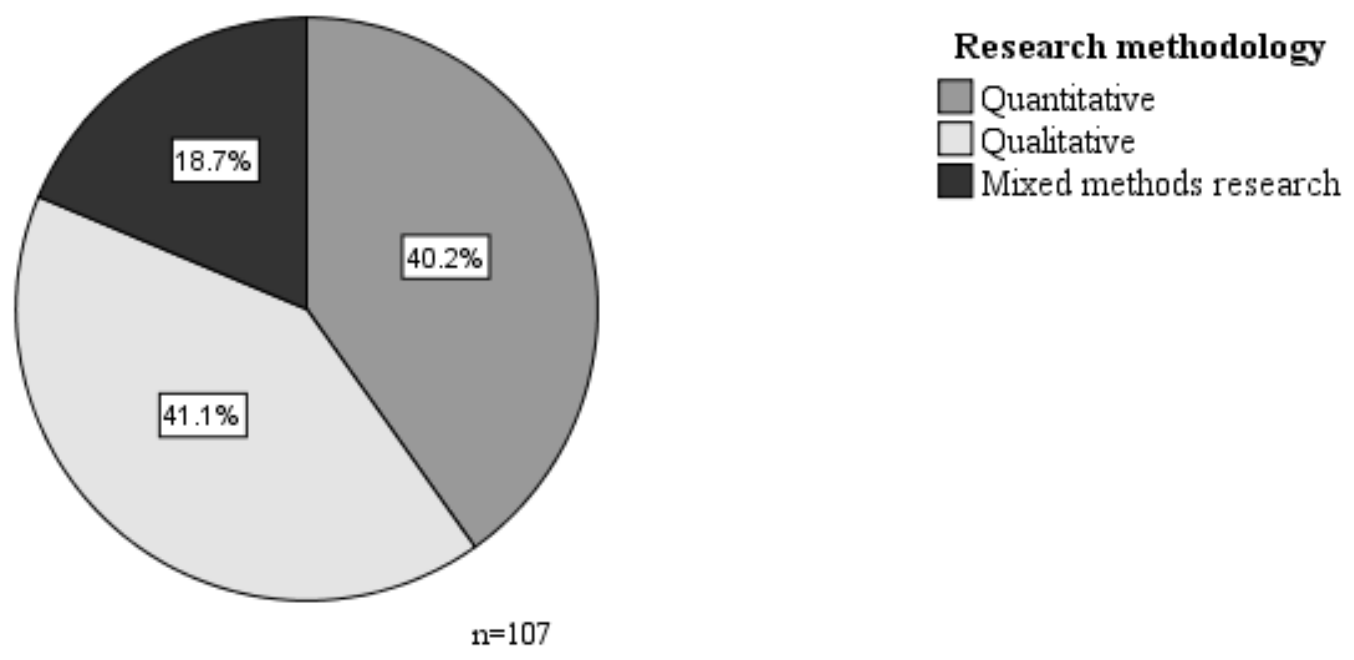

Figure 2 shows that qualitative and quantitative methodologies are equally represented: a quantitative methodology was employed in $40.2 \%$ (43) of the research published, while $41.1 \%$ (44) of the cases reported on employing a qualitative methodology. The remaining $18.7 \%$ of articles reported a mixed methods research methodology. While some of the literature refers to the possibility that qualitative research may be dominating sociological research, the results of the cross-sectional analysis presented in Figure 2 indicate that the frequency of published qualitative and quantitative research differed by less than $1 \%$, and that mixed methods research methodology is much less present than the other two methodologies.

Proceeding to a longitudinal view of the methodologies employed, Table 8 indicates the frequency with which each methodology occurred across the year intervals specified earlier:

\footnotetext{
${ }^{16}$ Four articles (see A72, A150, A360 and A480 in Addendum C) did not provide sufficient detail when describing the methods employed to allow for methodology to be determined.
} 


\begin{tabular}{l|r|r|r|r}
\hline \multicolumn{6}{l}{ Table 8: Changes over time in research methodology employed, 1990-2009 } \\
\hline & \multicolumn{1}{|c|}{$\mathbf{1 9 9 0 - 1 9 9 9}$} & \multicolumn{1}{|c|}{$\mathbf{2 0 0 0 - 2 0 0 4}$} & \multicolumn{1}{|c|}{$\mathbf{2 0 0 5}-\mathbf{2 0 0 9}$} & \multicolumn{1}{c}{ Total } \\
\hline Quantitative & $15(48.4 \%)$ & $11(35.5 \%)$ & $17(37.8 \%)$ & $43(40.2 \%)$ \\
Qualitative & $12(38.7 \%)$ & $15(48.4 \%)$ & $17(37.8 \%)$ & $44(41.1 \%)$ \\
Mixed methods & $4(12.9 \%)$ & $5(16.1 \%)$ & $11(24.4 \%)$ & $20(18.7 \%)$ \\
\hline Total & $\mathbf{3 1}(\mathbf{1 0 0 . 0 \%})$ & $\mathbf{3 1}(\mathbf{1 0 0 . 0 \%})$ & $\mathbf{4 5}(\mathbf{1 0 0 . 0 \%})$ & $\mathbf{1 0 7}(\mathbf{1 0 0 . 0 \% )}$ \\
\hline
\end{tabular}

The results show that across these time periods, the percentages of articles reporting in particular methodologies have changed. Among the articles published in the period 1990-1999, those reporting on a quantitative methodology constitute almost half $(48.4 \%)$ of the sample, whereas those reporting on qualitative research and mixed methods research constitute $38.7 \%$ and $12.9 \%$, respectively. Among the articles published during the next time period, 2000-2004, the proportion of articles reporting on a quantitative methodology decreased to $35.5 \%$, while those reporting on a qualitative and mixed methods methodology increased to $48.4 \%$ and $16.1 \%$, respectively. Among the articles published during the most recent time period, 2005-2009, articles reporting on a quantitative and qualitative methodology were equally distributed at $37.8 \%$ each, while the percentage reporting on mixed methods research again increased to $18.7 \%$ of the sample. Although it seems as if mixed methods research has been increasingly employed over the past two decades, and that quantitative research has been published less frequently, these observed changes over time are not statistically significant (chi-square $=2.78$, d.f. $=4, \rho>.05$ ), which is probably a function of the very few cases of mixed methods research recorded for the first 15 years.

\section{4. $\quad$ Research designs}

Collecting data on research designs proved a complicated task, as more than half $(54 \%)$ of the articles did not explicitly state what research design had been employed. Even when the research design was stated, it was often in a vague manner, for instance only stating that a case study was conducted, but not which type of case study. The problem of research designs rarely being named in articles was, however, anticipated, and thus it was decided that a research design classification system would be developed prior to data collection, by making use of the research designs distinguished by Mouton (2008:148-180), as well as other social science research textbooks (see Chapter 3). Still, the classification of the articles in terms of research design reported, required a high degree of interpretation. The methods and logic reported in each article had to be judged holistically to determine into which predefined research design it could be classified. To further complicate matters, a single study can have elements of more than one research design (Bryman, 2008:54; Blaikie, 2010:41). Consequently, many articles (15.3\% of the sample) could not be 
classified with certainty into a predefined research design category. Thus, the findings presented in Table 9 apply only to the remaining 92 cases, and need to be approached with caution.

Table 9: Research designs employed

\begin{tabular}{l|r}
\hline Survey & $33(35.1 \%)$ \\
Case study (unspecified) & $18(19.1 \%)$ \\
Secondary data analysis & $13(13.8 \%)$ \\
Historical studies and narrative analysis & $11(11.7 \%)$ \\
Content and textual analysis & $6(6.4 \%)$ \\
Comparative, cross-cultural and cross national studies & $5(5.3 \%)$ \\
Ethnographic research (unspecified) & $4(4.3 \%)$ \\
Other & $4(4.3 \%)$ \\
\hline Total & $\mathbf{9 2 ( 1 0 0 . 0 \% )}$ \\
\hline
\end{tabular}

Table 9 presents the frequencies of the sampled articles that report on the various research designs. At $35.1 \%$, survey design seems to have been the most popular research design (as well as the design most often explicitly stated, with only two articles not doing so). Case studies were the second most frequently employed (19.1\%) with 16 of those articles explicitly stating this as their research design. Surprisingly, secondary data analysis was the third most represented (13.8\%) design, while historical studies and narrative analysis were reported in $11.7 \%$ of the articles. The remaining designs - content and textual analysis; comparative, cross-cultural and cross national studies; and ethnographic research - were reported in relatively equal, small percentages (4-6\%) of the articles. The research designs included in the "other" category are life history design (in one case) and “interventions" (in three cases).

\section{Sampling methods}

The first set of research methods investigated, relates to sampling, i.e. the manner in which units that were investigated, had been selected. As described in Chapter 2, researchers using quantitative and qualitative methodologies have very different goals in mind when collecting and analysing data, and thus also when selecting cases. Quantitative studies aim to generalise to a larger population and as such, probability sampling suits this goal. Qualitative studies, on the other hand, aim to gain an in-depth understanding of an actor's reality and context, and therefore tend to involve collection of data from data sources sampled using a non-probability technique, such as the purposive selection of key informants (Babbie \& Mouton, 2008).

It is important to keep in mind that in the case of some articles, sampling may not apply in the research they report. For example, a few articles (13) employed a SDA research design and in seven of these cases, sampling was deemed not applicable when it was determined that the SDA included 
all of the data the original research collected, in the same sense that sampling is not applicable in a census. Although it is recognised that this is a debatable point, the sampling for the original study was not taken into consideration when data were collected for this thesis, as it is argued that the original study, and thus the sampling employed in that study, was not conducted by the authors of the SDA article. These 7 articles were therefore excluded from the analysis and from the results presented in the remainder of this section.

The analysis of sampling methods included an examination of the frequency with which the articles reported the use of probability sampling (i.e. the articles are the units of analysis), as well as a count of specific methods/techniques across all articles (i.e. the methods/techniques are the units of analysis) to indicate which types of specific methods/techniques were favoured, while keeping the above distinction between sampling in qualitative and quantitative research in mind.

\subsection{Probability and non-probability sampling methods}

The first important, but also troubling, result of the analysis is that of the sampled articles to which sampling applied, more than two-thirds (41.4\%) did not report a sampling method, or did not do so with sufficient detail to allow one to ascertain what type of sampling method (i.e. probability or non-probability) was conducted. This is difficult to substantiate with examples, as one cannot provide an example of the absence of something. However, the following illustrate cases where sampling was not explained in sufficient detail to classify. In one article the authors stated that their "data comprised of letters submitted to local newspapers by the white residents of a coastal town in the Cape Province ${ }^{17}$." The coastal town may have been picked as a specific case, which would imply a purposive sample, but how the letters themselves were sampled was not explained in any more details than in the above quote. Another example can be drawn from an article reporting on the secondary analysis of data, which explained that, in the original study, "[t]hirty interviews were conducted with groups of between two and six teachers from 22 schools in the urban area of Johannesburg, from upper as well as lower socio-economic areas ${ }^{18}$ ". This description does not, however, explain the sampling process in sufficient detail to determine how these schools and teachers were originally selected.

The insufficiently detailed sampling reporting raised the question whether not reporting sufficiently on sample methods differs between the different methodologies. The data show that $58.1 \%$ of the articles which reported a qualitative methodology did not report their sampling method in sufficient detail: a much larger percentage than the $27 \%$ and $35 \%$ of articles which reported a quantitative methodology and mixed methods research, respectively. Thus, even though

\footnotetext{
${ }^{17}$ See article A078 in Addendum C

${ }^{18}$ See article A048 in Addendum C
} 
the lack of detailed sampling reporting is a feature of all of the methodologies, it is particularly prominent in articles that report on a qualitative methodology.

The high incidence of insufficiently detailed sampling reporting also meant that the analysis of sampling methods only includes 58 articles as valid cases. Figure 3 presented below shows that, of those 58 articles, only approximately a third (34.5\%) reported the use of probability sampling, while more than half $(53.4 \%)$ reported the use of non-probability sampling, and $12.1 \%$ reported the use of both. Thus, for the past two decades, non-probability sampling was used more often than probability sampling.

Figure 3: Sampling strategy employed

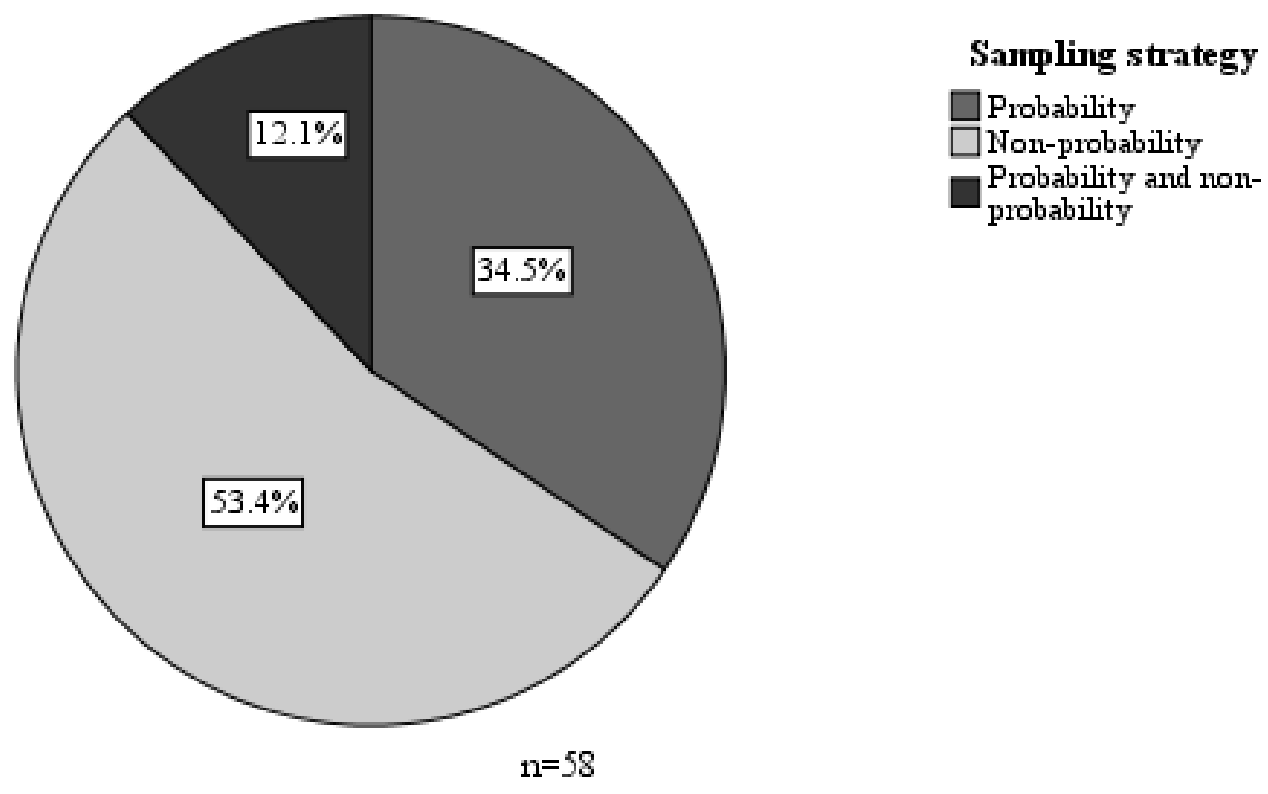

\subsection{Sampling methods and techniques as the unit of analysis}

The sampling techniques reported in each article were recorded in a single variable in SPSS, with the aim of developing a typology of such techniques, instead of classifying articles according to a predefined typology. However, the development of such a typology, and a frequency analysis thereof, proved very difficult, because of the wide variety and combination of techniques found both across and within articles. To illustrate the latter, one-fifth of the 58 articles that provided sufficient information to allow categorisation according to sampling technique, reported a combination of techniques.

It was therefore decided to analyse sampling techniques, instead of articles, as the unit of analysis, in order to determine which sampling techniques were most often employed. Table 10 below was created using data captured in MS Excel. It lists all the techniques reported across all the articles for which one or more sampling technique could be identified, and shows the frequencies 
with which those techniques occurred, as well as the way in which they were categorised as probability or non-probability methods.

\begin{tabular}{|c|c|c|}
\hline Methods/techniques & Frequency & Percentage \\
\hline \multicolumn{3}{|l|}{ NON-PROBABILITY } \\
\hline Purposive or judgemental & 23 & 32.0 \\
\hline Reliance on available subjects (convenience/availability/volunteer) & 14 & 19.4 \\
\hline Snowball & 4 & 5.6 \\
\hline Quota & 1 & 1.4 \\
\hline Sub-total & 41 & 56.9 \\
\hline \multicolumn{3}{|l|}{ PROBABILITY } \\
\hline Simple random & 14 & 19.4 \\
\hline Stratified & 13 & 18.1 \\
\hline Systematic & 2 & 2.8 \\
\hline Sub-total & 29 & 40.3 \\
\hline OTHER $^{19}$ & 1 & 1.4 \\
\hline TOTAL & 72 & 100.0 \\
\hline
\end{tabular}

From Table 10 it is clear those techniques that Babbie and Mouton (2008) classify as nonprobability in nature were most often reported, which confirms the results when articles were treated as the units of analysis (see section 5.1 above). Among the non-probability techniques, purposive or judgemental sampling was the one most often applied, followed by reliance on available subjects. Snowball and quota sampling techniques also featured, but much less frequently. Among the probability sampling techniques, simple random and stratified sampling seem most popular in almost equal measure, followed by systematic sampling.

\section{$5.3 \quad \underline{\text { Summary }}$}

In this section, sampling methods and techniques were analysed to determine whether probability or non-probability sampling methods dominate. It is interesting to note that, although neither qualitative nor quantitative methodologies have been found to dominate since 1990, non-probability sampling, particularly those techniques most often associated with qualitative research, (purposive or judgemental sampling) was most often reported. These are also the sampling methods that are less likely to be representative of the population from which they are drawn, and do not permit a researcher to estimate, on the basis of probability theory, the accuracy or representativeness of the sample (Babbie \& Mouton, 2001). However, the finding that less than $60 \%$ of articles report their sampling methods at all is by far the more intriguing.

\footnotetext{
${ }^{19}$ Other sampling methods include "clinic data".
} 


\section{Data collection methods}

The next section of the reporting of the results deals with the topic of data collection. As is the case with sampling methods, it is difficult and often inappropriate to classify a data collection method as quantitative or qualitative, as it depends on the type of data collected through the method. Some techniques do, however, cater better for the collection of qualitative data than quantitative data, e.g. in-depth, face-to-face interviews. This thesis therefore considers the types of methods and techniques which were used in the articles, irrespective of the methodology with which they are traditionally associated. With this in mind, the specific data collection methods and techniques reported in the articles, and the frequency with which they were reported, were determined.

\subsection{Data collection methods}

This section describes the data collection methods that were reported in the articles. The raw data were grouped and then re-coded into more general categories, to provide an aggregate overview of data collection methods used. As such, detail on, for example, specific interviewing techniques are not presented here, but further in this section interviews and questionnaires are expanded upon separately. Table 11 below presents the data collection methods.

Table 11: Data collection methods employed

\begin{tabular}{l|r|r}
\hline & Frequency & Percentage \\
\hline Interviews & 35 & 36.1 \\
Collection of textual data & 13 & 13.4 \\
Interviews and collection of textual data & 11 & 11.3 \\
Interviews and observation & 8 & 8.2 \\
Questionnaires & 7 & 7.2 \\
Questionnaires and interviews & 6 & 6.2 \\
Observation and collection of textual data & 4 & 4.1 \\
Observation & 3 & 3.1 \\
Other data collection methods ${ }^{20}$ & 10 & 10.3 \\
\hline Total & $\mathbf{9 7}$ & $\mathbf{9 9 . 9}$ \\
\hline
\end{tabular}

In $87.4 \%$ (97 out of 111) of the sample, data collection methods were reported in sufficient detail to allow classification, or were deemed applicable ${ }^{21}$. Table 11 shows that the interview method was most often reported.

\footnotetext{
${ }^{20}$ The "other" category includes articles that reported on unique methods, or unique combinations of methods, that did not fit into any of the other categories.
} 
Not only do $36.1 \%$ of the articles solely make use of interviews (of various types), but interviewing was also often used in conjunction with other methods, rendering it by far the most prominent data collection method used (i.e. in $61.8 \%$ of all the research reported). The collection of textual data was the second most popular technique: as a sole technique it was reported in $13.4 \%$ of the sample, but it was also used in conjunction with other methods such as interviews, observation and questionnaires, as reported in a further $15.4 \%$ of articles. On their own, or in conjunction with other methods, observation was reported in $15.4 \%$ of the articles, and questionnaires were used in $13.4 \%$ of the research reported.

\subsubsection{Interview techniques}

Table 11 showed that the interview method was the most popular one for collecting primary data and as such, it was deemed important to investigate in more detail the different techniques used for interviewing. In Table 12 below, the combination of interviewing techniques was expanded upon, not only to tabulate the different types of interviews, but also the combination of interviews, that had been conducted.

Table 12: Interview techniques employed

\begin{tabular}{|c|c|c|}
\hline & Frequency & Percentage \\
\hline Interview (unspecified) & 22 & 33.8 \\
\hline Interview (unspecified) and focus group interview & 14 & 21.5 \\
\hline Semi-structured interview & 10 & 15.4 \\
\hline In-depth interview & 7 & 10.8 \\
\hline Structured interview & 5 & 7.7 \\
\hline Face-to-face interview (unspecified) & 3 & 4.6 \\
\hline $\begin{array}{l}\text { Household interview (unspecified), focus group and interview } \\
\text { (unspecified) }\end{array}$ & 2 & 3.1 \\
\hline Telephone interview (unspecified) & 1 & 1.5 \\
\hline Focus group interview & 1 & 1.5 \\
\hline Total & 65 & 100 \\
\hline
\end{tabular}

As the table shows, among the 65 articles that reported on the use of an interview method, the majority $(33.8 \%)$ did not specify the type of interview conducted. Others specified the manner in which the interviews were conducted (i.e. household, face-to-face, or by telephone), but not how the interviews were structured (e.g. semi-structured, in-depth or structured). In most cases it seemed that the unspecified interviews referred to individual interviews, and the second most popular combination of interview techniques would then be a combination of focus group interviews and individual interviews (21.5\%), followed by semi-structured interviews and then by in-depth

\footnotetext{
${ }^{21}$ In six cases data collection were not reported in sufficient detail, and in eight cases the collection of data was deemed not applicable. The latter 8 cases all involve SDA, where, as argued in Section 5, the original study, and thus the methods employed in that study, was not conducted by the authors of article reporting on the SDA..
} 
interviews. Here again, the (interview) techniques more closely associated with the qualitative methodology (i.e. focus group and in-depth interviews) seem to be more prominent than those associated with the quantitative methodology (structured interviews).

However, it could often be deduced that data were collected through a structured interview, but the authors of an article reported the use of a questionnaire, in which case the data collection method was coded as an administered questionnaire of the appropriate type. For example, in article A60 it was stated that "[i]nterviews took place at the hospital over a 5-day period". However, it was further stated that "[f]our black interviewers ( 3 male and 1 female) received a one-day structured training course with practice and discussion sessions on questionnaire administration". The data collection method could therefore also have been coded as an administered (in contrast to a selfadministered) questionnaire. The option chosen for this thesis was that, when an article explicitly stated structured interviews had been conducted, it was coded as such, and when it explicitly stated that a questionnaire was administered (with no specific reference on how this was done), it was coded as an administered questionnaire.

\subsubsection{Questionnaire techniques}

As mentioned earlier, even though questionnaires were not used as often as interviews, a variety of types of questionnaires are possible. To determine which questionnaire techniques were used, the 22 articles that reported making use of questionnaires were investigated more closely. The majority (11) of these were self-administered questionnaires and nine were administered, potentially through an interview of some kind. Only in 2 cases were the type questionnaire not specified. As noted in the discussion on interview techniques above, an interview schedule was often referred to as a questionnaire, and thus the frequencies with which these two were reported should be treated with circumspection. This overlap of questionnaire and structured or semi-structured interview made the occurrence of these data collection methods difficult to track

\subsection{Data collection methods and techniques as the unit of analysis}

As was the case with sampling techniques, the great variety of data collection techniques, of which more than one was often employed in a single study, gave rise to too many permutations to allow for a detailed analysis using the article as the unit of analysis. Half (50.5\%) of the articles that reported data collection methods reported more than one data collection method and $14.4 \%$ of the articles reported more than two data collection methods. Thus, as in section 5.2 above, the unit of analysis in this section is the data collection methods/techniques, not the articles, and MS Excel was used to analyse the data on data collection methods/techniques according to the frequency with which they occurred. 
Table 13 below shows that interviews featured most often (46.8\%) as a data collection method, especially if one adds the various administered questionnaires to this amount, as this increases the prevalence to $52.6 \%$. When specified, the most popular interview technique is focus group interviews $(10.4 \%)$.

The second most frequently employed data collection method is textual data collection, but it was reported with a much lower prevalence (20.1\%) than interviews. Questionnaires constitute $14.3 \%$ of the techniques employed, with administrated questionnaires as the most frequently specified questionnaire technique. However if one considers administered questionnaire as an interview then the most often specified questionnaire technique is the self administered questionnaire. Observation constituted $12.0 \%$ of the techniques mentioned, with participant observation most often specified as the technique (the observation technique was, however, rarely specified).

\begin{tabular}{|c|c|c|}
\hline Methods/techniques & Frequency & Percentages \\
\hline \multicolumn{3}{|l|}{ INTERVIEWS } \\
\hline Interview (unspecified) & 31 & 20.1 \\
\hline Focus group interview & 16 & 10.4 \\
\hline In-depth interview & 13 & 8.4 \\
\hline Structured interview & 7 & 4.5 \\
\hline Semi-structured in-depth interviews & 2 & 1.3 \\
\hline Household interview (unspecified) & 2 & 1.3 \\
\hline Telephone interview (unspecified) & 1 & 0.6 \\
\hline Sub-total & 72 & 46.8 \\
\hline \multicolumn{3}{|l|}{ QUESTIONNAIRES } \\
\hline Administered questionnaire & 8 & 5.2 \\
\hline Self-administered questionnaire & 7 & 4.5 \\
\hline Mailed questionnaire & 4 & 2.6 \\
\hline Questionnaire (unspecified) & 2 & 1.3 \\
\hline Household questionnaire & 1 & 0.6 \\
\hline Sub-total & 22 & 14.3 \\
\hline \multicolumn{3}{|l|}{ OBSERVATION } \\
\hline Observation (unspecified) & 15 & 9.7 \\
\hline Participant observation & 3 & 1.9 \\
\hline Non-participant observation & 1 & 0.6 \\
\hline Personal observation & 1 & 0.6 \\
\hline Sub-total & 20 & 12.0 \\
\hline TEXTUAL DATA COLLECTION & 31 & 20.1 \\
\hline PHYSICAL EXAMINATION & 4 & 2.6 \\
\hline OTHER $^{22}$ & 5 & 3.2 \\
\hline TOTAL & 154 & 100.0 \\
\hline
\end{tabular}

\footnotetext{
${ }^{22}$ Other data collection methods are unique ones that were reported only once.
} 


\section{Data analysis methods}

The data analysis methods in the sample were investigated firstly by illustrating the frequency with which statistical analysis techniques were employed in the published research. Secondly, the distribution of qualitative and quantitative analysis methods/techniques was investigated. Thirdly, the frequency of the use of descriptive statistics are presented and lastly, the use of specific data analysis methods/techniques is discussed.

\section{1. $\quad$ Statistical analysis}

Statistical analysis - such as frequency analysis, the calculation of percentages, or the mode, mean or median of a sample - is most commonly associated with the quantitative methodology, because one of the aspects of this methodology is to quantify the aspects that are being investigated. By examining the prevalence of statistical analysis, an indirect indication of the prevalence of quantitative analysis was thus obtained. The aim was not, however, to determine whether statistical analysis was the central or only type of analysis conducted in the study.

In the majority of the cases it was not problematic to determine whether an article reported on statistical analysis or not, even when the exact techniques themselves could not be identified. Only three $^{23}$ articles did not report sufficiently on data analysis to allow one to determine whether statistical analysis was conducted (i.e. it was unclear whether the statistics presented originated from a secondary source, from referenced articles or from an analysis of the data collected for the study). In two other articles it was explicitly stated that analysis had not yet been conducted ${ }^{24}$, thus those articles reported on incomplete research. It was found that this was sometimes the case when an article reported on the data collection phase of a research project which was about to enter the analysis phase. Table 14 presents the results of both a cross-sectional (in the Total column on the right) and a longitudinal analysis of the frequency with which statistical analysis was conducted, as reported in the remaining 106 articles:

Table 14: Prevalence of statistical analysis, 1990-2009

\begin{tabular}{l|c|c|c|r}
\hline & $\mathbf{1 9 9 0}-\mathbf{1 9 9 9}$ & $\mathbf{2 0 0 0}-\mathbf{2 0 0 4}$ & $\mathbf{2 0 0 5}-\mathbf{2 0 0 9}$ & \multicolumn{1}{c}{ Total } \\
\hline Statistical analysis conducted & $22(66.7 \%)$ & $18(60.0 \%)$ & $26(60.5 \%)$ & $66(62.3 \%)$ \\
No statistical analysis conducted & $11(33.3 \%)$ & $12(40.0 \%)$ & $17(39.5 \%)$ & $40(37.7 \%)$ \\
\hline Total & $\mathbf{3 3}(\mathbf{1 0 0 \%})$ & $\mathbf{3 0}(\mathbf{1 0 0 \%})$ & $\mathbf{4 3 ( 1 0 0 \% )}$ & $\mathbf{1 0 6}(\mathbf{1 0 0 \%})$ \\
\hline
\end{tabular}

\footnotetext{
${ }^{23}$ See A342, A360 and A445 in Appendix C. In these cases very little information about both the data collection and data analysis were provided.

${ }^{24}$ See A840 and A708 in Appendix C.
} 
Table 14 shows that the majority of the articles (62.3\%) report that some type of statistical analysis was conducted. Although it seems as if there has been some decrease, from the period 1990-1999 to the subsequent periods, in the frequency with which statistical analysis has been employed, a chisquare test indicates that this change over the years is not significant (chi-square $=1.78$, d.f. $=4, \rho>$ $.05)$. Some articles (21) reported the use of statistical and non-statistical analysis methods, and this approximately one in five $(19.8 \%)$ of the articles which reported analysis methods, made use of statistical and other types of data analysis methods.

\subsection{Quantitative and qualitative data analysis}

Unlike the aforementioned analysis, this section directly investigates the frequency of qualitative and quantitative methods/techniques. Where the previous section only investigated whether statistical analysis was conducted, this one also considers the extent to which qualitative analysis was conducted. Such qualitative analyses had to be sufficiently described or named before they could be identified as such.

Only three-quarters $(74.3 \%)$ of the articles (excluding those two which reported on research that did not involve data analysis) reported sufficiently on analysis methods to allow one to identify whether qualitative or qualitative analysis took place. As seen in Figure 4 below, of those 81 articles, only $18.5 \%$ reported the use of qualitative methods, while references to quantitative analysis methods were found in $55.6 \%$ of the articles, making this the type of method most commonly reported.

Figure 4: Prevalence of quantitative and qualitative analysis methods

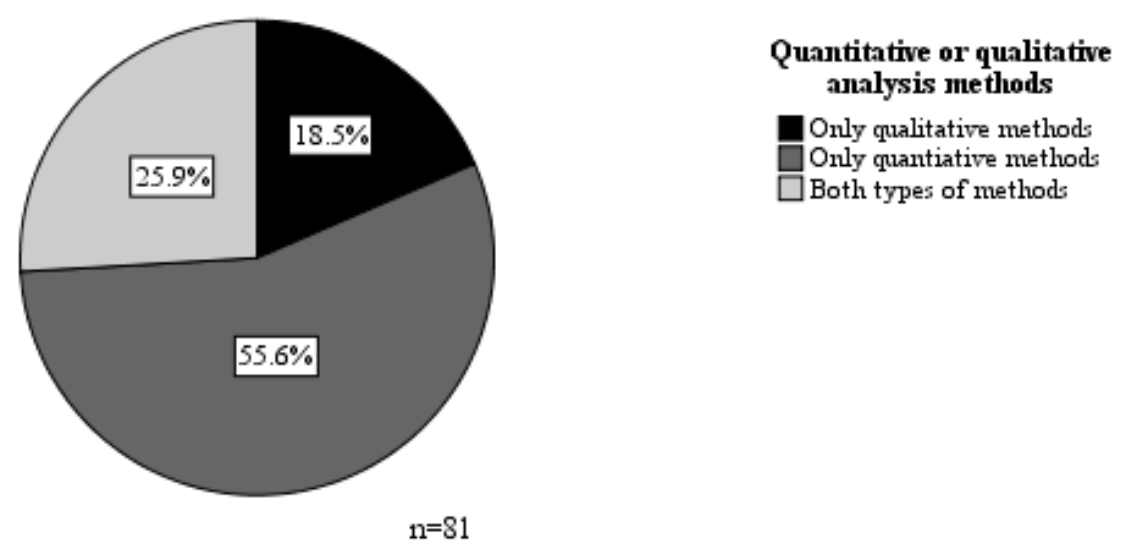

Both types of methods were reported in $25.9 \%$ of the articles, which is an even higher incidence than was found to be the case with qualitative only methods. The articles which report the use of both types of methods should not be interpreted as articles which report on a mixed methods 
research methodology, as descriptive statistics are often used in studies with a qualitative methodology, but this does not necessarily constitute mixed methods research.

Table 15 below provides a longitudinal representation of the prevalence of quantitative and qualitative analysis methods. It seems as if the use of qualitative data analysis methods on their own and in conjunction with quantitative methods has increased decade or two, while the use of quantitative methods on their own has decreased. However, due to the relatively small number of articles (15) which report qualitative data analysis methods, a chi-square test was not viable, and without a larger sample, the observed trend can unfortunately not be verified.

\begin{tabular}{|c|c|c|c|c|}
\hline & 1990-1999 & 2000-2004 & 2005-2009 & Total \\
\hline Only qualitative methods & $4(15.4 \%)$ & $3(14.3 \%)$ & $8(23.5 \%)$ & $15(18.5 \%)$ \\
\hline Only quantitative methods & $17(65.4 \%)$ & $11(52.4 \%)$ & $17(50.0 \%)$ & $45(55.6 \%)$ \\
\hline Both types of methods & $5(19.2 \%)$ & $7(33.3 \%)$ & $9(26.5 \%)$ & $21(25.9 \%)$ \\
\hline Total & $26(100.0 \%)$ & $21(100.0 \%)$ & $34(100.0 \%)$ & $81100.0 \%)$ \\
\hline
\end{tabular}

\section{3. $\quad$ Descriptive statistics}

During data collection it was noted that the use of descriptive statistics was often reported. Thus, it was decided to record whether the research reported in an article made use of descriptive statistics, or not. Of the 81 articles that reported data analysis methods and for which data analysis reporting was applicable, a large majority $(80.2 \%)$ reported the use of descriptive statistics. This does not mean this research made use of this data analysis method only, or that descriptive statistics were the main focus of the analysis, but it does indicate a very high frequency of use of this data analysis method. Two qualitative studies also made use of descriptive statistics, as did 19 instances of mixed methods research. It could be reasoned that the high occurrence of descriptive statistics is due to the descriptive nature of many qualitative studies (even though qualitative studies tend to not describe through numbers, some very basic descriptive statistics do sometimes appear), as well as it being the most basic of statistical methods and the basis of many other analyses (Merriam, 2002:5).

\subsection{Data analysis methods and techniques as the unit of analysis}

Similar to the previous sections in which sampling and data collection methods/techniques were analysed as the units of analysis, this section presents results in terms of the data analysis methods/techniques as the unit of analysis. The section above already indicated which type of data analysis method (quantitative or qualitative) was most frequently employed, when articles are treated as the units of analysis. Table 16 is presented here to primarily to indicate the vast range of different data analysis methods identified in the articles, as well as how these were classified. 
Table 16: Data analysis methods and techniques employed

\begin{tabular}{|c|c|c|}
\hline Method & Frequency & Percentage \\
\hline \multicolumn{3}{|l|}{ QUANTITATIVE } \\
\hline Univariate analysis (descriptive analysis) & 2 & 1.2 \\
\hline Distributions (frequency analysis/tables) & 5 & 2.9 \\
\hline Subgroup comparisons (between-/within-group analysis) & 2 & 1.2 \\
\hline t-test & 2 & 1.2 \\
\hline Bivariate analysis (cross-tabulations/contingency tables) & 7 & 4.1 \\
\hline Statistical methods & & \\
\hline Descriptive statistics & 57 & 33.3 \\
\hline Measures of association & & \\
\hline Pearson's product moment correlation & 3 & 1.8 \\
\hline Spearman's rank order correlation coefficient & 2 & 1.2 \\
\hline Biserial correlation & 1 & 0.6 \\
\hline Regression analysis & 2 & 1.2 \\
\hline Multivariate & 3 & 1.8 \\
\hline Multinominal & 1 & 0.6 \\
\hline Multiple & 2 & 1.2 \\
\hline Multiple linear & 2 & 1.2 \\
\hline Multiple logistic & 3 & 1.8 \\
\hline Logistic (binary logit) & 4 & 2.3 \\
\hline Backward stepwise elimination & 1 & 0.6 \\
\hline Hierachical & 1 & 0.6 \\
\hline \multicolumn{3}{|l|}{ Other multivariate techniques } \\
\hline Factor analysis & 1 & 0.6 \\
\hline ANOVA & 10 & 5.8 \\
\hline MANOVA & 1 & 0.6 \\
\hline Kruskal-Wallis & 1 & 0.6 \\
\hline Scheffe post hoc comparison & 1 & 0.6 \\
\hline \multicolumn{3}{|l|}{ Inferential statistics: Tests of statistical significance } \\
\hline Chi-square & 9 & 5.3 \\
\hline Jack knife repeated replications simulation & 1 & 0.6 \\
\hline Quantitative modelling & 1 & 0.6 \\
\hline Rate ratios & 1 & 0.6 \\
\hline Sub-total & 126 & $\mathbf{7 3 . 7}$ \\
\hline \multicolumn{3}{|l|}{ QUALITATIVE } \\
\hline Content analysis (thematic/textual/documentary) & 23 & 13.5 \\
\hline Discourse analysis (discursive) & 3 & 1.8 \\
\hline Grounded theory & 6 & 3.5 \\
\hline Linguistic & 1 & 0.6 \\
\hline Sub-total & 33 & $\mathbf{1 9 . 3}$ \\
\hline \multicolumn{3}{|l|}{ OTHER } \\
\hline Survival & 3 & 1.8 \\
\hline Life-table & 2 & 1.2 \\
\hline Sensitivity & 1 & 0.6 \\
\hline Comparative & 2 & 1.2 \\
\hline Subject & 1 & 0.6 \\
\hline Policy & 1 & 0.6 \\
\hline General livelihoods & 1 & 0.6 \\
\hline Multiple classification & 1 & 0.6 \\
\hline Sub-total & 12 & $\mathbf{7 . 0}$ \\
\hline TOTAL & 171 & 100.0 \\
\hline
\end{tabular}


Table 16 strongly supports the finding that quantitative data analysis methods are more often employed than qualitative ones, and indicates an even higher frequency of the former $(72.5 \%)$, with the latter representing less than one-fifth $(18.7 \%)$ of all the methods/techniques used. This increased frequency in quantitative data analysis methods is due to the occurrence of multiple statistical methods in a single article, as well as the large amount of descriptive statistics, which, as a category on its own, constitutes almost half (46.0\%) of all the quantitative data analysis methods/techniques used.

Interestingly, in only three cases it was stated that computer-assisted data analysis was conducted (once with SPSS, once with SAS and once with Atlas.ti), although this does not necessarily reflect the actual extent of the use of such software, which one could reasonably expect to be much higher, especially to conduct complicated statistical analysis.

\section{Other methodological features}

During data collection for this thesis, data were collected on other aspects of research reported in the articles that do not relate directly to the research methods already analysed. These include the time frames of the research projects, and whether pilot studies were conducted. The decision that data on time frame and pilot studies would also be collected was made later on in the study, and was retroactively collected from the articles. This was possible, because all the data sources (articles) were readily available on file, making it easy to re-examine articles from which other data had already been collected.

\section{1 $\quad$ Time dimension}

Following Babbie and Mouton (2001:92), the time dimension of a study refers to whether a crosssectional or a longitudinal analysis was conducted. If an article reported on research that involved both, it was classified as a longitudinal analysis. Even though historical studies usually cover lengthy time periods, they were not classified as longitudinal studies, as historical studies do not involve collecting data systematically at different points in time in order to draw comparisons across these data points. Historical studies were thus classified as constituting a time dimension separate from cross-sectional and longitudinal studies.

Again, authors did not always explicitly state whether they had conducted cross-sectional or longitudinal analysis. However, it was often easy to determine the time dimension of a study by merely examining the analysis itself and specifically whether it reported on data collected across different points in time (longitudinal) or simply at one moment in time (cross-sectional). Longitudinal studies can further be divided into trend, cohort and panel studies, and longitudinal 
studies were therefore further classified into these subtypes. When the subtype was not explicitly stated, the sampling design and methods also had to be examined. Of the 111 articles, $72.1 \%$ reported detail sufficient to classify the studies in terms of time dimension. Of the articles that could be classified $12.7 \%$ could be classified as historical. Table 17 below presents the results of both a cross-sectional analysis (in the total column on the right) and a longitudinal analysis of the frequency with which cross-sectional and longitudinal analysis were employed, as reported in the remaining 70 articles (excluding historical studies):

Table 17: Time dimension, 1990-2009

\begin{tabular}{l|r|r|r|r}
\hline & \multicolumn{1}{|c|}{$\mathbf{1 9 9 0 - 1 9 9 9}$} & \multicolumn{1}{|c|}{$\mathbf{2 0 0 0 - 2 0 0 4}$} & \multicolumn{1}{|c|}{$\mathbf{2 0 0 5}-\mathbf{2 0 0 9}$} & \multicolumn{1}{c}{ Total } \\
\hline Cross-sectional & $15(79.0 \%)$ & $14(73.7 \%)$ & $21(65.6 \%)$ & $50(71.4 \%)$ \\
Longitudinal & $4(21.0 \%)$ & $5(26.3 \%)$ & $11(34.4 \%)$ & $20(28.6 \%)$ \\
\hline Total & $\mathbf{1 9 ( 1 0 0 \% )}$ & $\mathbf{1 9}(\mathbf{1 0 0 \%})$ & $\mathbf{3 2}(\mathbf{1 0 0 \%})$ & $\mathbf{7 0}(\mathbf{1 0 0 \%})$ \\
\hline
\end{tabular}

Of the ones that reported a time frame, by far the majority $(62.5 \%)$ were cross-sectional, while $25.0 \%$ were longitudinal and $12.5 \%$ historical in nature. In Table 17 above, it seems as if the frequency of cross-sectional analyses decreased over the past two decades, and longitudinal analyses have increased, this change was not statistically significant (chi-square $=1.1$, d.f. $=2, \rho>$ $.05)$. The disaggregation of the 20 longitudinal studies into subtypes is presented in Table 18 below:

Table 18: Longitudinal subtypes

\begin{tabular}{l|r|r}
\hline & Frequency & \multicolumn{2}{|c}{ Percentage } \\
\hline Longitudinal (unspecified) & 9 & 45 \\
Longitudinal - trend & 3 & 15 \\
Longitudinal - cohort & 5 & 25 \\
Longitudinal - panel & 3 & 15 \\
\hline Total & $\mathbf{2 0}$ & $\mathbf{1 0 0}$ \\
\hline
\end{tabular}

In the majority (45\%) of cases, the type of longitudinal study was not specified, and could not be deduced from the information provided in the article. Although the number of remaining longitudinal studies (11) is too small to allow for any definite conclusions to be drawn, it is still interesting to note that these studies were almost equally divided between the trend, cohort and panel subtypes, although cohort studies were slightly better represented among the three subtypes.

\subsection{Tendency to pilot}

During the data collection process it was noted that some articles reported on pilot studies that had been conducted, and it was therefore decided to determine the extent to which pilot studies (or any form of pre-testing of, for example, a questionnaire) were reported. Again, what should be kept in mind is that the results merely reflect whether articles reported piloting, and not necessarily the 
extent to which pilot studies were actually conducted, as some articles may have simply omitted this information. It would be reasonable to expect that this would quite often be the case, as pilots are per definition studies conducted prior to the research described in the article to check feasibility of the study or the appropriateness of the methods (See Chapter 3, section 5.1.). Of the 111 empirical articles, only $13 \%$ mentioned any type of pilot study, while in two further articles it was stated that the research that was being reported on, was itself a pilot study.

\section{9. $\quad$ Author collaboration}

In this final section, the results are reported of an investigation of the extent to which South African sociologists publish (and therefore, by extension, conduct research) alone or with others, and in the case of the latter, whether those collaborators are South African or not. Thereafter, trends over time with regard to both the extent and type of collaboration are presented. Also considered in this section is whether the extent and type of collaboration are related to a central variable in this thesis, namely the research methodology employed (i.e. qualitative, quantitative or mixed methods research).

\subsection{Extent and type of author collaboration}

The thesis examines South African sociological publications. To qualify for inclusion in the population and sample, an article therefore had to have at least one South African author. Thus, in the case of collaborative research, only one author needed to have a South African affiliation at the time the article was published, as explain in Chapter 2. What follows is a cross-sectional analysis of variables related to the authors of the articles, specifically the frequency and type of collaboration (international or local).

Whether an article had a South African author was known in all cases (111), as this was one of the inclusion criteria used for an article to be included in the sampling frame. However, is was recorded during data collection only whether as author had a South African affiliation or not, and more detailed data on the affiliation of all the authors of all the articles were not collected, as an analysis of such data, although sure to produce interesting results, falls outside the scope of this thesis.

Table 19: Frequency of author collaboration

\begin{tabular}{l|r|r}
\hline & Frequency & Percentage \\
\hline Multiple South African authors & 41 & 36.9 \\
Only one South African author & 39 & 35.1 \\
Multiple South African and international authors & 31 & 27.9 \\
\hline Total & $\mathbf{1 1 1}$ & $\mathbf{1 0 0 . 0}$ \\
\hline
\end{tabular}


Of all the articles, 80 (or 72\%) had only South African authors. Approximately half of those 80 articles (39, or 48.8\%) had only one author. As Table 19 shows, international collaboration occurred in only $27.9 \%$ of the cases, and collaboration with other South Africans in $36.9 \%$ of the cases. This indicates that South African sociologists collaborated more frequently than they author publications alone, as $63.0 \%$ of the articles had multiple authors, but collaboration (in 72 of the cases) was more likely between fellow South Africans (56.9\% of the multiple-authored articles), and less so with international authors (43.1\% of the multiple-authored articles). Another question suggested by the literature is whether South African sociologists have increased the extent of their international research collaboration since 1990, as conditions became more favourable for such collaboration.

Table 20: Author collaboration, 1990-2009

\begin{tabular}{|c|c|c|c|c|}
\hline & 1990-1999 & 2000-2004 & 2005-2009 & Total \\
\hline Only South African authors $^{25}$ & $31(93.9 \%)$ & $26(78.8 \%)$ & $23(51.1 \%)$ & $80(72.1 \%)$ \\
\hline South African and other authors & $2(6.1 \%)$ & $7(21.2 \%)$ & $22(48.9 \%)$ & $31(27.9 \%)$ \\
\hline Total & $33(100.0 \%)$ & $33(100.0 \%)$ & $45(100.0 \%)$ & $111(100.0 \%)$ \\
\hline
\end{tabular}

The findings in Table 20 would suggest that this is indeed the case: from 1990 to 2009, South African authors publishing in the field of sociology have been publishing increasingly with international collaborators, and the difference across the three time periods is statistically significant $($ chi-square $=18.40$, d.f. $=2, \rho<.05)$.

\subsection{The relationship between type of author collaboration and methodology}

In Chapter 2 the issue of the lack methodological pluralism was discussed, with particular focus on both international and local concerns about the issue. Results presented earlier in this chapter show that, during the past two decades, neither the quantitative nor qualitative methodology has dominated sociological research published by South African authors. However, according to Seekings (2001), within the field of economics "it is striking how much of the new [quantitative] research [on South Africa] is done by scholars from outside South Africa”, especially by American and British researchers, some of whom collaborate with South Africans. He further cites examples to show "how foreign expertise and links are also integral to quantitative work in political science". In general, he argues that:

\footnotetext{
${ }^{25}$ Here, and in the results presented in the following subsection, the "only South African authors" category includes sole authors, as no collaboration also implies that no international collaboration took place.
} 
[m]ost large-scale surveys have been financed by grants from foundations or other sources in the USA and; to a lesser extent, Europe, and American or European researchers have often played the leading role in accessing these funds. Quantitative social science research on South Africa is still heavily dependent on skills and finance from elsewhere (Seekings, 2001:26-27).

For this reason, this thesis also investigated whether the type of methodology reported in research articles relates to the configurations of authors who published them. In particular, it was hypothesised that South African authors are more likely to publish qualitative research when publishing alone or with other South Africans, and more likely to publish quantitative research when collaborating with international authors.

Table 21: Methodology employed by type of authorship collaboration

\begin{tabular}{|c|c|c|c|}
\hline & $\begin{array}{c}\text { Only South African } \\
\text { authors }\end{array}$ & $\begin{array}{c}\text { South African and } \\
\text { other authors }\end{array}$ & Total \\
\hline Quantitative methodology & $26(34.2 \%)$ & $17(54.8 \%)$ & $43(40.2 \%)$ \\
\hline Qualitative methodology & $37(48.7 \%)$ & $7(22.9 \%)$ & $44(41.1 \%)$ \\
\hline Mixed methods research & $13(17.1 \%)$ & $7(22.6 \%)$ & $20(18.7 \%)$ \\
\hline Total & $76(100.0 \%)$ & $31(100.0 \%)$ & $107(100.0 \%)$ \\
\hline
\end{tabular}

The figures presented in Table 21 seem to support this hypothesis: a much larger percentage of articles authored by a mix of South African and international authors (54.8\%) than the percentage of articles authored only by South Africans (34.2\%) reported the use of a quantitative methodology. Conversely, a much smaller percentage of articles authored by a mix of South African and international authors $(22.9 \%)$ than the percentage of articles authored only by South Africans (48.7\%) reported the use of a qualitative methodology. Interestingly, mixed methods are more frequently reported when non-South Africans are included as authors. These differences are all statistically significant (chi-square $=6.33$, d.f. $=2, \rho<.05)$.

\section{Summary}

This chapter presented the results of an analysis of various methodological aspects of a sample of articles published from 1990 to 2009, in the field of sociology by South Africans. First, the articles in the sample were examined to determine which methodology they employed - quantitative, qualitative or mixed methods research - in order to ascertain to what extent methodological pluralism is reflected in sociological research that was published during the period under investigation. A surprising finding was that both quantitative and qualitative methodologies were employed to an equal extent (representing approximately $40 \%$ each). Although there seems to have been a decrease over time in the frequency of quantitative research (from $48.4 \%$ in the period 
1990-1999 to $37.8 \%$ in the period 2005-2009), this change was not statistically significant. Mixed methods research was reported in the remaining, smaller proportion (approximately one-fifth) of the sample, and although it seems to have doubled its representation over time (from $12.9 \%$ in the period 1990-1999 to $24.4 \%$ in the period 2005-2009), the small number of mixed methods studies precluded testing for the statistical significance of this trend.

Sampling methods were poorly reported in the articles: in more than $40 \%$, sampling methods were not sufficiently reported to identify whether probability sampling was conducted or not. The type of sampling methods most often employed (i.e. in more than half of the articles which reported on sampling method) are non-probability in nature. Of the sampling techniques identified, the one most often employed (in almost a third of the sample) was purposive sampling, a technique often identified with a qualitative methodology.

Not only were sampling methods insufficiently reported in the research articles, but a general lack of reporting of methods was also observed. Table 22 below shows how often methods were reported on, disaggregated according to the different methodological aspects investigated in this thesis. Sampling was by far the aspect reported on worst, with just over half of the articles reporting whether probability sampling was conducted or not. In the case of time frame, almost half of the longitudinal analyses were unspecified. In only three-quarters of the articles were data analysis methods named or described in sufficient detail to determine whether they were quantitative or qualitative in nature.

\begin{tabular}{|c|c|}
\hline Aspect & Percentage methods reported \\
\hline METHODOLOGY & 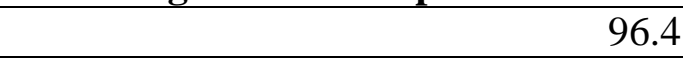 \\
\hline \multicolumn{2}{|l|}{ SAMPLING PHASE } \\
\hline $\begin{array}{l}\text { Probability and non probability methods } \\
\text { Specific methods }\end{array}$ & $\begin{array}{l}58.6 \\
58.6\end{array}$ \\
\hline \multicolumn{2}{|l|}{ DATA COLLECTION PHASE } \\
\hline Specific methods & 94.6 \\
\hline \multicolumn{2}{|l|}{ DATA ANALYSIS PHASE } \\
\hline $\begin{array}{l}\text { Statistical methods } \\
\text { Qualitative or quantitative analysis }\end{array}$ & $\begin{array}{l}97.3 \\
74.8\end{array}$ \\
\hline RESEARCH DESIGN & 84.7 \\
\hline TIME FRAME & 72.1 \\
\hline
\end{tabular}

For data collection, interviewing was most often employed: it was reported in more than a third of the articles and constituted almost half of all the data collection methods reported. Where interview

\footnotetext{
${ }^{26}$ Piloting is not included, as one cannot measure how often it was successfully reported as a study could simply just not have done a pilot and thus reasonably not have reported on it.
} 
techniques were specified, focus group interviews - a technique that is strongly associated with a qualitative methodology - were most often reported.

Terminological inconsistency among and within the articles, as well as between the articles and the methodology textbooks used as a basis for this thesis, was also noted. The terms methodology and research design were used interchangeably in the articles, which rendered classification of articles on both these variables challenging. Structured interview schedules and questionnaires were also not distinguished consistently from each other in the articles, which not only hindered the reliability of the observed extent to which each method occurred, but also of the reporting of the variety of data collection methods used in general.

Other methodological features were analysed including research design, time dimension of the study and piloting. The research design most often employed was the survey, which was conducted in approximately a third of the articles, and cross-sectional studies were much more often employed than longitudinal ones. The data on pilot studies were collected owing to the iterative nature of the thesis. However, only $13 \%$ of the studies mentioned any kind of piloting, while two articles reported only on pilot studies.

In addition to the analysis of the methodological features of the research reported in the articles, author collaboration was investigated with a focus on the extent of international collaboration and its relationship to methodology. The majority of the articles had only South African authors, and almost half of these articles only had one author. However, the extent of international collaboration increased statistically significantly, and almost eight-fold, from the period 1990-1999 to the period 2005-2009. With regard to the relationship between the collaboration and methodology, quantitative research was statistically significantly more likely when South Africans collaborated with international authors, and qualitative research was significantly more likely when no international collaborators were involved. In the next chapter these findings will be interpreted, where possible in relation to the literature, and the implications of the results will be discussed. 


\section{CHAPTER 5: CONCLUSIONS AND RECOMMENDATIONS}

\section{Introduction}

The central research problem this thesis sets out to address is: what methodologies and methods have been employed by South Africans publishing in the field of sociology between 1990 and 2009? Underlying this is the objective of determining whether methodological pluralism is present in South African sociological research. This research problem was divided into four research questions. The first asks what sampling, data collection and data analysis methods have been employed; the second whether there have been any changes in the methods used from 1990 to 2009; the third asks whether collaboration has increased since 1990; while the fourth asks whether research conducted in collaboration with international authors tends to employ different methodologies compared to research conducted by only South Africans.

The main findings regarding each of the questions, as well as some additional ones that emerged from the study, are summarised and interpreted by comparing the results with what was presented in the literature review, in Chapter 2. Also in this chapter, the complications encountered during the research conducted for this thesis are again highlighted, and results that deviate from what is predicted by the literature are presented here to emphasise the contribution made to knowledge of the topic under investigation, as well as to suggest recommendations for further research.

The research questions referred to above were investigated by collecting data from a representative sample of articles that were sourced from a range of databases, thereby avoiding the critiques levelled against previous studies. As outlined in Chapter 2, previous studies have been criticised for using one only or a select few journals when investigating research trends in the field of sociology in a specific country, as a single journal or small, purposively selected sample of journals may produce biased results, as, for example, the editors may have a methodological bias; authors making use of other methods may publish in journals other than those selected. With regard to South African sociology specifically, it would be unwise to conduct a longitudinal analysis of research published in only one journal in an attempt to generalise to all South African research in that field, as the history of South African sociology - i.e. the existence of different sociological associations, each with their own associated journal, preferred ideology, language, and methodology - renders this especially problematic, as was explained in detail in Chapter 2.

Another aspect to consider is that articles reporting on sociological research are not only published by sociologists. Thus a sociological topic was the key criterion for the selection of articles, rather than whether the authors are sociologists. Also, it needs to be reiterated that not all 
research is published in peer-reviewed journal articles (though funding pressures to publish in this medium are increasingly strong) and as such, this thesis's results only pertain to research that has been communicated in this format.

\section{Summary of the results}

The following sections summarise the results of the analysis (as presented in Chapter 4), which aimed to answer the research questions referred to above. These results are therefore related to methodology; research design; sampling, data collection and data analysis methods; and lastly, results related to author collaboration. Also discussed are possible explanations for the results with some recommendations for future research.

\section{1. $\quad$ Methodologies}

The key research problem underlying this thesis stems from a concern with methodological pluralism as expressed in both the local and international literature reviewed in Chapter 2. In particular, a concern is expressed that the qualitative methodology may be over-represented in sociological research. A study by Payne et al. (2004) confirms that the qualitative methodology has been dominating the publications of the BSA, and this thesis set out to investigate whether this is the case in South African sociology.

The concern regarding methodological pluralism relates to the competency of the researchers to apply the methods associated with different methodologies, and in particular to an apprehension that if researchers do not have a sufficiently wide skill set, the discipline in which they work will become increasingly myopic (Williams et. al., 2008; Oosthuizen, K., 1991; Payne et.al.,2004 ). One of the ways in which the extent of the problem has been measured, is to investigate what methodologies researchers employed, as reported by them when they publish the research in a journal article (e.g. Payne et al., 2004), and this approach was also taken for this thesis.

Considering results from previous research conducted elsewhere, which suggests that sociological researchers are making use of a predominantly qualitative methodology (see Chapter 2), it was quite unexpected to find that among South African sociologists, both quantitative and qualitative methodologies have been employed with equal frequency in the past 20 years, and that there has been no (statistically) significant change in this regard from 1990 to 2009. Mixed methods research was also reported, but approximately half as frequently as quantitative and qualitative methodologies. Mixed methods research could lean towards being either more quantitative or qualitative (Creswell \& Plano Clark, 2011:65), but as this aspect was not investigated here, it could be an aspect for future studies to consider in finer detail. 
The almost equal representation of quantitative and qualitative methodologies, which in itself is a significant finding, may be interpreted as indicating that, in the field of sociology in South Africa, researchers are roughly equally divided between those who prefer a quantitative methodology, and those who are partial to a qualitative methodology. However, the approach used in this study is limited in the extent to which it can provide evidence of such a conclusion, as it only allows one to determine to what extent a variety of authors report on using various methodologies, and not whether a particular researcher has made use of a variety of different methodologies. This approach also cannot measure researchers' competency in these methods beyond the observation that these authors collectively are competent enough in the methods to get their results published in peerreviewed journals.

Another explanation could be that researchers have become more aware of, and competent in, a variety of methods. Possible reasons for this could be: the emergence and increasing popularity of mixed methods research; an increase in collaboration; articles such as those published by Payne (2007) creating awareness of the concern with methodological pluralism; and courses in social science methods building the competencies of young researchers in a variety of methods. The fact that no statistically significant change in terms of methodology has been observed over the past two decades seems to counter these explanations. However, even though the use of mixed methods research has not shown a statistically significant increase, the frequency with which it is reported has doubled in the past 20 years, and the statistically non-significant result could be due to the relatively small sample drawn for this Master's thesis. These explanations and others could be explored in further research by perhaps considering the research output of departments which offer courses aimed to develop research skills in the different methodologies.

\section{2. $\quad$ Research design}

Research design was investigated under the key research questions, as it relates to research methodology and the type of research conducted. As explained in Chapter 3, the research reported in the articles was quite difficult to classify in terms of research design. Not only did very few researchers explicitly state what research design they employed, but those that did so, often provided imprecise terms and/or descriptions, e.g. in an article "case study" would be explicitly identified as the research design applied, but no further details on the type of case study would be offered. Another challenge arose from the fact that often a single research project would involve aspects of various research designs. These problems are mainly due to the fact that, generally, the research designs discussed in research methodology textbooks are neither mutually exclusive, nor exhaustive. Definitions of research designs tend to focus on only certain parts of the research 
process, and thus a single research study can incorporate aspects of multiple research designs (Blaikie, 2010:40-41). A similar complication relates to inconsistent use of the term "research design". For example, often the term "survey" was used to refer to a data collection method and not a research design. The survey research design was the most popular research design, utilised in more than a third of the sample, perhaps precisely because of this inconsistency. The second most popular research design, the case study, was reported only half as often, and the type was very rarely specified. Both the most and second-most popular research designs illustrate the abovementioned problems.

\section{3. $\quad$ Sampling methods}

Sampling methods were investigated in terms of the scope of the different types of sampling techniques used, and the frequency according to which probability and non-probability sampling was reported. This focus on sampling originated from the concerns Van Staden and Visser (1991:38) expressed - on the basis of their analysis of the methods and processes reported in articles published in the South African Journal of Sociology during the eighties - about sociological researchers' tendency to use non-random sampling methods, or to neglect adequately describing the sampling methods they employ. Their concern about the lack of reporting of sampling methods seems to still apply: twenty years later, the study conducted for this thesis also found that nonprobability sampling methods were favoured above probability sampling methods. When trying to understand the seemingly persistent popularity of non-probability sampling methods, it should be noted that, not only did all the qualitative studies (or at least those that sufficiently reported on their sampling methods) make use of these methods, but more than a third of the cases of quantitative research and the majority of mixed methods research made use of non-probability methods, either solely or in combination with probability methods. The reason for this preference of non-probability sampling methods, even research applying a quantitative methodology, is that social research is often conducted in situations where a probability sample cannot be drawn: for example, when no list of the study population exists and creating one is not feasible. In other cases, such as qualitative studies, a probability sample is not desirable and purposive sampling (used by three-quarters of all the qualitative studies) is preferred. This also explains, on the level of technique, the observation that purposive sampling has been the most popular sampling technique in recent South African sociological research. Lastly, the inexpensive and uncomplicated nature of non-probability techniques such as reliance on available subjects (Babbie \& Mouton, 2008:166) could have contributed to the attractiveness of non-probability sampling methods. 
It is however, a cause for concern that reliance on available subjects has been the second-most frequently used sampling technique among sociologists since 1990. As Babbie and Mouton (2008:166) state, in social research in general, "[r]elying on available subjects [...] is an extremely risky sampling method, although it is used all too frequently". On the other hand, Babbie and Mouton's (2008:90) statement that "[s]imple random sampling [SRS] is seldom used in practice" is not supported by the results, as it was recorded (together with reliance on available subjects) as the second most popular sampling technique, and the most popular probability method (with stratified sampling almost as popular, followed by systematic sampling). According to Babbie and Mouton (2008:190),

SRS typically requires a list of elements. When such a list is available, researchers usually employ systematic sampling rather than simple random sampling [...] By now, debates over the relative merits of simple random sampling and systematic sampling have been resolved largely in favour of the latter, simpler method”.

It therefore seems that South African sociology researchers tend to be unaware of the merits of SRS in relation to those of systematic sampling. More than 20 years ago, Olzak (1990) and Van Staden and Visser (1991) expressed a concern about South African social researchers' knowledge and expertise in advanced research techniques. The finding that researchers are apparently unaware of the merits of SRS, and tend to rely quite heavily on available research participants, shows that their concern is still justified today.

A further troublesome finding was that only slightly more than half of the articles reported on sampling methods in sufficient detail to allow one to determine what is arguably a key concern: whether the assumptions of probability theory were employed. Thus, not only do sociology researchers rarely describe how they conducted their sampling, but articles that omit basic sampling information are accepted for publication in peer-reviewed journals. In other words, the editors and reviewers of these journals accept this as standard practice, and it seems to have become the norm in the field of sociology to not report sampling methods or techniques in any detail.

Van Standen and Visser expressed concern about articles not reporting their sampling methods (1991). Their main concern was that inferential statistics require probability sampling, and as such it is important that researchers using such statistics report on their sampling procedures (1991). Although the requirements of probability theory and inferential statistics do not apply to qualitative studies, a description of sampling or selection methods is still important, as the researcher needs to illustrate, for example, that an in-depth understanding of the context could be gained from a sample and that a sufficient range of aspects of the context have been investigated. The analysis revealed that those conducting qualitative studies are indeed less likely to report on their sampling techniques 
than those applying the other two methodologies. One explanation for this finding is the possibility that theoretical sampling was conducted in these qualitative studies, but the link between theory and sampling was not explicitly stated.

\subsection{Data collection methods}

In order to describe the data collection methods used by South African sociologists, the focus was on the frequency with which different data collection techniques (in particular questionnaires and interviews) were reported. Compared to sampling methods, data collection methods were relatively well reported, and the data show that the past two decades the most popular data collection method has been the interview, followed by the collection of textual data. However, it should be noted that researchers tend to use the terms questionnaire, interview schedule and structured interview interchangeably and in such a way that they could be referring to either a questionnaire or a structured interview. This complicated the analysis of and reporting on data collection techniques, and the finding that interview methods are the most popular, should be approached with caution. The difficulty arose partly because of the approach followed throughout this thesis, i.e. that methods and techniques would be reported as stated in the articles, in order to avoid unnecessary (subjective) interpretation by the researcher. Interpretation was only considered justified if a method or technique was not named but described, or if it did not fit into an existing categorisation system.

\subsection{Data analysis methods}

The analysis of data analysis methods focused on an examination of the rate at which statistical analysis methods were reported in comparison to the rate of qualitative-analysis-methods reporting. It was expected that many studies would have involved some form of descriptive statistics, as it was the most popular analysis method used in Van Staden and Visser's study (1991) and that quantitative techniques and tools would be described in detail (Greener, 2011).

After discovering that only slightly more than half of the articles reported on sampling methods, it was a relief to find that in all but $5 \%$ of the articles it was possible to determine whether researchers made use of some type of statistical analysis or not. In the large majority of the cases some type of descriptive statistics were indeed reported. When delving deeper to investigate to what extent quantitative and qualitative types of analysis were conducted, the classification of the research became more difficult, and approximately a quarter of the sample had to be excluded from the analysis on the basis of insufficient description of analysis methods.

Quantitative data analysis methods were still dominant, especially if one also considers research that used both methods, but this is arguably a reflection of the types of methods that were best described and reported on, rather than of those most often used, as evident from the large 
number of "not reported" cases. Qualitative analysis was perhaps not explicitly named as often as quantitative analysis, because of the very nature of qualitative research: methods are emergent (i.e. they are often decided upon and changed during a study), data collection and analysis are often conducted simultaneously, researchers strive to avoid pre-existing ideas, and the narrative form might lead to an avoidance of technical terms (Creswell, 2007; Hennink, Hutter \& Bailey, 2011:32; Suter, 2012:346). Quantitative research, on the other hand, tends to focus much more on naming methods and techniques in fine detail and using pre-determined techniques (Greener, 2011:3-4). However, a lack of rigour and neglecting to clearly report the methods used in a study are detrimental to the validity of the findings, regardless which methodology was followed (Creswell, 2007:46).

Although Van Staden and Visser (1991) and Seekings (2001) express a concern about the lack, among South African sociologists, of skills to use sophisticated statistical methods, the level of sophistication with which (statistical) analysis methods were applied, was beyond the scope of this thesis. What can be concluded is that such a wide range of methods, techniques and tools were used, that analysis with IBM SPSS, with articles as the unit of analysis, proved unfeasible, and therefore only a frequency analysis in MS Excel, with methods/techniques/tools as the unit of analysis could be conducted. Most of these methods/techniques/tools were of a quantitative nature, and it would be interesting for future researchers to investigate the level of skill required to use these methods, and how skilfully they were implemented.

\section{6. $\quad$ Author collaboration}

The research question on author collaboration focussed on the types of methodologies that tend to be employed when South African authors collaborate with international authors, and when they do not. The researcher also investigated the extent to which South African sociologists collaborate, and with whom.

What was found was that the majority of articles were authored by South Africans only, and that almost half of those articles had only one author. However, collaboration (including international collaboration) has increased significantly since 1990. Related to the discussion of methodological pluralism is the notion that authors should collaborate more and share expertise (Payne, 2007:904-905; Alexander, 2004b; Oosthuizen, 1991). The fact that collaboration has increased significantly is encouraging for the discipline. The increase in collaboration could be due to the increasing focus in South Africa on international visibility and competitiveness. To illustrate, recommendations for a strategic approach to publishing, made relatively recently by the Academy of Science in South Africa (ASSAf) include a focus on promoting research and journals that are of 
international quality and are internationally recognised (Gevers, 2006:2). Another reason for the increase in collaboration could be due to initiatives such as those implemented by the International Education Association of South Africa (IEASA), which in 2003 presented a strategy to enhance the international visibility of South African higher education by recruiting international students to attend South African universities (Council on Higher Education, 2004:219). Collaboration could also have been enhanced by researchers engaging more with topics and questions that have international relevance, and which would therefore attract international collaborators (although the specific topics investigated was not explored in the thesis). More financial assistance for travel and sabbaticals abroad may also have enhanced chances for collaboration and an updated skill set (Olzak, 1990)

In the literature review the concern was expressed that quantitative expertise emanates from international authors and sponsors (Seekings, 2001:26). The findings seem to support this, as articles that included non-South African authors were more likely to report on quantitative research than those authored solely by South Africans. One should, however, be careful when drawing conclusions from these results. One cannot, for example, conclusively deduce from these findings that international authors bring the quantitative expertise to the research. Another interpretation could be that the nature of quantitative research, particularly large-scale surveys, might lend itself more to international collaboration than qualitative research does (Seekings, 2001:26-27). Quantitative research generally aims to generalise to a large, even cross-national, population, while qualitative studies, because they are usually focussed on a very specific context (in this case South Africa), arguably do not require or attract the input from researchers from other countries or contexts.

\section{Key insights}

This section reports on secondary findings, lessons learned and general observations that do not relate directly to the research questions, but were uncovered during the research process. These findings serve as recommendations and advice for future research on the topics touched on in this thesis and using the same or similar methods this thesis did, by highlighting potential challenges. These relate to constructing a sampling and a coding system, the use of research articles as rhetorical devices, and the low rate at which methods were reported. 


\subsection{Databases}

As described in Chapter 3, the sampling frame for this thesis was created by making use of a variety of online databases, which were searched to identify South African sociological research articles. The search results were checked for duplicates and other errors, whereafter the final sampling frame was constructed. Other potential strategies for creating a sampling frame were considered, but were not feasible, as discussed in Chapter 3.

Creating the sampling frame from a variety of databases was beneficial as a learning opportunity. First, it revealed how difficult it is to determine whether a research article is "sociological" in nature, especially since sociology is quite a vast field. In this thesis a sociological article was defined not only as an article published by a sociologist (i.e., by an author with an institutional affiliation to a department of sociology), or containing the term sociology (or its derivatives), but also articles which are published in sociological journals (i.e., journals which have the term sociology in their title, or describe themselves as covering sociological topics). With regard to the latter criterion, it could be argued that the researcher was perhaps too lenient by including even multi-disciplinary journals. However after investigating the journals from which articles were sampled, only a very small percentage were from journals which state that they cover multiple social science disciplines without specific reference to sociology. All the other journals either only focus on sociology or explicitly include sociology in the list of disciplines covered. The question, "what makes research sociological research?" was an important one the author of this thesis needed to grapple with, and an important one to carefully consider if a similar research project is approached in future.

Secondly, using the databases to construct a sampling frame also illustrated different ways to determine whether a journal is peer-reviewed, and therefore the journal accreditation system of the DHET (previously the DoE) was introduced. This system, which identifies South African journals that qualify for subsidy even if they are not indexed by WoS and IBSS, is not without criticism. For example, concern has been expressed about the quality of the articles contained within the journals on the so-called "DoE" list, as the journals, not the articles themselves, are evaluated to decide whether their content qualifies for subsidy (Mouton et al., 2006), however this also true of the WoS and IBSS. Another concern relates to whether the journals on the list are continuously monitored to determine if they still meet the requirements (as elaborated in Chapter 3) for inclusion in the list (Mouton et al., 2006). Ensuring that the content of only peer-reviewed, accredited or high-quality, internationally recognised journals was considered for inclusion was problematic, even if this list was available, as the list changes every year and journals may change their titles over time. Future researchers are therefore advised to explore other methods to select peer-reviewed journals. 
Thirdly constructing the sampling frame taught the author of this thesis a lot, not only about online databases, journals and different document types, but also of the field of sociology and its past in South Africa, which was fundamental to understand trends identified in the literature and the trends found as a result of the research conducted for this thesis.

\section{2. $\quad$ Coding system}

At the onset of the thesis it was determined that an inductive method would be most appropriate to develop at least some of the coding systems used in this thesis. A deductive method would have required classifying articles in terms of pre-defined lists of research methods and techniques, while an inductive method involved first recording the terms for methods and techniques, as used by the authors of the articles, and afterwards - and as part of an iterative process during data collection creating categories from these.

At first this researcher aimed to collect data on both the methods and the techniques (used for sampling, data collection and data analysis) named in the articles. The inductive approach showed that this would not be possible, as very few articles made any distinction between methods and techniques. The inductive approach thus assisted the researcher in adapting to the data as they were collected. This approach did, however, create a large number of categories which were later recoded in SPSS and used to code articles as the unit of analysis. However, in cases where a huge variety of dissimilar categories were produced, this was not possible, and then the methods themselves were analysed, in MS Excel, as the unit of analysis. The inductive approach, which is normally associated with a qualitative methodology (Babbie \& Mouton, 2008:273; Creswell, 2007:38-39; Greener, 2011:3), was quite successfully implemented in this quantitative study, because of its primarily descriptive nature. The aim was to investigate which methods have been used, and a pre-defined list of methods would have led the researcher to only consider the items on the list, thereby increasing the extent to which data were defined as "missing", or to adapt the data to fit the list imposed upon them, which would be questionable from a validity point of view. The main lesson learned from the development of the coding system was that researchers do not use the same terminology to refer to the same concept, even if the majority of them are working in the same discipline and country. Using an inductive method to create the data collection categories was very helpful to explore a discipline in which terms are clearly not used in the same way by all its members; however, it could also lead the researcher to rely on a high level of subjective interpretation, which should be guarded against. 


\section{3. $\quad \underline{\text { Rhetoric }}$}

Some of the challenges experienced during data collection for this thesis relate to the nature of a research article as a rhetorical device. As found in both the pilot and main study, it was often difficult to determine whether an article reviewed an author's past research, or whether it reported on a new and original piece of research. This is due to some of the assumptions this thesis is based upon, which need to be revisited in this concluding chapter.

One such assumption is that each article represented a single, unique research project, which is not necessarily the case, as indicated by authors stating that they were reporting on a pilot study or that their study was part of a larger research project. This assumption was also undermined by applications of SDA research designs. Such studies, it was assumed, would report how sampling and data analysis were conducted in the original study, which was sometimes the case in this thesis. This complicated the coding of SDA articles. The stance taken by this thesis is that the methods used by the authors of the current article for the current project was reported and that data collection, for SDA articles, was not applicable as the sampling and data collection methods reported on were not methods the sociologist themselves employed. However this is a debatable stance to take and future studies should select the option most appropriate for their aims.

Another assumption was that a research article would describe all the methods used in each step of the research project it is reporting on, i.e. that it is a complete reflection of the actual research project. This is clearly not the case, especially when one considers the amount of missing data. Sampling was by far the aspect reported on worst; with just over half of the articles reporting whether probability sampling was conducted or not, while it is arguably an extremely important aspect that should be explicitly reported on. However, the data collection methods were somewhat better reported than the sampling methods, and data collection methods could be analysed in more detail in more than $90 \%$ of the cases. In only three-quarters of the articles were data analysis methods named or described in sufficient detail to determine whether they were quantitative or qualitative in nature.

This is perhaps due to a research article being an attempt to convince the audience of the findings of the research. As discussed in Chapter 3, the research is thus presented in the most convincing way, possibly only including the most prominent findings and merely a selection of the details of the research methodology. With this in mind, the author of a research article also presents the research in the way which would make the audience (which could be quite broad in the case of multi-disciplinary journals) understand the research best by, for example, reducing jargon (Greener, 2011:1). The lesson learned from this is that, even though a research project is defined in this thesis 
as comprising different stages for sampling, data collection and analysis, a research article will not necessarily report in similar detail on all of these aspects.

\section{Concluding comments}

The main conclusion of this thesis is that, in the past two decades, both qualitative and quantitative research methodologies have been used to an equal extent by South African sociologists, and this would suggest that methodological pluralism is present. The fact that collaboration of an international nature has increased over the years is an encouraging sign that ideas and skills are being shared, and in that sense, methodological pluralism is likely. When one more carefully considers the methods employed in different research phases, a different picture does, however, present itself. Non-probability sampling methods were used in more than half of the research analysed, and during data analysis, statistical analysis methods were reported much more often and in far more detail than qualitative methods. Also, South African sociological research is more likely to be of a quantitative nature when international collaborators are involved. Another important feature of published South African sociological research is that methods, especially those related to sampling and qualitative data analysis, often go unreported and that this does not impede its acceptance for publication by editors and peer-reviewers.

During the course of the research conducted for this thesis, it became clear that an investigation of the theoretical construct of methodological pluralism is too complicated to be relegated to a mere keyword search. Other factors, such as the way in which methods are reported, influence the results greatly: at the level of methodology quantitative and qualitative methodologies seem to have been applied in equal measure, while at the level of methods the lack of reporting on qualitative analysis methods does not reflect this balance between the two methodologies. Even though methodological pluralism is evident in sociological research in South Africa (at least as reflected by the methodologies employed), the fact that sociologists in general do not report their methods well, renders this finding somewhat contentious. Neglecting to report methods in itself poses a large threat to the quality of the sociological research in South Africa and is worth researching further. It is the hope of this researcher that this thesis can provide a base and guidance for future researchers aiming to determine whether the methodological practises covered herein has changed since 2009, much like Van Staden and Visser (1991) provided for this thesis. 


\section{LIST OF REFERENCES}

Alexander, P. 2004a. The National Research Foundation and priorities for critical research. Society in Transition, 35(2): 319-327.

Alexander, P. 2004b. Context, comparisons and critical research. Unpublished thought paper for National Research Foundation.

Alexander, P., Basson, L. \& Makhura, P. 2006. Sociology research in contemporary South Africa. South African Review of Sociology, 37(2):218-240.

Babbie, E. \& Mouton, J. 2008. The practice of social research (South African ed.). Cape Town: Oxford University Press Southern Africa.

Babbie, E. 2011. Introduction to social research. Belmont: Wadsworth.

Blaikie, N. 2010. Designing social research: The logic of anticipation. Cambridge: Polity.

Botes, L.J.S., Van Rensburg, H.C.J. \& Groenewald, D.C. 1991. Reply to Van Staden and Visser: perhaps something more and something else happened in the SAJS of the 1980s. South African Journal of Sociology, 2(22):50-52.

Bryman, A. 2008. Social research methods ( ${ }^{\text {rd }}$ ed.). Oxford: Oxford University Press.

Burawoy, M. 2004. Public sociology: South African dilemmas in a global context. Society in Transition, 35(1):11-26.

Burawoy, M. 2005. 2004 Presidential address: For public sociology. American Sociological Review, 70(1):4-28

Cock, J. 2006. Public sociology and the social crisis. South African Review of Sociology, 37(2):293-307.

Cock, J., Hassim, S. \& Webster, E. 2004. Sociological dilemmas in a local context. Society in Transition, 35(2):328-333.

Council on Higher Education. 2004. South African higher education in the first decade of democracy. Pretoria: Council on Higher Education.

Coutsoudis, A., Coovadia, H.M. \& Wilfert, C.M. 2008a. HIV, infant feeding and more perils for poor people: New WHO guidelines encourage review of formula milk policies. Bulletin of the World Health Organization, 86(3):210-214.

Coutsoudis, A., Coovadia, H.M. \& Wilfert, C.M. 2008b. HIV, infant feeding and more perils for poor people: New WHO guidelines encourage review of formula milk policies. World Hospitals and Health Services, 44(1):45-48.

CREST. 2007. SA Knowledgebase [Online]. Available: http://sun025.sun.ac.za/portal/page/portal/Arts/CREST/knowledge_resources/saknow [2013, April, 17]. 
Creswell, J.W. \& Plano Clark, V.L. 2011. Designing and conducting mixed methods research $\left(2^{\text {nd }}\right.$ ed.). London: Sage.

Creswell, J.W. 2007. Qualitative inquiry and research design: Choosing among five approaches. London: Sage.

Creswell, J.W. 2009. Research design: Qualitative, quantitative, and mixed methods approaches ( ${ }^{\text {rd }}$ ed.). London: Sage.

Crotty, M. 1998. The foundations of social research. London: Sage.

Della Porta, D. \& Keating, M. 2008. Approaches and methodologies in the social sciences: A pluralist perspective. Cambridge: Cambridge University Press.

Ellison, G.T.H. 1996. Why do pouched mice (Saccostomus campestris) hoard food? Physiology and Behavior, 59(2):375-381.

Gevers, W. 2006. Introduction and background, in Academy of Science of South Africa. Report on a strategic approach to research publishing in South Africa. Pretoria: Academy of Science of South Africa. 1-8.

Greener, I. 2011. Designing social research: A guide for the bewildered. London: Sage.

Groenewald, C.J. 1991. The context of the development of sociology in South Africa: A response to Visser and Van Staden. South African Journal of Sociology, 22(2):46-49.

Groenewald, C. 1984. Die institusionalisering van die Sosiologie in Suid-Afrika. Unpublished doctoral dissertation. Stellenbosch: University of Stellenbosch.

Harzing, A. 2013. Document categories in the ISI Web of Knowledge: Misunderstanding the social sciences? Scientometrics, 94:23-34.

Henn, M., Weinstein, M. \& Foard, N. 2009. A critical introduction to social research. London: Sage.

Hennink, M., Hutter, I. \& Bailey, A. 2011. Qualitative research methods. London: Sage.

Hess, D.J. 1950. Science studies: An advanced introduction. New York: New York University Press.

Hood, W.W. \& Wilson, C.S. 2001. The literature of bibliometrics, scientometrics, and informetrics. Scientometrics, 52(2):291-314.

Howell, D.C. 2008. Fundamental statistics for the behavoiral sciences. Australia: Thomson Wadsworth.

Johnson, R.B., Onwuegbuzie, A.J. \& Turner, L.A. 2007. Toward a definition of mixed methods research. Journal of Mixed Methods Research, 1(2):112-133.

JSTOR. 2012. At a glance [Online]. Available: http://about.jstor.org/sites/default/files/jstorfactsheet-20120213.pdf [2012, March, 31]. 
Jubber, K. 2007. Sociology in South Africa: A brief historical review of research and publishing. International Sociology, 22(5)527-546.

Kumar, R. 2011. Research methodology: A step-by-step guide for beginners ( ${ }^{\text {rd }}$ ed.). London: Sage.

May, C. 2005. Methodological pluralism, British sociology and the evidence-based state: A reply to Payne et al. Sociology, 39(3):519-528.

Merriam, S.B. and Associates (eds.). 2002. Qualitative research practice: Examples for discussion and analysis. San Francisco: Jossey-Bass.

Mouton, J. 2006. Understanding social research. Pretoria: Van Schaik.

Mouton, J. 2008. How to succeed in your Master's and doctoral studies: A South African guide and resource book. Pretoria: Van Schaik.

Mouton, J., Boshoff, N. \& Tijssen, R. 2006. A comprehensive analysis of South African research journals, in Academy of Science of South Africa. Report on a strategic approach to research publishing in South Africa. Pretoria: Academy of Science of South Africa. 29-59.

Nakao, K. 1998. Sociological work in Japan. Annual Review of Sociology, 24:499-516.

Neuman, W.L. 2011. Social research methods: Qualitative and quantitative approaches $\left(7^{\text {th }}\right.$ ed.). Boston: Allyn \& Bacon.

Oloyede, O. 2006. The first ten years: A review of African Sociological Review, 1997-2006. African Sociological Review, 10(1):193-297.

Olzak, S. 1990. Report to the Human Sciences Research Council. South African Sociological Review, 3(1):62-68.

Oosthuizen, J.S. 1991. South African sociology during the eighties as mirrored in the South African Journal of Sociology. South African Journal of Sociology, 2(22):43-45.

Oosthuizen, K. 1991. Response: The state of sociology in South Africa revisited. South African Sociological Review, 3(2):93-99.

Payne, G. 2007. Social divisions, social mobilities and social research: Methodological issues after 40 years. Sociology, 41(5):901-915.

Payne, G., Williams, M. \& Chamberlain, S. 2004. Methodological pluralism in British sociology. Sociology, 38(1):153-163.

Prozesky, H. 2008. A career-history analysis of gender difference in publication productivity among South African academics. Science Studies, 21(2):47-67.

Prozesky, H. 2006. Gender differences in the publication productivity of South African scientists. Unpublished doctoral dissertation. Stellenbosch: University of Stellenbosch.

RefWorks. 2012. Home page [Online]. Available: http://www.refworks.com/ [2012, March, 31]. 
Science Studies. 2012. About the journal [Online]. Available: http://www.sciencestudies.fi/ [2012, March, 22].

Scott, J. 2005. Sociology and its others: Reflections on disciplinary specializations and fragmentation. Sociological Research Online, 10(1) [Online]. Available: http://www.socresonline.org.uk/10/1/scott.html [2013, March, 23].

Seekings, J. 2001. The uneven development of quantitative social science in South Africa. Social Dynamics, 27(1):1-36.

Sismondo, S. 2004. An introduction to science and technology studies. Malden: Blackwell.

Stellenbosch University. 2010. Addendum B: Guidelines for submission of journals for accreditation [Online]. Available:

http://www0.sun.ac.za/research/assets/forms/outputSurvey_Addendum\%20BSubmJournals_0 .doc [2012, March, 22].

Suter, W.N. 2012. Introduction to educational research: A critical thinking approach ( $2^{\text {nd }}$ ed.). Los Angeles: Sage.

Sztompka, P. 2010. One sociology or many?, in Patel, S. (ed.). The ISA handbook of diverse sociological traditions. London: Sage. 21-28.

Van Staden, F. \& Visser, D. 1991. The South African Journal of Sociology during the eighties: An analysis of theoretical and empirical contributions. South African Journal of Sociology, $2(22): 33-42$.

Van Staden, F. \& Visser, D. 1992. Comparison of methodology used in contributions to the South African Journals of Education, Psychology and Sociology. South African Journal of Science, 88(1):76-77.

Webster, E. 2004. Sociology in South Africa: Its past, present and future. Society in Transition, 35(1):27-41.

White, P. 2009. Developing research questions: A guide for social scientists. London: Palgrave Macmillan

Williams, M., Payne, G., Hodgkinson, L. \& Poade, D. 2008. Does British sociology count? Sociology students' attitudes toward quantitative methods. Sociology, 42(5):1003-1021.

Yong-Hak, J. 2011. Thomson Reuters: Web of Science factsheet [Online]. Available: http://thomsonreuters.com/content/science/pdf/Web_of_Science_factsheet.pdf [2012, April, $1]$.

Zuyderduin, J.R., Ehlers, V.J. \& Van der Wal, D.M. 2008. The impact of a buddy system on the self-care behaviours of women living with HIV/AIDS in Botswana. Health SA Gesondheid, 13(4)4-15. 
Zuzowski, R. 1992. The impact of nationalism on communism: The case of Poland, Canadian Review of Studies in Nationalism, XIX(1-2):9-17.

Zuzowski, R. 1994. The impact of nationalism on communism: The case of Poland. History of European Ideas, 18(1):33-39. 


\title{
AdDENDUM A: JOURNALS / PERIODICALS' ARTICLES EXCLUDED ON THE BASIS OF NON- ACCREDITED / NON-PEER-REVIEWED NATURE
}

\author{
African Sociological Review/Revue Africaine de Sociologie ${ }^{27}$ \\ Al'Ilm \\ Artes Natales \\ Bilateralism Review \\ Bulletin of the Southern African Institute of Ecologists and Environmental Scientists \\ Bulletin: News for the Human Sciences Researcher \\ Journal of Comprehensive Health: Codicillus \\ Democracy in Action \\ Developing a Smart Province \\ Development Update \\ Education Bulletin \\ Ek en My Kind \\ Enterprise \\ Farmer's Weekly \\ Financial Mail \\ Focus on \\ Frontiers of Freedom \\ Hervormde Teologiese Studies \\ Housing in Southern Africa \\ Indicator South Africa \\ Kopanong \\ MIE \\ Mining Mirror \\ Nursing RSA \\ Orientation \\ Archives of Physical Medicine and Rehabilitation \\ Progressio \\ RDP Development Monitor \\ Relations News \\ RSA Policy Review \\ S.A. Barometer \\ SA Builder \\ Senior News \\ Siyaya \\ Social Dynamics ${ }^{28}$ \\ Fast Facts \\ South African Journal of Linguistics \\ South African Labour Bulletin \\ Southern African Journal of Gerontology \\ The Child Care Worker \\ Theoria (Pietermaritzburg) \\ Toktokkie \\ Urban Forum \\ Urbanisations and Health Newsletter
}

\footnotetext{
${ }^{27}$ This journal appeared in the 2012 DoE list and not in the 2009 one.

${ }^{28}$ This journal is indexed by the WoS, but under a different title, i.e. "Social Dynamics - a journal of the centre for African Studies university of Cape Town". Too late in the study it was noticed that this is in fact a major journal in which South African sociologists publish, and which has existed since 1987. Its content should have been considered for inclusion in the sampling frame.
} 


\section{ADDENDUM B: ARTICLES REPLACED IN THE SAMPLE}

\begin{tabular}{|c|c|c|}
\hline $\begin{array}{l}\text { Sample } \\
\text { number }\end{array}$ & $\begin{array}{l}\text { Reason for } \\
\text { replacement }\end{array}$ & Reference \\
\hline A168 & Book review & $\begin{array}{l}\text { Crothers, C. 1997. Extending Levine's models of sociological research traditions. History of the Human } \\
\text { Sciences, 10(2): 149-162. }\end{array}$ \\
\hline A180 & Book review & $\begin{array}{l}\text { Webster, E. 1997. Democratic transition: South African sociology. Contemporary Sociology, 26(3):279- } \\
282 .\end{array}$ \\
\hline A181 & Duplicate & $\begin{array}{l}\text { Webster, E. 1997. Democratic transition: South African sociology. Contemporary Sociology, 26(3):279- } \\
282 .\end{array}$ \\
\hline A252 & Opinion piece & Senekal, A. 1999. Towards a Christ-centred sociology: An envisioned ideal. Koers, 64(1):65-81. \\
\hline A372 & $\begin{array}{l}\text { Author's affiliation } \\
\text { not South African }\end{array}$ & $\begin{array}{l}\text { Hurd, R.W. 2002. Contesting the dinosaur image: The U.S. labour movement's search for a future. Society } \\
\text { in Transition, 33(2):227-240. }\end{array}$ \\
\hline A373 & $\begin{array}{l}\text { Authors' affiliation } \\
\text { not South African }\end{array}$ & $\begin{array}{l}\text { Wood, G. \& Brewster, C. 2002. Decline and renewal in the British labour movement: Trends, practices and } \\
\text { lessons for South Africa. Society in Transition, 33(2):241-257 }\end{array}$ \\
\hline A444 & Discussion paper & $\begin{array}{l}\text { Owen, C.P. \& Locker, D. 2003. Demographic, psychological, sociological, and economic variables and } \\
\text { other factors that justify the need for prosthodontic services, and that help to assess the outcome of care. } \\
\text { The International Journal of Prosthodontics, 16(Supplement):S19-S20. }\end{array}$ \\
\hline A612 & Letter & $\begin{array}{l}\text { Nell, V. 2006. Author's response: Cruelty and the psychology of history. Behavioral and Brain Sciences, } \\
29(3): 246-257 .\end{array}$ \\
\hline A642 & Editorial review & $\begin{array}{l}\text { Peltzer, K., Niang, C.I., Muula, A.S., Bowa, K., Okeke, L., Boiro, H. \& Chimbwete, C. 2007. Editorial } \\
\text { review: Male circumcision, gender and HIV prevention in sub-Saharan Africa: A (social science) research } \\
\text { agenda. Journal of Social Aspects of HIV/AIDS, 4(3):658-667. }\end{array}$ \\
\hline A774 & $\begin{array}{l}\text { Author's affiliation } \\
\text { not South African }\end{array}$ & $\begin{array}{l}\text { Crothers, C. 2008. Encyclopaedias, handbooks, dictionaries, collections and companions: Assessing } \\
\text { collective works in sociology. International Sociology, 23(2):171-179. }\end{array}$ \\
\hline A775 & Book review & Sooryamoorthy, R. 2008. Untouchability in modern India. International Sociology, 23(2):283-293. \\
\hline A780 & Book review & $\begin{array}{l}\text { Soudien, C. \& Torres, C.A. 2008. Review symposium. British Journal of Sociology of Education, } \\
\text { 29(6):719-725. }\end{array}$ \\
\hline
\end{tabular}




\section{ADDENDUM C: REFERENCES OF SAMPLED ARTICLES}

The following is a list of all the references for the empirical articles in the sample, including their reference numbers and ordered according to publication date.

A006 Herbert, R.K. 1990. Sex-based differences in compliment behavior. Language in Society, 19(2):201-224.

A030 Miller, T. \& Swartz, L. 1991. Integration or marginalisation? Clinical psychology as a strategy for dealing with psychosocial issues in a South African neurosurgery ward. Sociology of Health and Illness, 13(3):293-309.

A048 Shalem, Y. 1992. Teachers struggle: The case of white English-speaking teachers in SouthAfrica. British Journal of Sociology of Education, 13(3):307-328.

A060 Westaway, M.S. \& Wolmarans, L. 1992. Depression and self-esteem: Rapid screening for depression in black, low literacy, hospitalized tuberculosis patients. Social Science and Medicine, 35(10):1311-1315.

A066 Song, A. 1993. The South African Chinese family. Journal of Comparative Family Studies, 24(3):353-365.

A072 London, L. 1993. The Ray Alexander Workers Clinic: A model for worker-based health services in South-Africa? Social Science and Medicine, 37(12):1521-1527.

A078 Dixon, J.A., Foster, D.H., Durrheim, K. \& Wilbraham, L. 1994. Discourse and the politics of space in South Africa: The "squatter crisis". Discourse and Society, 5(3):277-296.

A084 Chimere-Dan, O. 1994. Determinants of racial fertility differentials in some urban areas of South Africa. Journal of Biosocial Science, 26(1):55-63.

A096 Brookes, H.J. 1995. "Suit, tie and a touch of juju": The ideological construction of Africa: A critical discourse analysis of news on Africa in the British press. Discourse and Society, 6(4):461-494.

A102 Teer-Tomaselli, R. 1995. Moving towards democracy: The South African broadcasting corporation and the 1994 election. Media, Culture and Society, 17(4):577-601.

A108 Du Toit, D. 1995. A sociological analysis of the extent and influence of professional socialization on the development of a nursing identity among nursing students at two universities in Brisbane, Australia. Journal of Advanced Nursing, 21(1):164-171

A120 Kotze, H. \& Du Toit, P. 1995. The state, civil society, and democratic transition in South Africa. Journal of Conflict Resolution, 39(1):27-48.

A126 De Klerk, V. \& Bosch, B. 1995. Linguistic stereotypes: Nice accent - nice person? International Journal of the Sociology of Language, 116:17-37.

A132 Kritzinger, A. \& Vorster, J. 1996. Women farm workers on South African deciduous fruit farms: Gender relations and the structuring of work. Journal of Rural Studies, 12(4):339351.

A138 Cornwell, G. 1996. George Webb Hardy's “The Black Peril” and the social meaning of "Black Peril" in early twentieth-century South Africa. Journal of Southern African Studies, 22(3):441-453. 
A144 Ewert, J. \& Hamman, J. 1996. Labour organisation in Western Cape agriculture: An ethnic corporatism? The Journal of Peasant Studies, 23(2-3):146-165.

A150 Cunningham, P.W. \& Boult, B.E. 1996. Black teenage pregnancy in South Africa: Some considerations. Adolescence, 31(123):691-700.

A156 Gilbert, L. 1996. Urban violence and health: South Africa 1995. Social Science and Medicine, 43(5):873-886.

A162 Crothers, C. 1997. South African sociology departments in 1996. Society in Transition, 28(1):137-140.

A174 Chisanga, T. \& Kamwangamalu, N.M. 1997. Owning the other tongue: The English language in Southern Africa. Journal of Multilingual and Multicultural Development, 18(2):89-99.

A186 Kotze, H. \& Hill, L. 1997. Emergent migration policy in a democratic South Africa. International Migration, 35(1):5-35.

A192 Backmann, M.O. \& Makan, B. 1997. Salary inequality and primary care integration in South Africa. Social Science and Medicine, 45(5):723-729.

A198 Cooper, P.A. \& Sandler, D.L. 1997. Outcome of very low birth weight infants at 12 to 18 months of age in Soweto, South Africa. Pediatrics, 99(4):537-544.

A204 Venter, D. 1998. Dissing the sacred canopy: The state of sociology of religion in South Africa. Society in Transition, 29(3-4):143-151.

A210 Meyer-Weitz, A., Reddy, P., Weijts, W., Borne, B. \& Kok, G. 1998. The socio-cultural contexts of sexually transmitted diseases in South Africa: Implications for health education programmes. AIDS Care-Psychological and Socio-Medical Aspects of AIDS/HIV, 10(Supplement 1):39-55.

A216 Steenveld, L. \& Strelitz, L. 1998. The 1995 Rugby World Cup and the politics of nationbuilding in South Africa. Media, Culture and Society, 20(4):609-629.

A222 Breckenridge, K. 1998. The allure of violence: Men, race and masculinity on the South African goldmines, 1900-1950. Journal of Southern African Studies, 24(4):669-693.

A234 Kritzinger, A. \& Vorster, J. 1998. Women on South African farms: Empowerment across or along race and class divisions? Sociologia Ruralis, 38(3):331-350.

A240 Jewkes, R. \& Wood, K. 1998. Competing discourses of vital registration and personhood: Perspectives from rural South Africa. Social Science and Medicine, 46(8):1043-1056.

A246 Maree, J. 1998. The COSATU participatory democratic tradition and South Africa's new parliament: Are they reconcilable? African Affairs, 97(386):29-51.

A253 Ingram, C.F., Flemming, A.F., Patel, M. \& Galpin, J.S. 1999. Pregnancy- and lactationrelated folate deficiency in South Africa: A case for folate food fortification. South African Medical Journal, 89(12):1279-1284.

A258 Posel, D. 1999. Whiteness and power in the South African civil service: Paradoxes of the apartheid state. Journal of Southern African Studies, 25(1):99-119.

A264 Slone, M., Durrhein, K., Kaminer, D. \& Lachman, P. 1999. Issues in the identification of comorbidity of mental retardation and psychopathology in a multicultural context. Social Psychiatry and Psychiatric Epidemiology, 34(4):190-194. 
A276 Cock, J. \& Fig, D. 2000. From colonial to community based conservation: Environmental justice and the national parks of South Africa. Society in Transition, 31(1):22-35.

A294 Crankshwa, O., Gilbert, A. \& Morris, A. 2000. Backyard Soweto. International Journal of Urban and Regional Research, 24(4):841-857.

A300 Bekker, S., Leilde, A., Cornelissen, S. \& Hortmeier, S. 2000. The emergence of new identities in the Western Cape. Politikon: South African Journal of Political Studies, 27(2):221-237.

A306 Petersen, I. 2000. Comprehensive integrated primary mental health care for South Africa. Pipedream or possibility? Social Science and Medicine, 51(3):321-334.

A312 Erlank, N. 2000. Gendered reactions to social dislocation and missionary activity in Xhosaland 1836-1847. African Studies, 59(2):205-227.

A 318 Barkhuizen, G. \& De Klerk, V. 2000. Language contact and ethnolinguistic identity in an Eastern Cape army camp. International Journal of the Sociology of Language, 45(5):723729.

A324 Morrell, R. 2001. Corporal punishment and masculinity in South African schools. Men and Masculinities, 4(2):140-157.

A330 Machel, J.Z. 2001. Unsafe sexual behaviour among schoolgirls in Mozambique: A matter of gender and class. Reproductive Health Matters, 9(17):82-90.

A336 Fonn, S., Mtonga, A.S., Nkoloma, H.C., Bantebya Kyomunhendo, G., Dasilva, L., Kazilimani, E., Davis, S. \& Dia, R. 2001. Health providers' opinions on provider-client relations: Results of a multi-country study to test "Health Workers for Change". Health Policy and Planning, 16:19-23.

A342 Freund, B. 2001. Contrasts in urban segregation: A tale of two African cities, Durban (South Africa) and Abidjan (Cote d'Ivoire). Journal of Southern African Studies, 27(3):527-546.

A348 Vahed, G.H. 2001. Mosques, mawlanas and muharram: Indian Islam in colonial Natal, 1860-1910. Journal of Religion in Africa, 31(3):305-335.

A354 Christopher, A.J. 2001. Urban segregation in post-apartheid South Africa. Urban Studies, 38(3):449-466.

A360 Schneider, H. \& Stein, J. 2001. Implementing AIDS policy in post-apartheid South Africa. Social Science and Medicine, 52(5):723-731.

A366 Klanderman, B., Roefs, M. \& Olivier, J. 2001. Grievance formation in a country in transition: South Africa, 1994-1998. Social Psychology Quarterly, 64(1):41-54.

A384 Shefer, T., Strebel, A., Wilson, T., Shabalala, N., Simbayi, L., Ratele, K., Potgieter, C. \& Andipatin, M. 2002. The social construction of sexually transmitted infections (STIs) in South African communities. Qualitative Health Research, 12(10):1373-1390.

A396 Robins, S. 2002. At the limits of spatial governmentality: A message from the tip of Africa. Third World Quarterly, 23(4):665-689.

A402 Thomas, C.L., James, A.C. \& Backmann, M.O. 2002. Eating attitudes in English secondary school students: Influences of ethnicity, gender, mood, and social class. International Journal of Eating Disorders, 31(1):92-96. 
A408 Seedat, S., Stein, D.J., Berk, M. \& Wilson, Z. 2002. Barriers to treatment among members of a mental health advocacy group in South Africa. Social Psychiatry and Psychiatric Epidemiology, 37(10):483-487.

A414 Cocks, M. \& Moller, V. 2002. Use of indigenous and indigenised medicines to enhance personal well-being: A South African case study. Social Science and Medicine, 54(3):387397.

A432 Stadler, J.J. 2003. The young, the rich, and the beautiful: Secrecy, suspicion and discourses of AIDS in the South African lowveld. African journal of AIDS research, 2(2):127-139.

A438 Mouton, J. 2003. South African science in transition. Science, Technology and Society, $8(2): 235-260$.

A445 Burman, S. 2003. The best interests of the South African child. International Journal of Law, Policy and the Family, 17(1):28-40.

A450 Zere, E. \& McIntyre, D. 2003. Equity in self-reported adult illness and use of health service in South Africa: Inter-temporal comparison. Journal of Health Population and Nutrition, 21(3):205-215.

A456 Parle, J. 2003. Witchcraft or madness? The amandiki of Zululand, 1894-1914. Journal of Southern African Studies, 29(1):105-132.

A462 Amoateng, A.Y., Kalule-Sabiti, I. \& Ditlopo, P. 2003. Analysing cross-sectional data with time-dependent covariates: The case of age at first birth in South Africa. Journal of Biosocial Science, 35(3):353-367.

A474 Booysen, F. 2004. Social grants as safety net for HIV/AIDS-affected households in South Africa. Journal of Social Aspects of HIV-AIDS, 1(1):45-56.

A480 McIntyre, D., Thomas, S. \& Cleary, S. 2004. Globalization and health policy in South Africa. Perspectives on Global Development and Technology, 3(1-2):131-152.

A492 Mathee, A., Von Schirnding, Y., Montgomery, M. \& Rollin, H. 2004. Lead poisoning in South African children: The hazard is at home. Reviews on Environmental Health, 19:347361.

A504 Robins, S. 2004. "Long live Zackie, long live": AIDS activism, science and citizenship after apartheid. Journal of Southern African Studies, 30(3):651-672.

A510 Louw, D.A., Scherrer, R. \& Esterhuyse, K.G.F. 2004. Parents' perception and experience of the family advocate system. International Journal of the Sociology of Law, 32(2):167189.

A516 Kritzinger, A., Barrientos, S. \& Rossouw, H. 2004. Global production and flexible employment in South African horticulture: Experiences of contract workers in fruit exports. Sociologia Ruralis, 44(1):17-39.

A522 Kagee, A. 2004. Present concerns of survivors of human rights violations in South Africa. Social Science and Medicine, 59(3):625-635.

A528 Sideris, T. 2004. "You have to change and you don't know how!": Contesting what it means to be a man in a rural area of South Africa. African Studies, 63(1):29-49.

A534 Nel, E., Illgner, P., Hill, T. \& Gowela, J.P. 2005. Cultivating success in Malawi: Community-based mushroom growing as an alternative livelihood strategy. Africa Insight, 35(4):105-111. 
A540 Meel, B..L. \& Leenaars, A.A. 2005. Human immunodeficiency virus (HIV) and suicide in a region of Eastern Province ("Transkei"), South Africa. Archives of Suicide Research, 9(1):69-75.

A546 Jones, S.A., Sherman, G.G. \& Varga, C.A. 2005. Exploring socio-economic conditions and poor follow-up rates of HIV-exposed infants in Johannesburg, South Africa. AIDS Care: Psychological and Socio-Medical Aspects of AIDS/HIV, 17(4):466-470.

A558 Tewari, D.D. \& Khanna, S. 2005. Building and energizing water institutions: A case study of irrigation management transfer in Gujarat. Journal of Environmental Systems, 31(3):201-221.

A564 Zambuko, O. \& Mturi, A.J. 2005. Sexual risk behaviour among the youth in the era of HIV/AIDS in South Africa. Journal of Biosocial Science, 37(5):569-584.

A582 Skhosana, N.L., Struthers, H., Gray, G.E. \& McIntyre, J.A. 2006. HIV disclosure and other factors that impact on adherence to antiretroviral therapy: The case of Soweto, South Africa. African Journal of AIDS Research, 5(1):17-26.

A600 Skogmar, S., Shakeyly, D., Lans, M., Danell, J., Andersson, R., Tshandu, N., Odén, A., Roberts, S. \& Francois Venter, W.D. 2006. Effect of antiretroviral treatment and counselling on disclosure of HIV-serostatus in Johannesburg, South Africa. AIDS Care: Psychological and Socio-Medical Aspects of AIDS/HIV, 18(7):725-730.

A606 Abrahams, N., Jewkes, R., Laubscher, R. \& Hoffman, M. 2006. Intimate partner violence: Prevalence and risk factors for men in Cape Town, South Africa. Violence and Victims, 21(2):247-264.

A618 Simbayi, L.C., Mwaba, K. \& Kalichman, S.C. 2006. Perceptions of the combination of HIV/AIDS and alcohol as a risk factor among STI clinic attenders in South Africa: Implications for HIV prevention. Social Behavior and Personality, 34(5):535-543.

A624 Burrows, S. \& Laflamme, L. 2006. Suicide mortality in South Africa. Social Psychiatry and Psychiatric Epidemiology, 41(2):108-114.

A630 Minty, Z. 2006. Post-apartheid public art in Cape Town: Symbolic reparations and public space. Urban Studies, 43(2):421-440.

A643 Kagwanja, P. 2007. Calming the waters: The East African community and conflict over the Nile resources. Journal of Eastern African Studies, 1(3):321-337.

A648 Reddy, S. \& Dunne, M. 2007. Risking it: Young heterosexual femininities in South African context of HIV/AIDS. Sexualities, 10(2):159-172.

A654 Pattman, R. 2007. Student identities and researching these, in a newly "racially" merged university in South Africa. Race, Ethnicity and Education, 10(4):473-492.

A672 Steyn, M.E. \& Grant, T. 2007. A real bag of mixed emotions: Re-entry experiences of South African exiles. International Journal of Intercultural Relations, 31(3):363-389.

A678 Shackleton, C.M., McGarry, B., Fourie, S., Gambiza, J., Shackleton, S.E. \& Fabricius, C. 2007. Assessing the effects of invasive alien species on rural livelihoods: Case examples and a framework from South Africa. Human Ecology, 35(1):113-127.

A684 Maharaj, P. \& Munthree, C. 2007. Coerced first sexual intercourse and selected reproductive health outcomes among young women in KwaZulu-Natal, South Africa. Journal of Biosocial Science, 39(2):231-244. 
A696 Hosegood, V., Preston-Whyte, E., Busza, J., Moitse, S. \& Timaeus, I.M. 2007. Revealing the full extent of households' experiences of HIV and AIDS in rural South Africa. Social Science and Medicine, 65(6):1249-1259.

A702 Twine, R., Collison, M.A., Polzer, T.J. \& Kahn, K. 2007. Evaluating access to a childoriented poverty alleviation intervention in rural South Africa. Scandinavian Journal of Public Health, 35(Supplement 69):118-127.

A708 Goudge, J., Gumede, T., Gilson, L., Russell, S., Tollman, S.M. \& Mills, A. 2007. Coping with the cost burdens of illness: Combining qualitative and quantitative methods in longitudinal, household research. Scandinavian Journal of Public Health, 35(Supplement 69):181-185.

A714 Forsyth, B., Vandormael, A., Kershaw, T. \& Grobbelaar, J. 2008. The political context of AIDS-related stigma and knowledge in a South African township community. Journal of Social Aspects of HIV-AIDS, 5(2):74-82.

A720 Vearey, J. 2008. Migration, access to ART, and survivalist livelihood strategies in Johannesburg. African Journal of AIDS Research, 7(3):361-374.

A726 Cilliers, C., Naidoo, K. \& Smit, R. 2008. University academics, family politics and "the egalitarian discourse". Agenda, 22(76):106-115.

A732 Ng'ang'a, P.N., Shililu, J., Jayasinghe, G., Kimani, V., Kabutha, C., Kabuage, L., Kabiru, E., Githure, J. \& Mutero, C. 2008. Malaria vector control practices in an irrigated rice agroecosystem in central Kenya and implications for malaria control. Malaria Journal, 7(146). [Online], Available: http://www.malariajournal.com/content/7/1/146 [2012, March 4].

A744 Campbell, C., Nair, Y., Maimane, S. \& Sibiya, Z. 2008. Supporting people with AIDS and their carers in rural South Africa: Possibilities and challenges. Health and Place, 14(3):507-518.

A750 Myers, B., Louw, J. \& Fakier, N. 2008. Alcohol and drug abuse: Removing structural barriers to treatment for historically disadvantaged communities in Cape Town. International Journal of Social Welfare, 17(2):156-165.

A756 Sanders, D., Stern, R., Struthers, P., Ngulube, T.J. \& Onya, H. 2008. What is needed for health promotion in Africa: Band-aid, live aid or real change? Critical Public Health, 18(4):509-519.

A762 Schenk, K.D., Ndhlovu, L., Tembo, S., Nsune, A., Nkhata, C., Walusiku, B. \& Watts, C. 2008. Supporting orphans and vulnerable children affected by AIDS: Using communitygenerated definitions to explore patterns of children's vulnerability in Zambia. AIDS Care: Psychological and Socio-Medical Aspects of AIDS/HIV, 20(8):894-903.

A768 Nadasen, K. 2008. "Life without line dancing and the other activities would be too dreadful to imagine": An increase in social activity for older women. Journal of Women and Aging, 20(3-2):329-342.

A776 Akpan, W. 2008. Corporate citizenship in the Nigerian petroleum industry: A beneficiary perspective. Development Southern Africa, 25(5):497-511.

A786 Vincent, L. 2008. The limitations of “inter-racial contact": Stories from young South Africa. Ethnic and Racial Studies, 31(8):1426-1451.

A792 Czegledy, A.P. 2008. A new Christianity for a new South Africa: Charismatic Christians and the post-apartheid order. Journal of Religion in Africa, 38(3):284-311. 
A798 Joe, S., Stein, D.J., Seedat, S., Herman, A. \& Williams, D.R. 2008. Non-fatal suicidal behavior among South Africans. Social Psychiatry and Psychiatric Epidemiology, 43(6):454-461.

A810 Myer, L., Stein, D.J., Grimsrud, A., Seedat, S. \& Williams, D.R. 2008. Social determinants of psychological distress in a nationally-representative sample of South African adults. Social Science and Medicine, 66(8):1828-1840.

A816 Pronyk, P.M., Harpham, T., Busza, J., Phetla, G., Morison, L.A., Hargreaves, J.R., Kim, J.C., Watts, C.H. \& Porter, J.D. 2008. Can social capital be intentionally generated? A randomized trial from rural South Africa. Social Science and Medicine, 67(10):1559-1570.

A822 Seedat, S., Williams, D.R., Herman, A.A., Moomal, H., Williams, S.L., Jackson, P.B., Myer, L. \& Stein, D.J. 2009. Mental health service use among South Africans for mood, anxiety and substance use disorders. South African Medical Journal, 99(5):346-352.

A828 Ng'ang'a, P.N., Jayasinghe, G., Kimani, V., Shililu, J., Kabutha, C., Kabuage, L., Githure, J. \& Mutero, C. 2009. Bed net use and associated factors in a rice farming community in Central Kenya. Malaria Journal, 8(64):1-8.

A834 Vincent, L. \& Camminga, B. 2009. Putting the " $t$ " into South African human rights: Transsexuality in the post-apartheid order. Sexualities, 12(6):678-700.

A840 Andersson, N., Cockcroft, A., Ansari, N., Omer, K., Chaudhry, U.U., Khan, A. \& Pearson, L. 2009. Collecting reliable information about violence against women safely in household interviews: Experience from a large-scale national survey in South Asia. Violence against Women, 15(4):482-496.

A846 Steyn, F., Schneider, H., Engelbrecht, M.C., Van Rensburg-Bonthuysen, E.J., Jacobs, N. \& Van Rensburg, D.H.C.J. 2009. Scaling up access to antiretroviral drugs in a middle-income country: Public sector drug delivery in the Free State, South Africa. AIDS Care: Psychological and Socio-Medical Aspects of AIDS/HIV, 21(1):1-6.

A852 Visser, M.J., Makin, J.D., Sikkema, K.J., Forsyth, B.W.C. \& Vandormael, A. 2009. HIV/AIDS stigma in a South African community. AIDS Care: Psychological and SocioMedical Aspects of AIDS/HIV, 21(2):197-206.

A858 Corless, I.B., Wantland, D., Bhengu, B., McInerney, P., Ncama, B., Nicholas, P.K., McGibbon, C., Wong, E. \& Davis, S.W. 2009. HIV and tuberculosis in Durban, South Africa: Adherence to two medication regimens. AIDS Care: Psychological and SocioMedical Aspects of AIDS/HIV, 21(9):1106-1113.

A870 Breier, M. \& Ralphs, A. 2009. In search of phronesis: Recognizing practical wisdom in the recognition (assessment) of prior learning. British Journal of Sociology of Education, 30(4):479-493.

A876 Ferreira, R. \& Henk, D. 2009. “Operationalizing” human security in South Africa. Armed Forces and Society, 35(3):501-525.

A900 Wringe, A., Cremin, I., Todd, J., McGrath, N., Kasamba, I., Herbst, K., Mushore, P., Żaba, B. \& Slaymaker, E. 2009. Comparative assessment of the quality of age-at-event reporting in three HIV cohort studies in sub-Saharan Africa. Sexually Transmitted Infections, 85(Supplement 1):i56-i63. 